\title{
Indo-Fijian Fishing Communities: \\ Relationships with Taukei in Coastal Fisheries
}

\author{
Chinnamma Reddy \\ Thesis \\ ENVIRONMENT STUDIES 591
}

Submitted to Victoria University of Wellington in partial fulfilment of the requirements for the degree of Master of Environment Studies

School of Geography, Environment and Earth Sciences

Victoria University of Wellington

New Zealand

March 2019 


\section{Acknowledgements}

The completion of this thesis journey would not have been possible without the support, trust, friendship, and faith of some special people and institutions in my life.

My gratitude goes out to the following:

The New Zealand Ministry of Foreign Affairs and Trade (MFAT) who provided me this opportunity to pursue higher education in Aotearoa New Zealand. To the mana whenua of this land, tēnā koutou (thank you) for sharing your home and your manaakitanga (hospitality) in looking after my family and I this past two years. We have made some special memories and will treasure them forever.

My research contributors; the people whose voices I have attempted to share in this thesis. Thank you, Dhanyavad, and Vinaka Vakalevu for sharing your time, stories and experiences with me. Your contributions to this research are invaluable. I would also like to acknowledge the support provided by the WWF Fiji Office during the field research in $\mathrm{Ba}$. This project would not have been completed without your kind contributions and support through my field work.

To my ever-supportive supervisor, Dr Amanda Thomas, for being patient, kind and caring during my thesis journey. Your support and encouragement enabled me to push along this past 12 months. Special gratitude is extended to Professor Vijay Naidu of the University of the South Pacific (USP) who provided mentoring, critical feedback and support during my thesis journey.

To an amazing cohort of ENVI and DEVE studies students 2017/18, all of whom have been a source of inspiration, friendship and just wonderful people who I'm privileged to know. In particular Katy, Jerry, Janie, Maria, Michaela, Thomas and Prasanthi for sharing, caring and offering friendship and support throughout the thesis journey. My deepest gratitude is extended to my writing coaches, proof-readers, and in particular to Lorena De la Torre Parra and James Tremlett for their valuable insights, support and encouragement. Your passion for the Pacific and faith in me completing this research is what has kept my vaka sailing. To all of you, Vinaka vakalevu.

A special thank you is extended to the Reddy family in Wellington. Arnold, Karishma, Anya and Boj who have been my support base, pillar of strength and provider for me 
and my family. I am deeply indebted to your generosity and hospitality in welcoming me into your home and life. To my amazing family in Fiji; my parents, in-laws, sisters and brothers who have encouraged and guided me in more than one way. Thank you for your love and support when needed most.

Finally, but not the least, to my wonderful boys; Aman, Arnav and Aayush. We conquered this journey as a family and am so proud of our achievements. Your love and support kept me going. Thank you for motivating me and just being there.

And finally, but not the least, to the God Almighty who blessed me with this amazing opportunity and the wonderful people through which he worked to help me achieve and fulfil this journey.

This thesis is dedicated to my late grandmother and namesake Chinnamma Reddy who has been, and continues to be, my source of inspiration. To her I owe my passion for learning, exploring and desire to further my education. Amma, I hope I am a step closer to fulfilling some of those dreams you may have seen for yourself.

Nga mihi, vinaka vakalevu. 


\section{Abstract}

In the Pacific, customary marine tenure-ship and management has been practised for centuries. Community based marine resource management (CBMRM) initiatives have seen governments, local communities and non-government organisations adopt various management tools to improve coastal fisheries. Despite these efforts, there are growing concerns over the decline of fisheries resources and the subsequent social-ecological problems that affect coastal communities.

In the last three decades, Fiji, has implemented various forms of CBMRM initiatives with varying social-ecological successes. Marine management and conservation efforts across the 410 qoliqoli areas (fishing grounds) are predominantly driven by Indigenous Taukei communities and non-government conservation organisations (NGOs). Over the past two years local communities, NGOs, and government have led and supported new management efforts to improve fisheries sustainability in the country.

Non-Indigenous resource users are limited by social and political policies to access and participate in coastal resource management. Fijians of Indian descent (Indo-Fijians) represent the second-largest ethnic group in Fiji and are engaged in both subsistence and artisanal fisheries. Their involvement and participation within the broader socioeconomic and socio-political aspects of coastal fisheries is considerable, however, remains hidden. Using a qualitative approach, this study explores the issues, challenges, and opportunities that Indo-Fijian communities experience in the coastal fisheries sector in Ba Province, Fiji.

Findings from the research illustrate the informal yet complex nature of socio-economic and socio-cultural community relationships between customary Taukei qoliqoli owners and Indo-Fijian people. The role of Indo-Fijian women within the coastal fisheries sector is notable. The success of contemporary CBRMN in Fiji is dependent upon a reimagined, re-adapted, diverse approach. Most importantly, this research provides an opportunity to foster discussion within contemporary community based marine management and conservation efforts currently in place by customary Taukei qoliqoli owners, conservation organisations and the government.

Key words: coastal fisheries, Fiji, resource users, Indo-Fijians, community based marine management 


\section{List of Figures:}

Figure 1 Map of Fiji Islands.

Figure 2 Close-up of Ba Province with major centres. 9

Figure 3 Typical reef cross section. 10

Figure 4 Process for obtaining a commercial fishing licence under the Fisheries Act, 13

Figure 5 Epistemological canoe riding the waves of Indigenous, Postcolonial and 45

Figure 6 Commercial fishing boat operators docked at Lautoka wharf. 69

Figure 7 Fishing boats tied-up within mangrove stands in Ba and boats out at sea. 70

Figure 8 Typical half-cabin boats sheltered within mangrove patches in Ba.... .71

Figure 9 Conceptual overlays of social relationships in coastal fisheries in Ba. 91

Figure 10 Diverse economies ice-berg. 106

\section{List of Tables:}

Table 1a: Research contributors' information. 59

Table 1b: Summary of participants involved 62. 


\section{List of Acronyms:}

Food and Agriculture Organization (FAO)

World Wildlife Fund (WWF)

Wildlife Conservation Society (WCS)

University of the South Pacific (USP)

Food and Agriculture Organisation (FAO)

Fiji Bureau of Statistics (FBoS)

Fiji Locally Managed Marine Areas (FLMMA)

Maritime Safety Authority of Fiji (MSAF)

The Pacific Community (SPC)

Non-Government Organisation (NGO) 


\section{Contents Page:}

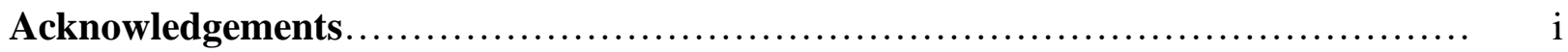

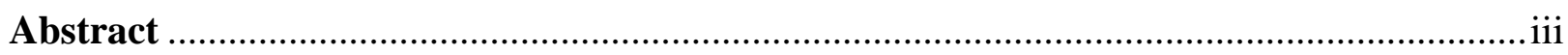

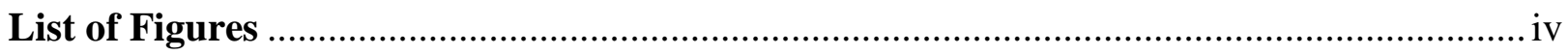

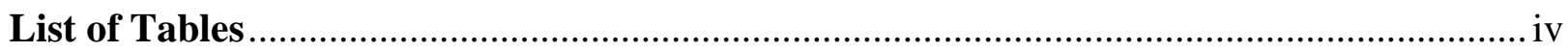

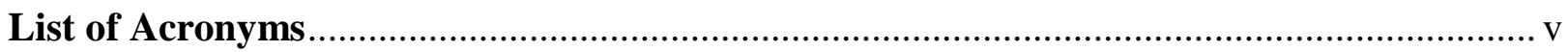

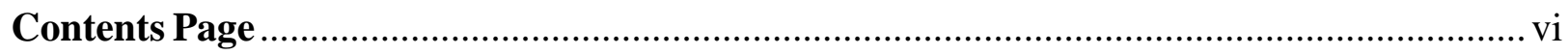

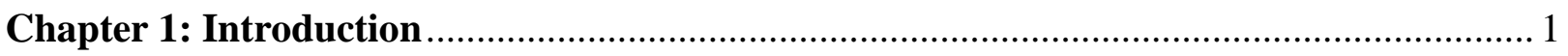

1.1 The big picture - oceans, fisheries, people and policies ........................................... 1

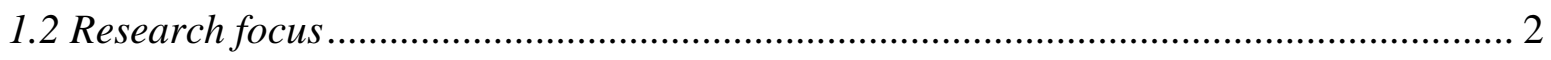

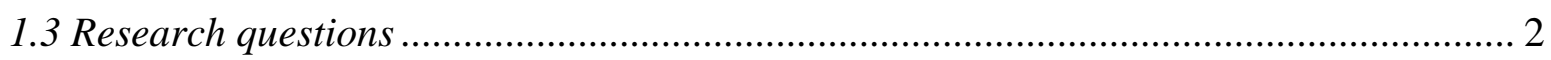

1.4 Significance and contribution of this research ........................................................... 3

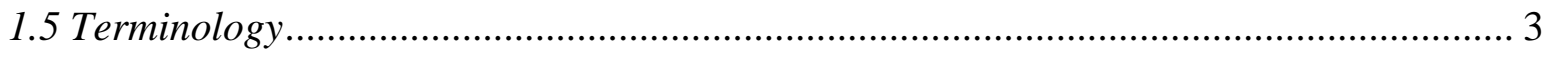

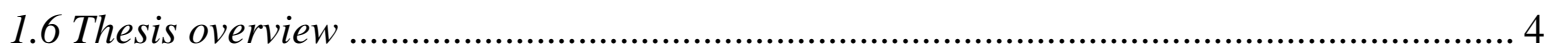

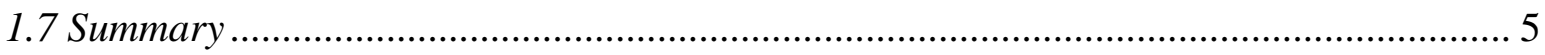

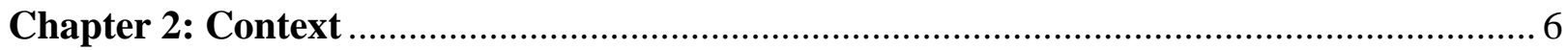

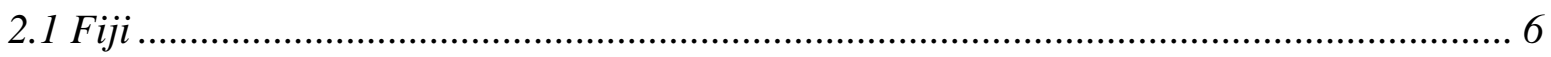

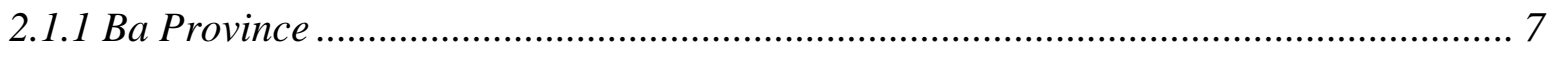

2.2 An overview of coastal fisheries in Fiji ............................................................... 10

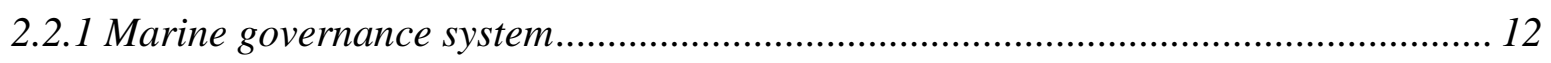

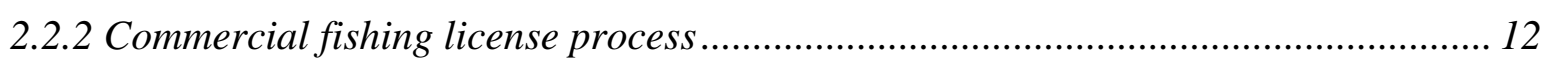

2.2.3 Community based coastal fisheries development in Fiji....................................... 15

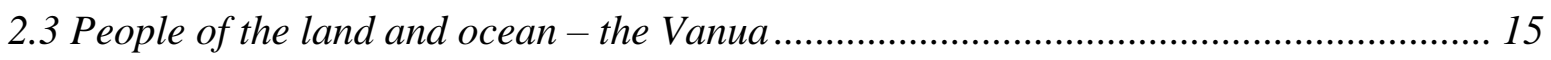

2.3.1 Land use, management and linkages to identity ................................................... 17

2.4 People from afar: Fijians of Indian descent........................................................... 19

2.4.1 Relationship between marine resource use and Indo-Fijians ................................... 23 
2.5 Fostering new cultural identities - to go forward, we must look back at our histories. ... 23

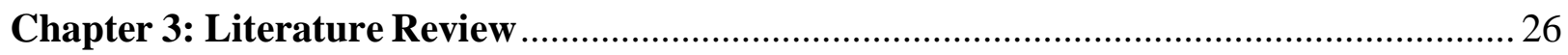

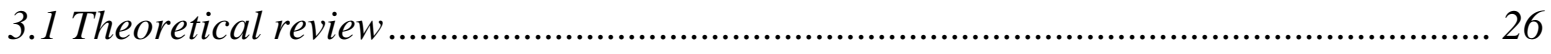

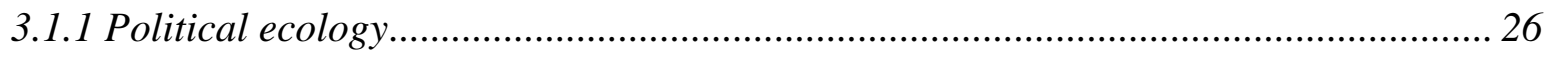

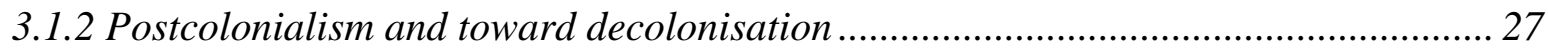

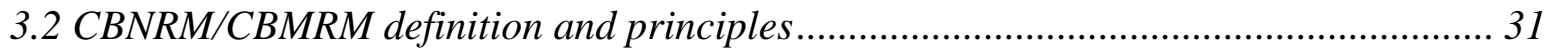

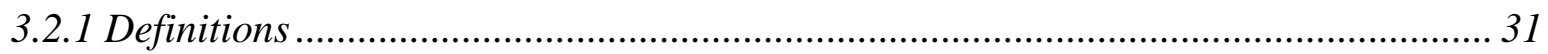

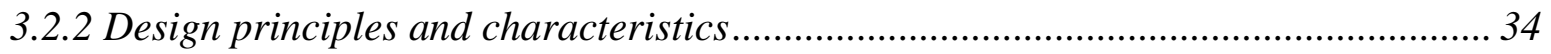

3.3 Renaissance of community based marine resource management ................................ 36

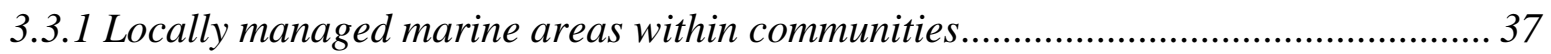

3.3.2 Community definitions in natural resource management ........................................ 39

3.3.3 The dilemma of community in post-colonial natural resource management .............. 40

3.4 The research gap and contribution to knowledge .................................................. 41

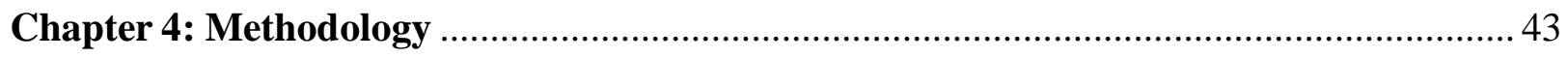

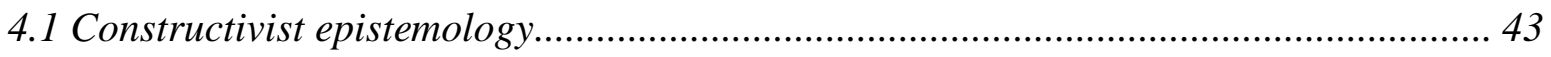

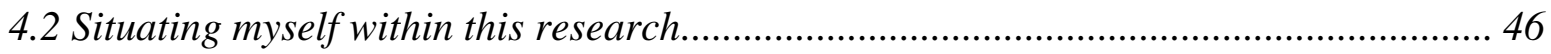

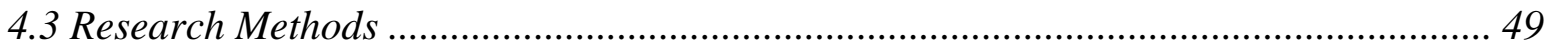

4.3.1 Pre-field preparation, participant recruitment, access and consent......................... 49

4.3.2 Semi-structured interview, snow-ball technique, convenience sampling.................... 54

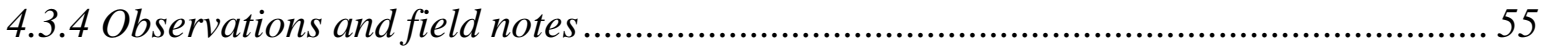

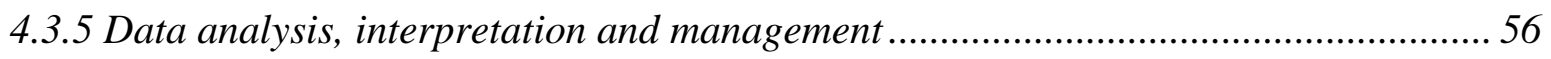

4.3.6 Ethical considerations, health and safety ........................................................ 57

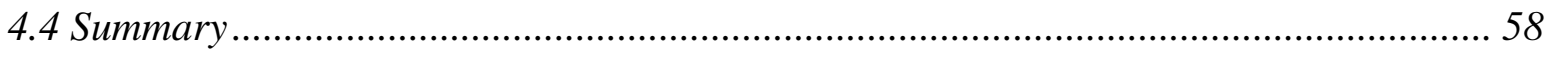

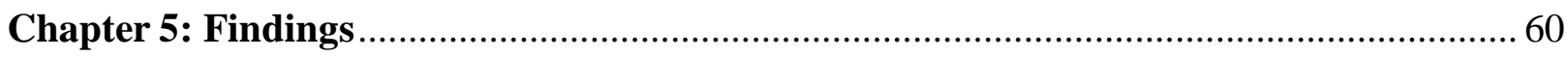

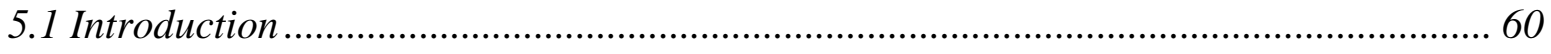

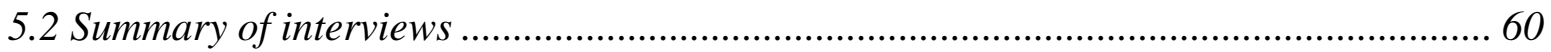

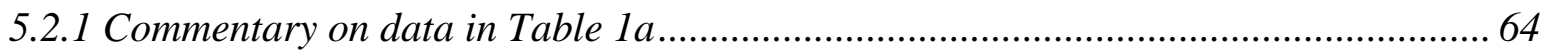


5.2.2 Commentary on data in Table $1 b$. 68

5.3 Representation, translation and interpretation of community 72

5.3.1 Representation and identity..... 72

5.3.2 Two sides of a coin-multiple or conflicting perspectives .... 73

5.3.3 Hidden figures:community linkages - roles of women in and within fishing spaces 78

5.4 Dependency and interdependency 83

5.4.1 Resource dependency, vulnerability, volatility. 83

5.4.2 Socio-political and livelihoods dependency between resource owners and users ...... 86

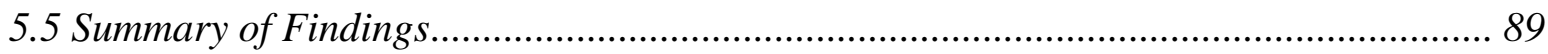

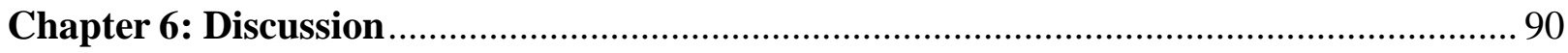

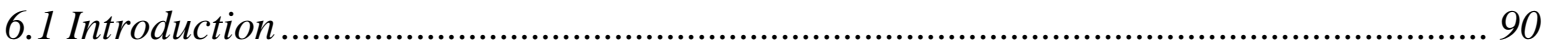

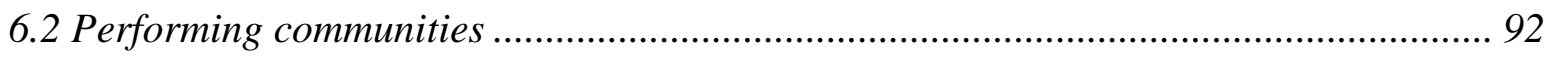

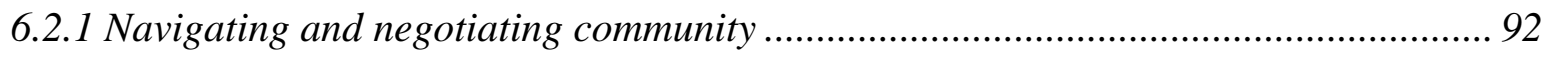

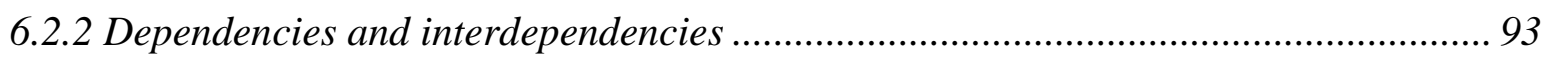

6.2.3 Informal economies, patron-client relationships .............................................. 97

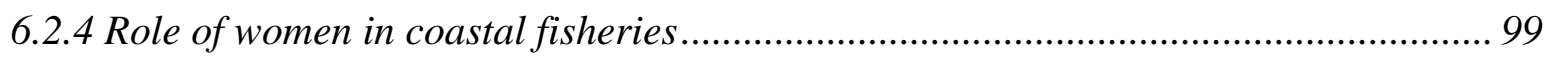

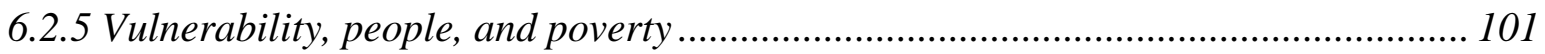

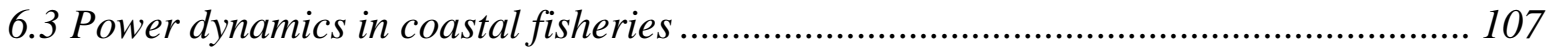

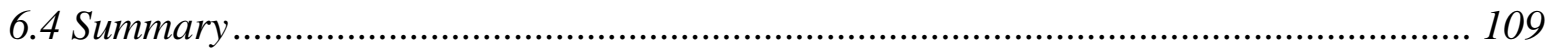

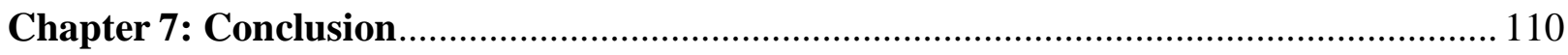

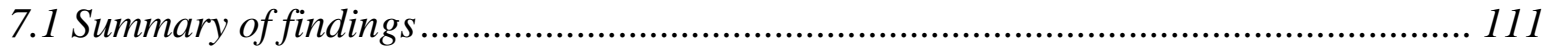

7.2 Suggested ways forward for a contemporary CBMRM in Fiji................................. 112

7.2.1 Engaging with and accepting the wider influences on Vanua structures and systems 112

7.2.2 Facilitating participation within coastal fisheries ............................................. 114

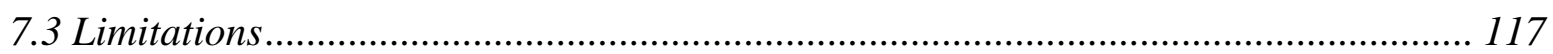




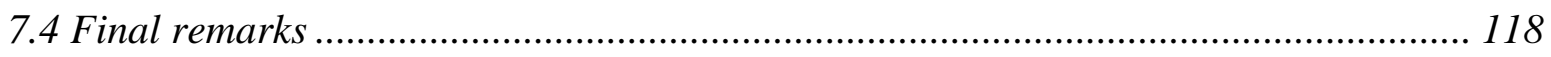

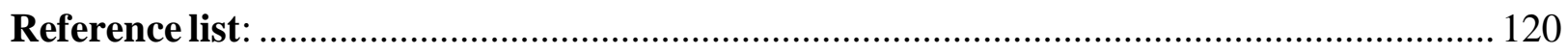

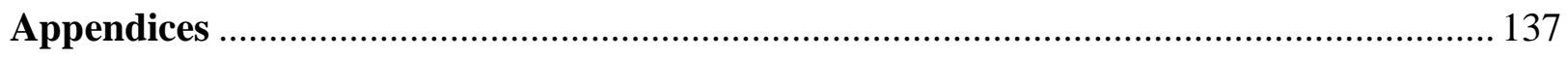

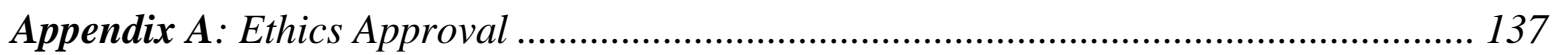

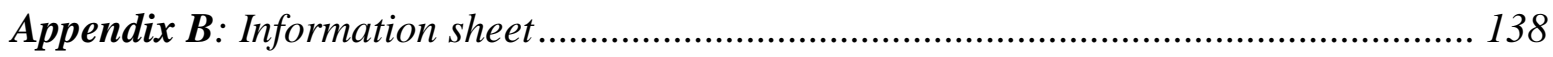

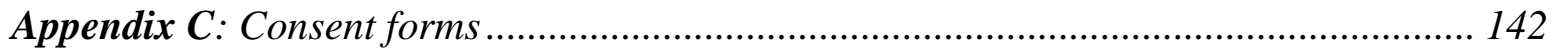

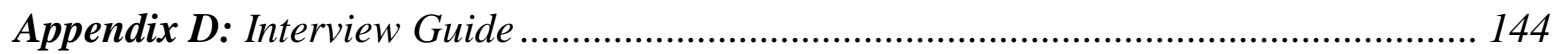




\section{Chapter 1: Introduction}

\subsection{The big picture - oceans, fisheries, people and policies}

Fisheries are a central tenet in the lives of many coastal communities around the world. The importance of coastal fisheries in contributing toward food security, protein needs, income and resilience highlight an important and complex socio-ecological relationship between fisheries resources, their users and their governing institutional structures (Beddington, Agnew \& Clark, 2007; Jupiter et al., 2017; Salas, Chuenpagdee, Seijo \& Charles, 2007). To highlight the importance of coastal fisheries contributions to meet global and local sustainable development needs, The World Food and Agriculture Organisation promotes the tagline for coastal fisheries as "contributing to food security and nutrition for all" (Food and Agriculture Organization [FAO], 2018). According to the United Nations (UN), the role of coastal fisheries is recognised as important towards contributing to eliminating hunger (UN Sustainable Development Goal 2: Zero hunger) and ensuring the sustainable management of marine resources (UN Sustainable Development Goal 14: Life below water) (United Nations Sustainable Development, 2019).

The Pacific Community forecasts that future fish needs of the Pacific will only be met by 6 out of the 22 Pacific island countries (The Pacific Community [SPC], 2015). In many Melanesian countries, including Fiji, the forecasted shortfall is between 20-30\% by 2030 , and is likely to be more pronounced in urban rather than rural areas of the country (Bell et al., 2009). Despite its significant importance in many Pacific diets, coastal fisheries face ongoing challenges in unsustainable use and management (SPC, 2015; Veitayaki et al., 2018).

Owing largely to a customary-led marine-resource management system, Fiji's marine tenure system is unique (Muehlig-Hofmann, Veitayaki, Polunin, Stead \& Graham, 2004; Veitayaki, 2000). Customary fishing rights belonging to the respective Taukei customary or qoliqoli owners are formally recognised under Fiji's 1942 Fisheries Act. Qoliqoli refers to a fishing space or area and i-qoliqoli refers to a fishing space or area belonging to a group of people.This allows Indigenous qoliqoli members to use and manage fisheries resources within its qoliqoli boundary. Additionally, the Act allows for commercial fisheries exploitation within those boundaries through a consent to access 
and licensing mechanism regulated through the provincial government and the Fiji Ministry of Fisheries. At the same time, the Act also allows for the subsistence use of coastal fisheries resources by all Fijian citizens. Unintentionally, this is where coastal resource use and management have become problematic despite best efforts to ensure a sustainable well-managed coastal fishery in Fiji (South \& Veitayaki, 1998).

While many approaches have been utilised to better manage the fisheries commons, community based (or led, focused) initiatives are by far the most prominent in the Pacific (Ruddle, Hviding \& Johannes, 1992; Johannes, 2002). Over the last three decades, Fiji has become renowned for its effort in reviving and promoting community based marine resource management (CBMRM) initiatives. More than 50\% of its $410 \mathrm{i}$ qoliqoli areas (fishing areas) are under some form of protection or management. These efforts are joint efforts initiated at community level and supported by various nongovernment organisations and the national government (Govan, 2009).

\subsection{Research focus}

Contemporary coastal fisheries management is a complex affair in Fiji. This research focuses on the involvement and participation of non-Indigenous fisheries user-groups. In particular, I focus on the involvement and contribution within the coastal fisheries sector of Fijians of Indian descent ${ }^{1}$, or Indo-Fijians as they will be referred to in this thesis. I aim to explore this through the following research questions.

\subsection{Research questions}

The central question in this research is: what are the roles and nature of involvement of Indo-Fijian fishing communities within the coastal fisheries sector in Ba Province? The following more specific sub-questions helped me better understand the nature of issues, challenges and opportunities faced by this group of people:

1. How do Indo-Fijians interpret their everyday social interactions in relation to coastal fisheries use and access in their communities?

2. How do community relationships enable the two ethnic groups to access

\footnotetext{
${ }^{1}$ The term Fijians of Indian descent is a more politically appropriate term to use, however, for the sake of simplicity and as Indians in Fiji have been referred to over the past decades, I have decided to use Indo-Fijians in this thesis
} 
fisheries, participate in and maintain power over fisheries activities in those communities?

3. What issues, challenges and opportunities do Indo-Fijian people face in the community coastal fisheries sector within Ba Province?

Given the complex historical and unique marine resource use and management system in Fiji, I have used a combination of theoretical approaches to frame this research. The historical colonial events leading up to and shaping Fiji's current socio-political environment, identity and relationship between the two major ethnic groups needed a post-colonial perspective. The complexities surrounding coastal resource use, its management, governance and future sustainability depends on how socio-political and socio-economic relations are negotiated. To understand these dimensions, I have used a political ecology framework. In addition, a de-colonial perspective offers a critical view of complex issues from a Pacific perspective. I explain the rationale for using these theoretical frameworks in more depth in Chapter 3, which comprises a literature review.

\subsection{Significance and contribution of this research}

This research seeks to contribute toward ongoing contemporary community based marine resource management (CBMRM) in Fiji. The role and involvement of IndoFijian community members has been largely neglected throughout the development of CBMRM in Fiji over the past three decades. This study aims to elucidate initial findings highlighting the socio-economic and socio-cultural relationships between the two major ethnicities.

\subsection{Terminology}

A variety of words, terms and phrases are interchangeably used throughout this thesis. These include references to coastal, inshore, and nearshore fisheries and are all used to describe community fishing grounds. Fishers, fisherfolks, fisherman and fisherwoman as the same and are all terms used to describe those who are involved as an individual or as groups in fishing activities. Middleman or middlewoman is a colloquial term used for an individual or a group who are involved as seafood brokers, buying seafood directly from fishers and selling it on to retailers. Fijians of Indian descent is the 
politically correct term, recently adopted at national level to identify people descending from India. This ethnic group were previously identified as "Indo-Fijians" as first described by Adrian Mayer (1963) to distinguish the Fiji-born from the India-born Girmitiya's (Naidu, 2017). I have chosen to represent this group as such in this thesis for consistency and flow in reading. Taukei refers to the Indigenous people of Fiji, while collectively all citizens are recognised as Fijians.

Non-English words are in italics and bold writing is used for emphasis where required. Other than these commonly used terms, any new terminology is explained within its context of use and in relation to colonialism. In relation to the term postcolonial/postcolonial, the hyphenated version is used to refer to the condition of life after the end of colonisation while the non-hyphenated version refers to the theory that studies colonisation and colonialism.

\subsection{Thesis overview}

This thesis is organised in seven main chapters. Chapter 1 introduces the topic, identifies the research focus, questions and theoretical framework underpinning this research. Chapter 2 provides an overall context of the relevance of coastal fisheries and their significance to Fijian communities. Chapter 3 reviews literature on key principles of community based coastal resource management, understandings and interpretations of "community" as applied in natural resource management discourses. In Chapter 4, I discuss the methodology used to address my research questions. I present the key findings in Chapter 5 while discussing the results and linking this to the literature review and research findings in Chapter 6. Chapter 7 presents an overall conclusion including some policy and in-field recommendations for advancing contemporary CBMRM at the community and national level in Fiji. 


\subsection{Summary}

This chapter introduces the research topic and articulates the research question which is to understand the role and involvement of Indo-Fijian fishing communities within the coastal fisheries sector in Ba Province, Fiji. It highlights the key theoretical frameworks used in the research. It also highlights the significance of this research in strengthening inclusion and participation of all stakeholders within contemporary community based coastal resource management in Fiji. An overview of the thesis ends this chapter. 


\section{Chapter 2: Context}

This chapter is presented in two parts. Part 1 offers an overview and contextual information about the study site and Part 2 provides an overall context for coastal fisheries use, management and development in Fiji.

\subsection{Fiji}

Fiji is an archipelagic country of more than 330 islands, of which 110 are inhabited and covers a total land area of 18,300 square kilometres (Figure 1). The two largest islands, Viti Levu on the south and Vanua Levu on the north, are the main administrative and economic centres of the country. A multicultural nation, consisting of more than four ethnic groups, Fiji's total population at the 2017 census, was 884,887 people. Indigenous Fijian's make up the majority at 57\%, followed by Fijian's of Indian descent at $38 \%$, the remaining 5\% is made up by Rotuman's, European's, other Pacific Islanders and Chinese (Fiji Bureau of Statistics [FBoS], 2018).

Fiji is also relatively well developed in comparison to other Pacific countries excluding Australia, New Zealand and Papua New Guinea. The tourism and sugar industries are the major sources of income for the country, contributing over $60 \%$ to overall gross domestic product (GDP). With an ocean area of 129,000 sq.km, Fiji has the third largest Exclusive Economic Zone (EEZ) in the region. The coastal and inshore area's boast of some very highly diverse and significant marine habitats, species and processes in the world. These include areas such as the Great Sea Reef region, the Vatu-I-Ra passage and the reefs of the outer islands in the Lau groups which provide economic and social support to Fijians (Nair, 2003).

The contribution of small-scale inshore commercial fisheries produces a value of FJ\$ $21.74-80.08$ (US\$ 10.8-40.09) per hectare per year, and a total national value of FJ\$ 14.57-53.69 (US\$ 7.30-26.88) million per year based on a 2015 national marine ecosystem service valuation for Fiji (Gonzalez et al., 2015). FAO estimates that 36, 420 $\mathrm{kg}$ of live fish is produced annually in the country of which an average $49.9 \mathrm{~kg}$ is consumed annually per person (FAO, 2018). 


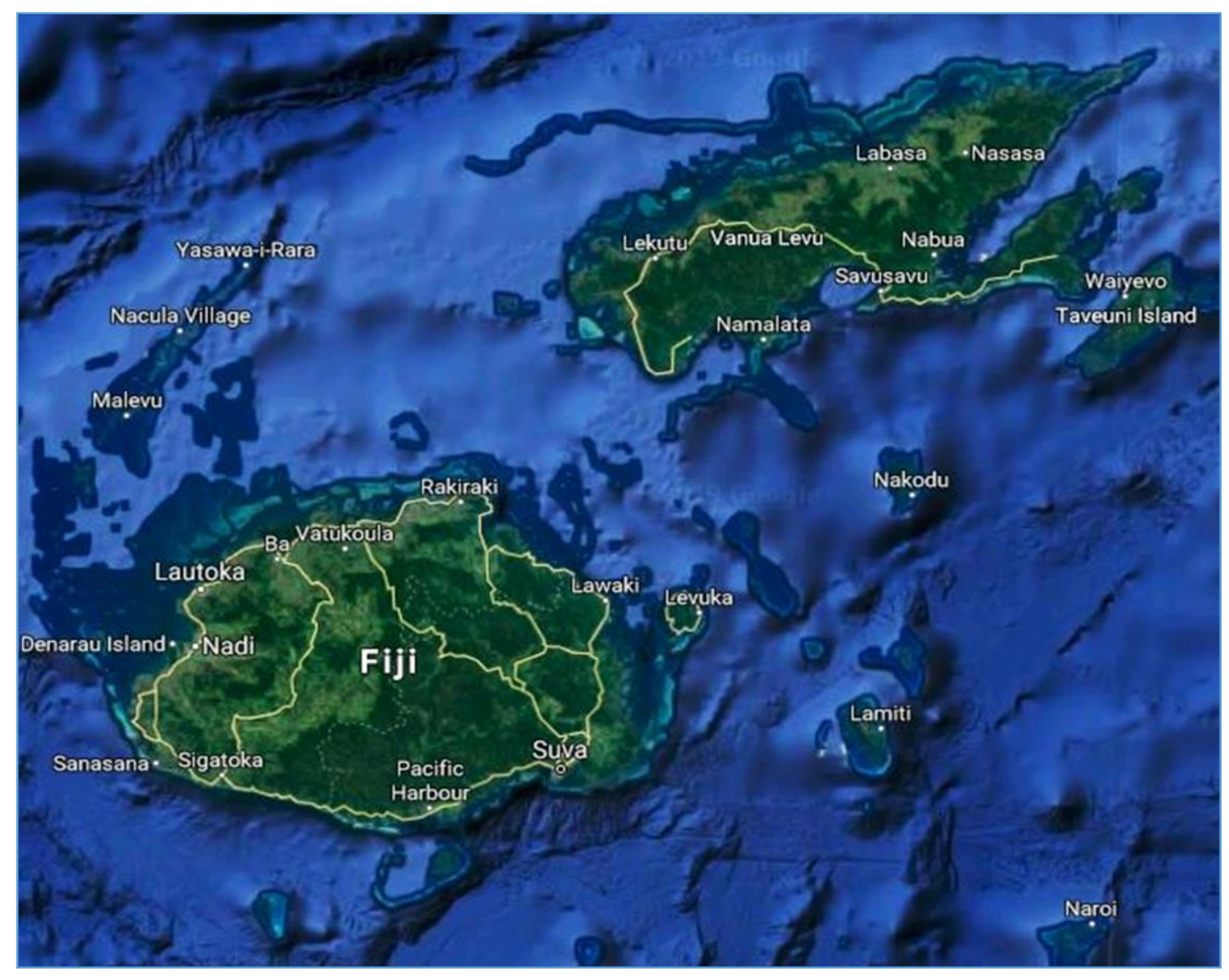

Figure 1: Map of Fiji Islands. Source: Google Maps

\subsubsection{Ba Province}

Ba is one of the eight Provinces on the northwest of Viti Levu, Fiji's main administrative island. The Provinces' main administrative centre, Lautoka is approximately 200 kilometres from the capital, Suva. Ba is also the country's most populous Province with more than a quarter of the total country's population $(247,708)$ people living in 21 districts and 107 villages (Fiji Bureau of Statistics, 2018). Indo-Fijians generally live on smaller settlements in rural areas and are mostly involved in the agriculture or sugarcane sector while some live in and around Towns and the city centre occupying day-jobs in administration, services or tourism. The Province has always been renowned for its abundance in natural resources, including fertile land for agriculture, sugarcane and dairy as well as one of the largest customary fishing (qoliqoli) areas, beaches and picturesque settings. The features contribute to the Provinces thriving tourism industry with the majority of hotels and resorts between Nadi and Rakiraki and the surrounding outer islands. It is home to Fiji's largest international airport in Nadi and many prominent Indo-Fijian businesses grew out of Ba following the economic success of the 
sugar industry in the late 1970's and early 1980's. While sugarcane continues to play a significant role in the lives of many Indo-Fijians in the area, its reliability as a viable source of income and livelihood has greatly declined over the past few years. Thus, in securing alternative livelihood options for themselves and their families, most caneproducing families are also involved in other livelihood sectors including coastal fisheries, as either subsistence, artisanal or commercial fishers, middlemen or retailers. While data to support this observation is limited, the steady decline in sugar-cane production is indicative that many people are turning to other forms of livelihoods in the Province. In 2017, there were approximately 200 Indo-Fijian fishers registered with the Ministry of Fisheries as semi-commercial or commercial fishers in the Ba Province (Ministry of Fisheries official, personal communication, 04 ${ }^{\text {th }}$ July, 2019). ${ }^{2}$

The sites selected for this study are within the Ba Province. (Figure 2). Interviews were carried out in five Indo-Fijian settlements and in one Taukei village between $\mathrm{Ba}$ and Tavua districts. Villages and settlements within these two districts have been assigned fictive alphabetic names while research contributors are assigned with pseudonyms in this study. This was done to ensure that research participants' identities were kept confidential. Given the small study site, where inter-ethnic relations are still evolving and fraught with possible tension, it was important to keep any identifiers such as names of participant or their location confidential.

However, most sites were typical of Indo-Fijian occupation similar to other locations in Fiji. The below excerpt from Lal (2015) vividly describes the set-up and structure of most common rural Indo-Fijian settlements in Fiji.

In Fiji, scattered settlements fringing the sugar mills or close to coastal areas became the norm. People who might have avoided each other back home for religious or cultural reasons shared the same social and geographical space in Fiji, as they did in all the other indenture colonies...It would have been a traumatic experience for the early settlers to build bridges of understanding with people from different social groups, who spoke different languages. Our immediate neighbour in Tabia was a Muslim, and there were

\footnotetext{
${ }^{2}$ Following the 2018 flooding in Ba, the Ba Fisheries Office was badly damaged, and most records destroyed, the officer in charge at the time was not able to give me an accurate figure for 2018, however, suggested that this might be slightly higher than in the previous years.
} 
South Indians on the edges of the village. Our relations with them were not socially close but there was no friction either...People cooperated for the performance of agricultural tasks (such as cane harvesting) or to build and operate schools, maintain the village cemetery. Initiative and enterprise were the drivers of change. An egalitarian, pragmatic ethos born of need and necessity is a hallmark of Indo-Fijian identity (p.60).

However, with a shifting socio-economic and socio-cultural base, the Indo-Fijian identity in agriculture and the sugar industry is becoming highly diversified. Fishing has been an important food and income source for Indo-Fijians and these typical farm sites are gradually becoming replaced by Yamaha boat engines mounted on racks under mango trees, wooden or marine ply board carved half cabins or long boats, and the associated fishing gear of nylon fishing lines, hooks and sinkers and freezer ice-chests.

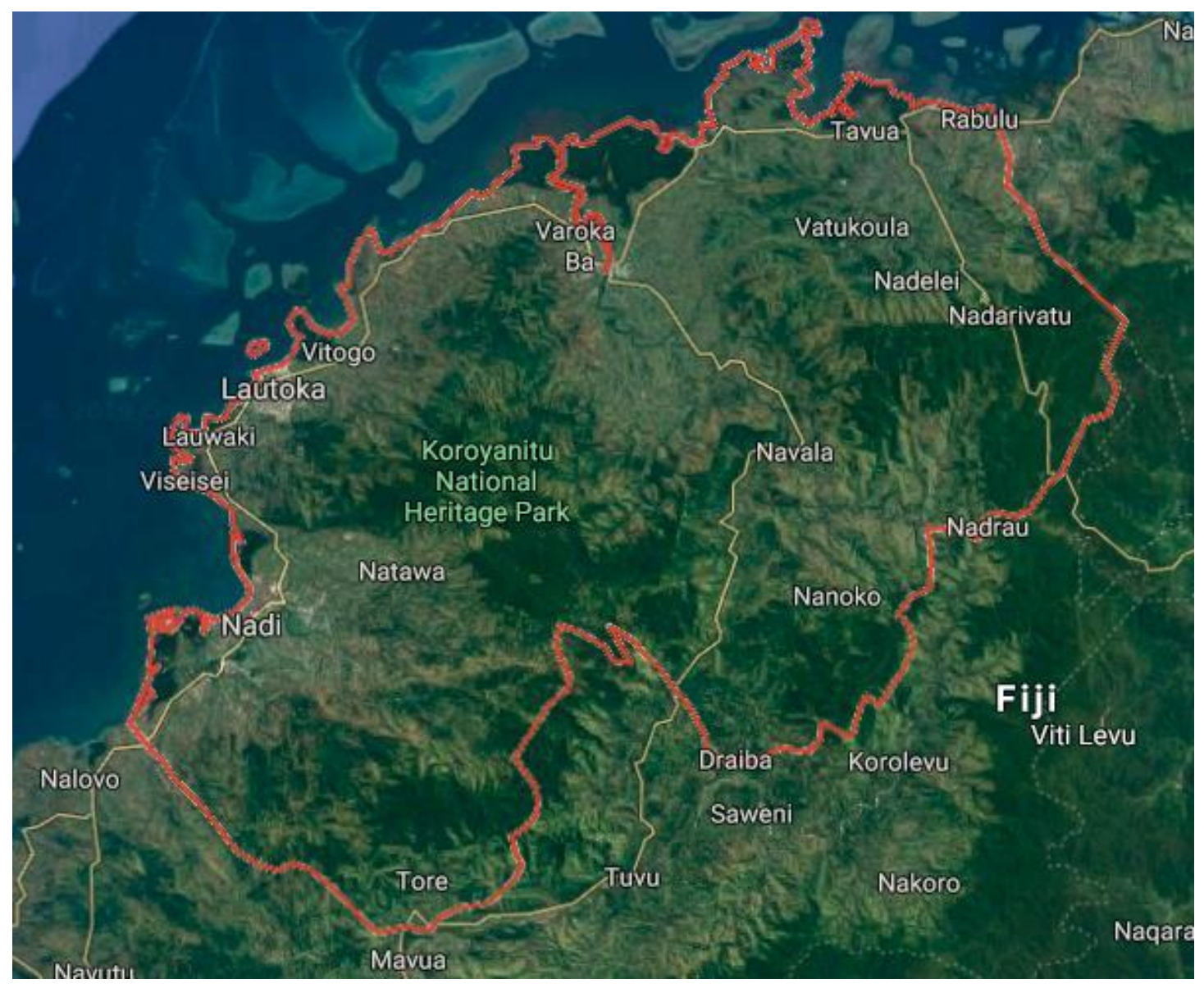

Figure 2: Close-up of Ba Province with major centres. Source: Google Maps 


\subsection{An overview of coastal fisheries in Fiji}

Coastal fisheries generally refer to the fishing activity (or exploitation) occurring within the high-water mark and the area up to the fringing or barrier reef and beyond. (Figure $3)$.

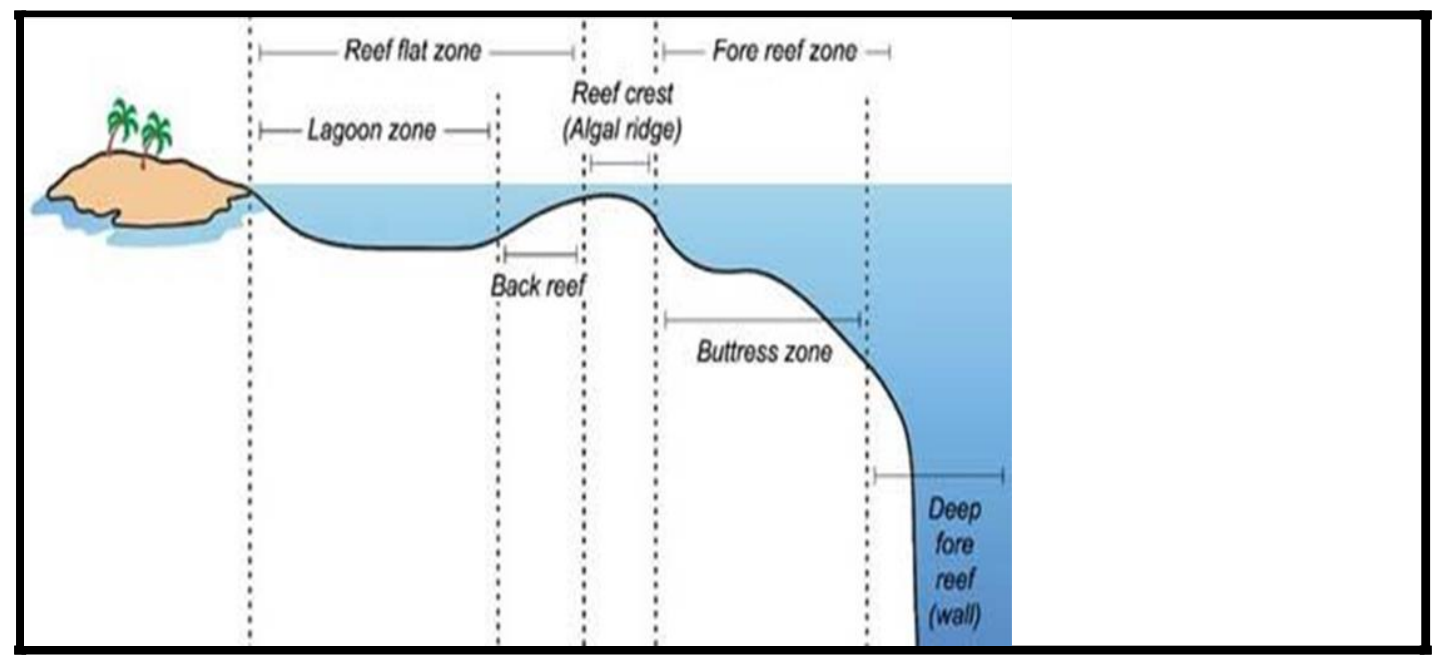

Figure 3: Typical reef cross section. Source: Gillette, Lewis \& Cartwright (2014).

Gillette, Lewis \& Cartwright (2014) suggest that Fiji's major coastal fisheries could be defined and grouped as follows: 1) by resource category such as reef fishes or invertebrates; 2) by fishing method such as gillnet or handline fishing; 3) by area such as customary area or qoliqoli area fishery; 4) by disposal of catch; subsistence or commercial and 5) some combination of all the above.

For the purposes of this research, which is looking into the fishing practices and fisheries related activities of Indo-Fijians, I will largely consider the catch disposal methods (subsistence or commercial) and the target fish species. According to the Fiji Fisheries Ministry, Indo-Fijian fishers are typically small-scale commercial or artisanal fishers targeting both reef and deep-sea species. Some commonly targetted species include Grouper (for example Epinephelus Plectropomus, Cephalopholis species), Snapper (Lutjanus species), Trevally (Caranx species), Parrotfish (Chlorurus species), Wahoo (Acanthocybium solandri), Walu (Scomberomorini) and Jobfish or Pakapaka (Pristipomoides species). These species are usually highly graded and sought after often fetching premium prices at the markets. 
There are a range of roles that make up the coastal fisheries labour and exchange. In 2010, an unpublished study ${ }^{3}$ on the socio-economic status of Indo-Fijian fisherman by a USP based Geographer, classified Indo-Fijians in the fishing business into five creative ${ }^{4}$ categories: 1) Machuas who are the actual fishermen; 2) Gayas who own the fishing resources and usually have two or three people accompanying them on fishing trips; 3 ) Dayas are usually someone who has a fish retail business and provides the necessary resources for fishing and would occasionally or never go on trips; 4) Maya, as usually the middlemen, buying directly from the Machua's and the Gaya's to resell for a profit, and 5) Jayas' who normally purchase from the Maya's, re-bundle the catch and sell them at a higher price often to other retailers, restaurants or hotels (Singh, 2008). No further information was available to follow up on this research.

With respect to fin-fish consumption patterns of Indo-Fijians, Rawlinson, Milton, Blaber, Sesewa \& Sharma (1995), suggest that Indo-Fijian's are more likely to purchase fresh fish from local markets or fish shops than to fish directly. However, the pattern is likely to be quite different now than it was over the last two decades. An increase in demand for fresh fish in urban centres has pushed fish prices up, making it a lucrative livelihood option for Indo-Fijians. In addition, a steady decline in the number of people involved in the sugar cane sector may also be contributing to an increase in the number of people turning to other livelihood options such as commercial fishing to sustain their livelihoods.

Data on coastal fisheries has always been problematic to collect in the Pacific region and Fiji's case is no exception. Despite being recognized as a significant contributor towards livelihoods and income for many rural communities, national government continues to underfund and under-resource this important sector (Teh, Teh, Starkhouse \& Sumaila, 2009; Gillette \& Tauati, 2018). In 2017, the Fijian government reformed the former fisheries department as a standalone Ministry. The revamped Fisheries Ministry has now adopted a mission "to drive sustainable resource management, economic growth and improve livelihoods through SMART fisheries and forest policies that is based on applied research and development" (Ministry of Fisheries [MoF], 2018). The MoF's primary role is to enforce the 1942 Fisheries Act which includes monitoring, compliance and policy

\footnotetext{
${ }^{3}$ Efforts to locate an actual published article on this newspaper story has been futile as the researcher has retired.

${ }^{4}$ Creative in the sense that these names are made-up and not recognized formally or even socially within the community structures.
} 
making in relation to fisheries resources and its management in the country.

\subsubsection{Marine governance system}

Marine management in Fiji is legally defined under its 1942 Fisheries Act. The 75-year old legislation has undergone several amendments and since 2010 regional and local agencies have been working on three separate pieces of legislation, including an inshore fisheries instrument which should enable an updated modern management regime. To this end the Fiji Environment Law Association (FELA) has produced a consultative policy and law discussion paper that proposes a holistic way forward for coastal/inshore fisheries management in Fiji (FELA \& EDO NSW, 2016).

Traditional management approaches place emphasis on customary fisheries management practices. Since 2000, the initiation of the Fiji Locally Managed Marine Areas (FLMMA) network has enlisted over 400 voluntary customary led marine management areas in the country (Govan, 2009; Jupiter et al., 2014). FLMMA's bottom- up, community initiated adaptive management approach has been widely appreciated amongst marine conservation scholars and practitioners (Cinner \& Aswani, 2007; Tawake et al., 2001).

Sloan and Chand (2015) have offered useful insights in their report "A Review of Nearshore Law and Governance" within the Fiji context, articulating the complexity of the dual government/community based fisheries management, which "incorporates a modern legal framework based on English common law.....and a traditional Taukei system of law and governance" (p.1). However, as Sloan and Chand note, while the modern, centralised government system applies to all Fijians regardless of ethnicity or heritage, the traditional Taukei worldview and management mechanism based on social hierarchy is reserved only for indigenous Fijians. According to Sloan and Chand (2015), this dual, non-inclusive and complex near-shore marine management system is one likely reason for non-compliance, ineffective and inequitable community-based fisheries management in Fiji.

Commercialisation of a once customary only fishing practice in the last few decades has led to confusion, dispute across many Fijian communities. The process of obtaining a commercial license is described below.

\subsubsection{Commercial fishing license process}

Any person or entity intending to carry out commercial or semi-commercial fishing activities in Fiji must obtain a fishing license to do so. The license approval as stipulated 
under the Fisheries Act, includes seeking consent from customary fishing ground owners prior to granting of the fishing license. In most cases, the traditional chief of the village is responsible for making communal decisions for village developments and resource management. In recognition of this reciprocal engagement, licensed fishing operators were expected to pay a goodwill payment in return for commercially fishing within customary fishing grounds. The payment is usually agreed and negotiated with the village chief and paid at the beginning of the year prior to obtaining the fishing license. The goodwill amount is rarely disclosed to other parties and is often negotiated based on familial and a 'selfserving' manner benefitting the chief in most cases. Thus, with no formal regulations and guidelines directing how this payment should be collected and used, the system has become subjected to abuse and corruption over the years (Veitayaki, 1998).

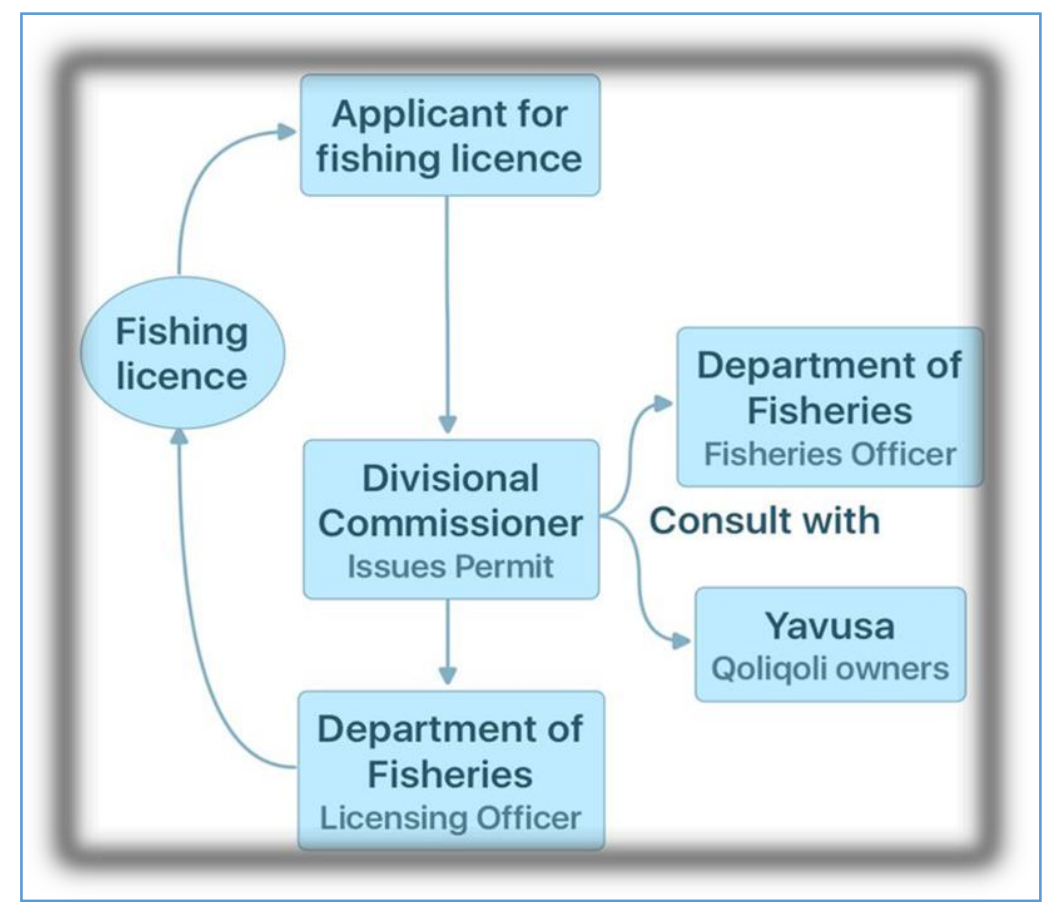

Figure 4: Process for obtaining a commercial fishing licence under the Fisheries Act, 1941. Adapted from Gillette, Lewis \& Cartwright (2014).

In January 2017, the Fisheries Ministry declared a complete ban on demand and payment of goodwill to qoliqoli owners until it had formulated a fishing access framework which determined how much to pay and who to pay. Commercial fishing license applicants were provisionally exempted from paying goodwill to qoliqoli owners until the guidelines are formalised. While initially anticipated to come into effect within six months 
of the ban, the guiding document is yet to be formalised and implemented. The ministry has noted several challenges in finalising a goodwill or access regulation including disputed fishing boundaries and ownership and challenges in standardising varying fishing area sizes, the large variability in fishing gear and resources used such as types of boats, engines, and methods used for fishing has made this process onerous. As of July 2018, two national consultations and several pocket stakeholder meetings have been held to discuss the proposed regulations, but an agreed framework is yet to be adopted.

The process for obtaining a fishing license prior to January 2017 were as follows:

1. Consent from the legal custodian of the fishing ground (Section 13 (2) of the Fisheries Act;

2. Support letter from Provincial office for verification of signatures;

3. Commissioner issues fishing permit (with conditions);

4. Fisheries issues license subject to the fulfilment of requirements.

The current requirements for a fishing license (as at July, 2018) were:

- $\quad$ Permit to fish (from Commissioner Office);

- $\quad$ Birth certificate;

- $\quad$ Photo identification;

- $\quad$ TIN letter;

- 2 passport photos;

- $\quad$ Maritime Safety Authority of Fiji (MSAF) Boat Master / Class 6 licence;

- MSAF vessel registration/survey certificate;

- $\quad$ Full length photo of vessel with engine to be inspected by a fisheries officer;

- Crew list with photo identification and contact details;

- $\quad$ List of all fishing equipment;

- Monthly catch data records for the previous year;

- $\quad$ Annual mooring fees - landing and berthing at Lautoka wharf. 


\subsubsection{Community based coastal fisheries development in Fiji}

Pre-colonisation, customary fishing methods were successfully utilised, and marine resources managed to avoid over exploitation and ensure its sustainability. While not all fishing practices were sustainable, there were adequate control mechanisms, such as low human population numbers, basic fishing gears and non-motorised boats to avoid over fishing and subsequently ensuring stable fisheries stock at the time. (Johannes, 1998; Ruddle, 1998; Veitayaki, 1998).

Following colonisation the social, cultural, economic and political landscapes across the Pacific, including in Fiji, have changed dramatically. A few factors are responsible for this alteration. Firstly, colonisation encouraged neoliberal agenda's and policies supporting the support and encourage efficient exploitation of coastal fisheries. Overfishing was further exacerbated as coastal fisheries became recognised as an important trade commodity within the Pacific and across Asian countries. Secondly, a growing population in many Pacific countries placed immense pressure on already scarce coastal resources. Thirdly, insufficient resources are allocated to coastal fisheries management with monitoring, enforcement and compliance of management plans facing the biggest challenges in the industry (Gillette \& Tauati, 2018). Last, but not least, inclusive and effective stakeholder participation within contemporary fisheries management is limited or non-existent in some cases (Veitayaki, 1997).

As such, customary management approaches were applicable, adequate and adaptable to most conditions. While not precisely termed as 'management', customary fishing practices were conducted within appropriate cultural/traditional structures such as the Vanua in Fiji. Within the Vапиa structure, fishing is a specific and skilled occupation, reserved for traditional fishers known as the gonedau's (Veitayaki, 1997, 1998). These customary practices and traditions are still important and relevant for sustainable fisheries management in the country.

\subsection{People of the land and ocean - the Vanua}

In Fiji, the term "Vanua" has several meanings but essentially is a concept that inextricably interrelates the physical, social and cultural dimensions (Ravuvu, 1983). Ravuvu describes it as a concept that encompasses land, flora and fauna to which a 
person or a group is identified with or belongs to. The Vanua also describes the members of a group who relate socially and politically to one another based on the kinship system of veiwekani.

Culturally, the word Vапиа also embodies the values and beliefs that people in a particular locality have in common. "It includes their philosophy of living, and their beliefs about life in this world and in the supernatural world, thus, "the concept of Vanua is an encompassing one; it is the totality of a Fijian community" (Ravuvu, 1987, pp.14$15)$.

It should be noted that the concept of Vanua while referring to land and place also encompasses the ocean and its resources, simultaneously acknowledging the people in a place who are bounded to that land (Overton, 1999). Spriggs and Scarr (2014) proffer an additional description such that Vanua could be considered in the light of three elements: spirits, places and human. They suggest that these three elements of Vanua are sources of physical and spiritual security for members of the group (yavusa) and formed the basis of their sense of belonging and identity. Spriggs and Scarr, (2014) express this as:

a person felt confident when they understood that they belonged to a particular yavusa; that they were associated with the territory in which the yavusa's roots were established; and that they were protected by the spirits associated with that yavusa. (p.27).

Drawing from these tenets of Vanua, concepts of vakavanua ${ }^{5}$ and bulavakavanua ${ }^{6}$ are useful in understanding the cultural protocols, beliefs, customary practices, and structures of the traditional Fijian way of life. Nainoca (2011) in her doctoral thesis uses of the concept of bulavakavanua in her research as "it conveys the distinctive historical richness of indigenous Fijian way of life" (p.9). However, such concepts in practice are much more complicated and follows complex negotiations between land, resources, kinship-based relations, and socio-cultural hierarchies. Nainoca adds that there is a complexity of relationships, dynamics, and politics in the bulavakavanua which is further complicated with external factors influencing traditional customary lifestyles,

\footnotetext{
${ }^{5}$ Vaka - translated in Taukei language as "way of" so vakavanua means the Vanua (traditional or customary) way of relating to something.

${ }^{6}$ Bula - translated in Taukei language as "life" so bulavakavanua means the Vanua way of life in this case.
} 
governance, culture and religion within the Vanua community context (p.205).

\subsubsection{Land use, management and linkages to identity}

Fijian land use, management, and its governance has been an important feature in the country's political history. Fiji's cession to Britain caused confusion and created insecurity amongst many Indigenous Fijians at the time. Largely due to the ambiguous nature and haste of the transfer, common Taukei's initially refused to acknowledge the signing of cession in 1879. Lack of transparency and inadequate communication led to further insecurities created within Indigenous Fijians as the British Empire went on to introduce land and agriculture reforms to maximise benefits for its settlers. The once communal lifestyle that most Indigenous Fijians had been leading until that time gradually eroded as Indigenous Fijians became subjected to a colonial cash-based system (Ramesh, 2016).

Ratuva (2012) noted that the cultural and "Vanua" way of life become compromised and was perceived to be in danger by a growing population and prosperity of Indo- Fijians. This insecurity led onto many unintended and some intended consequences to members of both communities. According to Rutz (1995, p.74, quoted in Ramesh, 2016):

both communities in Fiji embraced independence for vastly different reasons. Indians imagined a newly created "citizen" living in a civil society that subordinated the status of religion, race and a particularist culture to national solidarity, whereas Indigenous Fijian rhetoric was embedded in the paramountcy of Fijian interest informed by ethnic or communal voting system, hegemony of the chiefs and protection of Indigenous land. (p.124).

The Indo-Fijian articulation to place and in society further described by Ramesh (2016) refers to the metaphorical use of the three-legged stool by the Fijian Statesmen and high chief, Ratu Sir Lala Sukuna, an influential figure during Fiji's land demarcation. Presently, over $80 \%$ of land communally belongs to Taukei as native land, with around $10 \%$ belonging to the state and roughly $3 \%$ as freehold with individual titles. Following independence, Ratu Sukuna allowed for equal and distinct recognition for the IndoFijian community in Fiji, suggesting that Fiji as a country stood on three legs; labour of the Indo-Fijian farmers, land of the Indigenous Fijians, and British governance 
mechanisms. In contrast, Naidu, Matadradra, Sahib \& Osborne (2013) suggest that the colonial society founded upon racial and hierarchical divisions, created a "three-tiered economic structure" (p.10). Within this system, Europeans and Chinese were at the top, Indians in the middle, and Indigenous Fijians' at the bottom of the tier. Regrettably, Ratu Sukuna's vision for the "three-legged stool" struggled amidst inter-ethnic land issues and conflicts that perpetuated the ethnic divide between Taukei and Indo-Fijians (Lal, 2015; Naidu et al., 2013). The hierarchical socio-economic tiers resulted in political, civil unrest and further marginalisation of the most vulnerable in all communities (Naidu, et al., 2013).

In the past three decades, despite national efforts to socio-politically integrate the two communities, racial and ethnic conflict over land security, economic prosperity, control and access over land and marine resources has led the country to four military coups and a military mutiny since 1987. Ratuva (2012) writes that:

while affirmative actions taken by the state could potentially address inequality and provide social justice for those marginalized and disadvantaged community members, at the same time the practices of affirmative actions are much more complex and often tied up with the political, ideological and economic interest of powerful groups making and implementing those policies. (p.140).

He notes that in post-colonial Fiji, the fundamental moral imperatives of affirmative actions are undermined and are of more benefit to the self-serving interests of powerful elites controlling state institutions and resources. Naidu et al., (2013) also note this in a study of inter-ethnic relations, discrimination, and exclusion where respondents highlighted politics, discriminatory affirmative practices, and social and economic inequalities as contributors to inter-ethnic tension.

Reflecting back on the importance of land, or more broadly, the Vanua concept of the physical, social and cultural interconnectedness, the next section reviews socio-cultural Events in Fiji such as the introduction of Indian labourers in the country. 


\subsection{People from afar: Fijians of Indian descent}

Some four years on following Fiji's cessation to Britain in 1874, Indian labourers were brought to fill a labour shortage ${ }^{7}$ within the country's agricultural export sector to Britain and her colonies. Having seen the hardworking and industrious Indian men and women work the sugarcane farms of Trinidad, Tobago and Mauritius, the then Governor in Fiji, Sir Arthur Gordon, arranged for the shipment of nearly 60,000 Indians between 1879 and 1916 (Ali, 1979). This contractual period, known commonly as the Indenture period, or the Girmit era, holds a significant time in history for both Indigenous Fijians, the Indian labourers and subsequent Indian trade and opportunity migrants. The contract was initially a five-year term with the provision of accommodation and a basic-wage rate for the labourers. At the end of this contract, labourers could leave at their own expenses or stay on for another five years with and offer to have a free return passage, which depended on the availability of ships back to India. Essentially, this was a clever way to incentivise the Indian labourers to stay on in Fiji as by the end of a ten-year period, most would have settled and eventually choose to stay. While a considerable number of Indian labourers opted to return back to India, a significant proportion remained and now their descendants make up $38 \%$ of the Fijian population.

The Indo-Fijian community and their social identity in Fiji could perhaps be best articulated within three time periods: i) during colonisation as Indentured labourers; ii) post-colonisation and following Fijis' independence as democratic socio-political actors; and iii) recently that of an emerging "hybrid" community illustrated by various socio-political/socio-cultural reforms of the past decade.

Early accounts of Indians in Fiji are provided largely by Ali (1979), Gillion (1977), Lal (1999) and Mayer (1963) who describe the early process of bringing in Indian Indentured labourers into Fiji together with the socio-cultural experiences and social identity of the Girmit community (Rai, 2011; Prasad, 2014). Their contribution to the

\footnotetext{
${ }^{7}$ The labour shortage in Fiji during the early colonial days were mainly due to prohibition of Indigenous native Fijians in participating in commercial agriculture activities which was opposed to their Vanua lifestyle as well the situation with other Melanesian/Polynesian labourers being unavailable or too expensive for the colonial government
} 
literature through extensive research of historic Girmit documents and accounts of personal interviews with surviving Girmitiyas' highlight the social injustices, hardships and suffering within the "coolie lines"8 of Fiji. Adrian Mayer (1963) coined the term Indo-Fijian, referring to Indians brought under the British indenture system and their descendants is now widely and commonly used to identify this group of people.

The socio-cultural experiences and social identity of the Girmit community are well documented through the works of predominantly Indo-Fijian scholar activists' such as Brij Lal (1999), Vijay Naidu (2017), Ahmed Ali (1979) and Satish Rai (2010). Their contribution to literature through extensive research of historic Girmit documents and accounts of personal interviews with surviving Girmitiyas' highlight the social injustices, hardships and suffering within the "coolie lines"8 of Fiji (Girmit, n.d).

These early accounts of the Indian community in Fiji describe very little socio-cultural interaction between Indo-Fijians and Indigenous Taukei communities (Lal, 2015). The population at the time had three separate and distinct languages; over 300 native Fijian dialects, a mix of north and south Indian languages which included Bhojpuri, Urdu Tamil and Telugu and British English, to learn and use for communication. Nowadays, English is preferred for social mobility reasons but the Bauan dialect and Fiji Bhat, a cross of multiple languages including north and south Indian dialects is most commonly spoken (Naidu et al., 2013; Naidu, 2017).

There is sufficient evidence to suggest that the colonial administration reinforced separate ethnic and communal identities of the people as far as possible (Lal, 2015; Ramesh, 2016) and it is possible that language presented a key barrier to socialisation and integration between the communities at the time. As Lal (2015) writes, "A distinct 'Indian' sensibility has persisted in Fiji far more than it has in other places, and it is a direct consequence of the colonial Fijian policy of racial segregation" (p.53).

\footnotetext{
${ }^{8}$ Coolie lines - or as commonly referred to as "lanes" during Girmit and post-Girmit - refer to the accommodations and daily lives of Indentured Indian workers.
} 
In those often dark and turbulent times of crossing the kaala pani (dark waters) many Girmitiya's bonded over a fictive kin relationship known as jahajibhai's or the brotherhood of the crossing (Lal, 2015). According to Lal, bonding over this common identity "eased the pain of separation and isolation in all the indenture colonies" (p. 55). Lal (1999) adds;

The experience of a long sea voyage by a land-locked people, in often difficult and dangerous situations, without the comfort and security of family and community, produced a semblance of fictive kin relationship with real emotional and social significance which 'neither time nor circumstance would erase' (as cited in Lal, 2015, p.55).

Fighting to abolish the indenture system and claiming equal citizenship and recognition in Fiji has been an ongoing struggle for many Indo-Fijians. Ramesh (2016) highlights that post-independence, Indo-Fijians' made concerted efforts to gain political equality and access to fairer and longer periods of land leases. Indo-Fijian have also experienced social and economic marginalisation and discrimination across many sectors including public policy, education, and access to social services (Naidu et al., 2013). Setting up separate governance institutions such as the Native Lands Commission and the Native Fisheries Commission whose roles were to safeguard the land and natural resources in the interest of the "Indigenous Fijian paramountcy" has been noted to further discriminate and marginalise non-Indigenous community members in the country (Ramesh, 2014; Ratuva, 2012).

Ratuva (2012) notes that colonial administrators were strategic in forming and maintaining a "divide and rule" policy which further perpetuated ethnically based political representation within the legislative council. He adds that since independence in 1970, three official ethnic categories were identified: Fijians, Indians, and Other, referring to minority ethnic groups such as Chinese, European, other Pacific Islanders and those of mixed ancestry. Following independence, the country has made several attempts to define and assign a national identity through her various constitutions ${ }^{9}$.

\footnotetext{
${ }^{9}$ Fiji has had four different constitutions since Independence; 1970, 1990, 1997, and 2013. Each one made various attempts at reconciling and bridging ethnic differences.
} 
The 2013 constitution recognises that the term Fijian is applied to all citizens regardless of ethnic groups in a bid to foster and promote a common name and identity ideology in Fiji (Naidu, 2017).

In a more contemporary identity approach Naidu (2017), reflects;

The sense of being 'Fijian' among Indo-Fijians has increased over time with acculturation $^{10}$, and through their interactions with people of other countries including India. The more relaxed and islandness of Oceanian, and especially Taukei culture seem to have permeated their being. There has been a sea-change in culture(s) and identity (ies) over the generations between the humble, humiliated, illiterate Indian coolie who worked in plantations, and helped build the Fiji economy and society, and the current generally educated Fijians of Indian descent (p.24).

Not all groups are satisfied though, with many Indigenous Fijians' claiming that the term Fijian is for the Indigenous people and cannot be shared by outsiders (Naidu et al., 2013). Indo-Fijians, while generally positive about identifying as Fijians, are at times confused over its use. Naidu et al., (2013) highlighted that during their research, many Indo-Fijian participants struggled with articulations of identity and belongingness in Fiji. On one hand, many felt that using the term Fijian meant that they were being recognised as Fijians in the wider global context, while on the other hand at home, within the country, they felt insecure using the term due to the many cultural and ethnic differences. Paul Geraghty, a Fijian linguistic expert recommends using the word "Fijian" sensitively, "given the lingering tension over its use" and that it also must be a personal choice (Round, 2016). Despite these insecurities, Ramesh (2016) adds that the new ethno-class, emerging through the current Fiji First government in power, is, at least for now, uniting progressive Indigenous Fijians, Indo-Fijians and members of the military regime in a "new multiracial Fijian elite" (p.140).

\footnotetext{
${ }^{10}$ Acculturation is the process of social, psychological, and cultural change that stems from the balancing of two cultures while adapting to the prevailing culture of the society. Individuals of a differing culture try to incorporate themselves into the new more prevalent culture by participating in aspects of the more prevalent culture, such as their traditions, but still hold onto their original cultural values and traditions.
} 


\subsubsection{Relationship between marine resource use and Indo-Fijians}

Indo-Fijians are essentially resource users within the broader marine resource management systems in the country. They have various roles within this sector, including that as fishers, middlemen/women, retailers, wholesalers and exporters. However, their involvement in these various roles in coastal fisheries are not welldocumented, and this group of people have not been adequately represented or reflected in the country's socio-economic, cultural, and political participation in the coastal fisheries sector. As outlined in section 1.2.1 above, the country's dual management system of inshore marine resources limits non-Indigenous community members' participation in marine management and coastal governance processes. Nonetheless, this lack of engagement/representation/voice impacts the livelihoods, culture, and sense of community of all resource users within the broader coastal fisheries discussions in Fiji. I suggest that this group, whilst constitutionally able to access and utilise the marine environment for sustenance and livelihoods, are socially and culturally excluded from the management and decision-making processes of the very same resource. As suggested by Naidu et al., (2013):

Inter-ethnic relations have many dimensions at personal and inter-group levels. Issues relating to land and other natural resources, scholarships, employment, discrimination, and social inequality will continue to affect these relationships. (p.23).

There is hope though with recent socio-political developments between the two ethnic groups based on friendship, cohabitation and inter-marriages (Naidu, 2017).

2.5 Fostering new cultural identities - to go forward, we must look back at our histories.

In 1884, thirty-three Indian labourers died in a tragic shipwreck off the coast of Rewa Province. The ship, HMS Syria, was carrying 497 Indentured workers and 43 crew members when it struck the reef off Naselai passage (Chand, 2017). Between 55 to 59 people were unaccounted for and close to 35 people whose bodies were brought ashore were buried in Navilaca/Vuniselala village in Noco District (Chand, 2017). According to Chand's article, the rescue operation of the Indian passengers were largely colonial narratives and one in which the valiant rescue efforts by Indigenous Taukei people of Rewa Province were deliberately omitted. A contentious narrative, which Chand claims 
prioritised the involvement of colonial administrators while "silencing" the "native involvement in the Syria shipwreck" (p. 92).

Chand (2017) states:

the deliberate projection of them (Taukeis') as looters and plunderers of items belonging to the Indian workers, contributed in no small measure to keeping the indigenous and the Indians separate during the indenture period, and to maintaining the ideology of racial divide for over 130 years now. (p.92).

Stemming from this event and acknowledging the historical burial site of Indentured labourers, a recent event in Fijian history has been the adoption process of descendants of Indenture labourers within the Vanua system of Rewa and Ba Provinces in Fiji. The traditional naming rights ceremony or the I-cavuti recognises the children of all Indentured labourers as the children of the chief or "Luvedra na Ratu". This event contributes to developing and strengthening kin relations between Taukei and ethnic Indian communities and is anticipated to have positive social and cultural contributions to the overall Fijian community. Through an extensive and long negotiation process, the symbolic event honouring the 35 lost lives, has also begun a new socio-cultural relationship between Taukei and Indo-Fijian descendants in Fiji (Hill, 2017). Sashi Kiran, one of the lead researchers in the negotiation process explains:

Today this identity will give us a place and for some reason, we have been longing to be one of the people of the land. Despite being equal citizen, we all have been saying, we don't belong, why? We have had this longing to belong here. We hope these opportunities will open doors for new learning and new dialogues so that we don't fear each other and genuinely care for each other as we grow. (as quoted in Hill, 2017).

While Jese Saukuru, a spokesman for the Council of Chiefs of Ba Province, described the communal reconciliation process as "just the tip of the ice-berg" in improving race relations and easing tension over land tenure in the sugar industry. Saukuru explains:

What will happen is now that they've been accepted by our chiefs... it'll boil down to the very grassroots where you'll see landowners from the Taukei side will establish close relationships with the tenants, mostly they are Indo-Fijians or girmit descendants, 
the luvendra na ratu (as quoted in Hill, 2017).

Naidu (n.d) notes that this recent effort at the Vanua level to acknowledge the descendants of Girmitiyas reinforces belongingness and self-identity as Fijian for the Indo-Fijian community in Fiji. He concludes that:

self-identity of Indo-Fijians with their country of birth has been firmly reinforced by the proffered Vanua belongingness to Rewa as an expression of love and good neighbourliness, and at the national level the common identity of all citizens of Fiji as Fijians. This dual level of belongingness and identity has given Fijians of Indian descent a new standing among Taukei. We have a Vапиа, and we belong. (p.4).

Creating these new cultural identities are crucial for building social relationships between the two ethnicities. As Lal (2015) concludes, "A new community is emerging whose precise character is difficult to describe and whose future is unclear, but which is becoming increasingly more visible" (p.69). It is these identities of Indo-Fijians in coastal fisheries that this study hopes to understand.

The next chapter provides a review of literature in relation to the theoretical frameworks used, definition and understanding of community, community-based resource management, identifies the research gap and contribution to knowledge from this study. 


\section{Chapter 3: Literature Review}

This chapter reviews the literature on Community Based Natural Resource Management (CBNRM), focusing on the conservation and management efforts of coastal and marine resources. CBNRM literature is also the overarching and basic principles of most Community Based Marine Resource Management (CBMRM) literature as well. Thus, references to both these concepts will be interchangeably discussed throughout this chapter. Firstly, I review the basic premises of CBNRM and highlight the key principles and characteristics. This is followed by an overview of the theoretical discussions of community and sense of community discourses. I conclude this chapter by highlighting the research gap and the need for this analysis within Fiji's contemporary CBMRM initiatives.

\subsection{Theoretical review}

This study employs political ecology as its over-arching theoretical framework. In consideration of the historical colonial influence in the country, I engage with postcolonialism as a parallel, supporting theory to provide context specific understanding of people and fisheries resource use and management. At the same time, I feel a sense of uneasiness with postcolonialism's theoretical ability to provide meaningful solutions for contemporary marine resource use. Therefore, I also draw on aspects of decolonial theory to provide a richer, nuanced understanding and offer proposed solutions for contemporary CBNRM/CBMRM in Fiji. These theories are discussed below.

\subsubsection{Political ecology}

Political ecology as a field of research and action has emerged in the past thirty years (Robbins, 2011) with many suggested definitions and critical viewpoints within contemporary resource management and conservation scholarship (Tetreault, 2017). Drawing on a range of theoretical perspectives including cultural studies, anthropology, environmental ecology, commons theory, and postcolonial studies, Robbins (2011) describes this field as more of a community of practice than a theory or methodology. Watts (2000) suggests that political ecology is an approach that helps to understand the 
complexities of relationships between society and nature. Often these relationships are nested within unequal power distribution between different actors such as local communities, the state, and external partners. (Robbins, 2011)

Political ecology as a theory can be used to "understand the condition and change of social/environmental systems, with explicit considerations of relations of power" (Robbins, 2011, p.20). Power, as Robbins argues is gained, held, and negotiated in multiple ways. The impacts of unequal power relations affect the most vulnerable and marginalised within communities (Bryant, 1998). Marginalised people are politically and socially disempowered and pushed into narrow ecological, economic, and social positions, which creates increasing demands on the marginal and increasingly limited ecological functions.

Svarstad et al., (2018) further reinforce the critical role of power in political ecology by examining the different theoretical perspectives of power. The authors argue that contemporary power discourses can be understood through three approaches: actororientated, neo-Marxist, and Foucauldian, and these combine to form a set of power perspectives that provided a richer and nuanced understanding of human-natureenvironment relationships. As such the authors call for a continuous examination of power relations within multiple and diverse communities. Postcolonialism offers an interesting space for understanding how power relations have been created, negotiated and are maintained through the various colonial histories and knowledge/power relations between the colonisers and the colonised.

\subsubsection{Postcolonialism and toward decolonisation}

According to Young (2016) postcolonial theories are described in many ways by postcolonial scholars and critics. Some critics refer to postcolonialism as a form of resistance following the end of formalised practices of colonisation ${ }^{11}$. Others prefer to recognise this as the "aftermath of the colonial" (Young, 2016). The contextual use of postcolonial theory often determines how the theory is perceived. In some cases, such

\footnotetext{
${ }^{11}$ By using "formalised practices of colonisation" in this context, I acknowledge the on-going issues and conflicts in West Papua due to Indonesian colonisation. This is another reason for my uneasiness and limitations with using postcolonial theory, as the effects of colonisation could well and truly be never over from within colonised communities.
} 
as that between Indonesia and West Papua, scholar-activists are strongly advocating for autonomy over Indonesian colonisation. In this regard, it could be argued that colonialism is an ongoing effect in the Pacific region. Furthermore, many Pacific Island countries are relatively young independent democratic nations. There are still Pacific Islanders living today who experienced living as 'colonised' and who are now 'free' people living in their independent home countries. However, and most importantly, the physical, structural and emotional remnants of colonialism still linger within colonised people and nations. Therefore, I feel it is important to acknowledge Fiji's colonial history to better understand and comprehend the present socio-political environment and their implications for natural resource management in the country.

As a body of critical theory, postcolonialism emerged around the late 1970s with the work of Edward Said in Orientalism, "Orientalism” being a term Said used to describe western hegemony over anyone who was culturally and socially different from the west (Said, 1978). This hegemony depended upon a systematic process of "othering" of the people in the East/South, primarily perpetuated by people of the West, and resulted in "the Orient", a European perception, imagined as "a place of romance, exotic beings, haunting memories and landscapes" (Said, 1978, p.9). Said posits that through orientalism, the west has been accorded privileges with the knowledge and values they hold, while the Orient (or the Other) are deemed inferior and unknowledgeable. The east, therefore, have often become "subjects of interest" through this supposed superiority of the west (Said, 1978).

Drawing on the works of philosophers; Michael Foucault, Karl Marx, and Gillies Deleuze, Gayatri Spivak (1988) states that the oppressed, if given the chance under certain conditions, can speak of and about their conditions. However, she also argues that given the multiple disparities, binaries, economic, cultural and social marginalisation that colonised people become subjected to, it is doubtful that such people can truly have a voice or speak of and about their conditions. Spivak's work Can the Sub-altern Speak? Has been useful in understanding and recognising the continued subjugation and marginalisation of people in former colonised countries through western forms of knowledge, technology, and culture (Spivak, 1998). Homi Bhabha (1994) offers another take on postcolonial theory by proposing the principles of hybridity - a philosophic condition challenging the validity of colonialism and its impact on cultures. Bhabha argues that colonialisms' histories and culture continually 
works to transform cultural identities and relationships between the colonised and coloniser. Bhabha's contribution to the understanding of "third spaces", while critical of acknowledging Indigenous culture and concepts, could also be viewed as opportunities for reimagining contemporary cultural identities in post-colonised communities.

These early contributions to postcolonial theory have allowed us to further interrogate themes of marginalisation, inequity, representation and opportunities (Young, 2002). Young (2016) argues that postcolonial studies is about learning to challenge and think outside the norms of western assumptions. The author further proposes that postcolonial theory involves a "conceptual reorientation towards the perspectives of knowledges, as well as needs, developed outside the West”(p.6). In the Pacific, scholars such as Albert Wendt and Epeli Hau'ofa have also been influential in challenging notions of colonialism and postcolonial effects on Indigenous Pacific cultures, epistemologies, and practices.

Not entirely convinced that the Pacific can ever be post-colonial, Indigenous scholaractivists are now setting the course towards decolonising methodologies (Smith, 2012), reclaiming Indigenous knowledge, perspectives, wisdom and languages (Thaman, 2003; Nabobo-Baba, 2006; Gegeo; 2001, 2017) and reimagining the Pacific as part of a broader Oceania (Hau'ofa, 1993). Pacific scholars have also found it important to point out the need for remembering colonial pasts in a bid to ensure that Pacific people are learning from the past and creating new perspectives for themselves. Echoing his sentiments, Hau'ofa (1993) writes:

Any new perspectives of ourselves must be based to a large extent on our roots. We should look into our histories and traditions, as well as into other cultures, for ideas and inspiration. Whatever we produce must not be a version of our existing reality, which is largely a creation of imperialism; it must be different, and of our own making ... If we fail to create our own [reality], someone else will do it for us by default. (Pp.128-129)

Mishra (1993) argues that "the danger of forgetting our (colonial past) and post-colonial realties is the danger of repetition" (p.21). To this effect, Thaman (2003) concur that it is problematic and simplistic to view the Pacific only from a former European colonised perspective or reducing complex histories and realities to simple characterises and features and analysing politics and history as separate from culture. This perspective argues Thaman (2013), “does not do justice to region's Indigenous people” (p.12). She 
continues:

in my view, its ahistorical representation of social life as a continuing conflict between the colonizer and the colonized denies Oceanic cultures a past without Europeans and their colonizing activities. Indigenous peoples have cultural histories that are long, authentic, and material to the well-being of all their people, whether they live in the region or not. (p.12).

From a critical theory perspective, postcolonial theories have extended discussions between ideas and practices of conflict and harmony between different people and their cultures. It is being recognised as an intervention that introduces alternative knowledge beyond traditional western discourses and seeks to influence how people think, behave, and act to produce a fairer, more just society by removing inequitable power structures within communities. And perhaps for the Pacific, this involves a process of decolonisation and looking towards Indigenous approaches, values and principles of human-nature relationships, community, communality, and reciprocity, while acknowledging the existence and belief systems of others.

In relation to the focus of this research, both western and Pacific scholars have extended postcolonial critiques to integrate postcolonial theories within the human/nature and environmental/ecology relationships (Castree \& Braun, 1998; Jackson \& Maracle, 2014; Schulz 2017). Nature has often multiple meanings across space and time and has been represented in multiple ways depending on people's perspectives, needs, beliefs, and values systems. Nature ideologies in the west are vastly different from their conception in many Indigenous cultures, where nature is rooted in people's identity and representation. The concern has been as Castree \& Braun (1998) argue that on many occasions, representations of nature are framed within the social histories of colonialism and articulated through much of those colonial experiences. Furthermore, he adds that often such representation become incognisant of historical and cultural narratives and practices of human-nature relationships in communities that existed pre- colonisation.

In Indigenous Pacific cultures for example, human/nature relations are viewed as nonbinary, holistic ideologies that place humans within and as part of nature. Such strong cultural and traditional ideologies are deeply embedded within many Pacific oral and literally histories and depicted through many art-forms such as songs, dance and crafts (Teaiwa, 2012). As such Marine management in the Pacific followed a history of cultural practices (Veitayaki, 1998, 2000; Muehlig-Hofman et al., 2004) but which are 
now being layered by mostly western discourses of community-based resource management and conservation.

As Hau'ofa (1993) writes:

The realm of the mind and values, and that is culture, cannot be divorced from that of society and economy. They are two sides of the same coin. We are creatures of culture and history ... [and] each one of us carries a burden of history and tradition, as well as our physical needs to act on our natural environment for our survival. The two realms, 'The mind and the world', always inform each other. We ignore this cardinal fact ... and it is one reason why so many attempts to improve our lot have crashed so expensively (p.132).

Hau'ofa's argument is critical to my review of the next section in which I look into some of the notable definitions and principles of community based marine resource management (CBMRM) and its application and implication to marine management in Fiji.

\subsection{CBNRM/CBMRM definition and principles}

CBMRM in Fiji follows similar designs and implementation principles as other natural resources. Such projects are communally/collectively managed and administered at local level and are usually context, or location specific (Brosius, Tsing \& Zerner, 1998). For the purposes of this review, I discuss the overarching definitions and design principles of CBNRM then look at existing forms of community based marine management approaches in Fiji.

\subsubsection{Definitions}

Milupi, Somers \& Ferguson (2017) suggest that CBNRM is also referred to as community-based conservation in some literature. However, according to Armitage (2005), CBNRM does not have any one single definition. Armitage writes that:

CBNRM seeks to encourage better resource management outcomes with the full participation of communities and resource users in decision making activities, and the incorporation of local institutions, customary practices, and knowledge systems in management, regulatory, and enforcement processes. (p.703).

Another author, Fabricius (2009) proposes that CBNRM refers to the "collective use and 
management of natural resources in rural areas by a group of people with a self- defined, distinct identity, using communally owned facilities" (p.2). Most CBNRM initiatives take place in rural communities and become a central goal of many development programs. (Blaikie, 2006; Pomeroy, Pollnac, Predo, \& Katon, 1996). This is one reason for the rapid expansion and popularity of CBNRM initiatives amongst development and conservation partners in rural communities (Fabricius, 2009). Some authors attribute CBNRM success to a much-needed response to many failed and inefficient top-down, technically focused initiatives in communities where local issues and contexts are overshadowed by bureaucratic development paradigms. (Milupi et al., 2017; Gruber, 2010; Armitage, 2005).

Another factor to the uptake and relative success of many CBNRM initiatives has been the approach to resource management which is driven by a group or community at local level (Pomeroy et al., 1996; Gruber, 2010). The fundamental idea is that local people and communities are better equipped to take responsibility and ensure that such initiatives are seen through to completion. Across poor and marginalised communities, many CBNRM projects offer a mechanism to achieve equitable and just resource dividends while at the same time devolving power to balance the use and conservation of valued natural resources (Armitage, 2005; Blaikie, 2006; Brosius et al., 1998; Shackleton, Campbell, Wollenberg \& Edmunds, 2002). Cox, Arnold \& Tomás (2010) suggests that CBNRM institutions and governance structures may also be viewed as forms of panacea or blueprints for sustainable resource management.

However, not all scholars are convinced of the successes of CBNRM approaches. According to Blaikie (2006), there are many forms and approaches to CBNRM, and this set of beliefs imply CBNRM to be a normative, homogeneous process involving people, natural resources, and their capacity and ability to use and manage those. Also, such access and control regimes are determined through the degree of power and ownership that certain groups or communities have over those resources. (Brosius et al., 1998; Armitage 2005). Blaikie (2006) claims that the success of CBNRM initiatives are reproduced within a network involving external donor agencies, including government and non-government organisations in the recipient country. He states:

the discursive power of the theoretical benefits to environment and community of CBNRM, the need to proclaim success to other international audiences, and the 
diffuseness and range of the social and environmental objectives, all lie behind representations of this "success". (p.56).

Furthermore, Blaikie argues that communities rarely conduct their own assessments or monitoring of CBNRM projects and a result are usually unaware of the perceived "successes" that external donor partners and agencies refer to. In some cases, the successes have none or little value to the recipient local community (Blaikie, 2006).

In one example, such as in Mozambique's Moribane forestry program, CBNRM projects were viewed as a way of exerting power and control over post-war rural forest communities by the central government. (Schaefer \& Bell, 2002). In these communities, people were used to living without government influence for over twelve years and investing in CBNRM initiatives seemed like a feasible and democratic way to ascertain rule and control over such communities. In such cases, CBNRM initiatives were viewed as having limited benefits to the local community as power became continuously negotiated and shifted between central government and the local community (Schaefer \& Bell, 2002).

According to Shackleton et al., (2002), research in CBNRM has shifted from concerns over financial benefits to stakeholders involved in such projects to recognising the importance of power dynamics and complexities over rights, access, equity and justice. Green (2016), argues that devolution of power in CBNRM is "essentially scalar and inescapably political" (p.94). She adds that power devolution produces a particular "framing of reality" which involves providing opportunities and empowering some which disadvantaging others (p.94). Furthermore, she concludes that CBNRM outcomes are not fixed and often the scalar configuration of power is used by actors to negotiate power dynamics and renegotiate their position within the governance systems posing a challenge to existing power structures in place (Green, 2016).

Green (2016) argues that recognising the power configuration within CBNRM projects, identifying the potential winners and losers and how it effects their agencies would help identify potential major conflicts and points of struggle. As such Shackleton et al., (2002) propose a number of ways of devolving power to local communities including: creating opportunities for pluralistic decision-making through discussions, debates and planning; improving legal literacy for local people so that they are more familiar with 
management policies; creating clearer property rights at a local level; making livelihood enhancement central to devolution policies, strengthening local organisational capacity and political capital to enable better and more informed decision-making, and negotiating better benefits for local communities.

Ballet, Sirven \& Requiers-Desjardins (2007) suggest that factors such as building social capital amongst stakeholders or "strengthening stakeholder participation" in CBNRM "is neither a costless procedure nor a panacea in that a successful resource management in a given context may lead to different outcomes in another sociocultural environment" (p.368). The authors argue that in most cases the "black box" of power relationships is ignored in community-based management, further exacerbating inequality. By focussing on strengthening ties between and within communities, many CBNRM projects fail to recognise and embrace the diversity and opportunities they could present for sustainable resource management at local levels (Ballet et al., 2007).

\subsubsection{Design principles and characteristics}

To better understand how CBNRM may be contextualised within this research, the following section reviews some of the current critiques of CBNRM design principles and their key characteristics. There are many attempts at defining, evaluating, critiquing, analysing, and reporting on the implementation of CBNRM (Kellert, Mehta, Ebbin \& Lichtenfeld, 2000; Shackleton et al., 2002). This review focuses on three of the more recent comprehensive analyses of CBNRM.

Ostrom's (1993) design principles remain the fundamental building blocks for many CBNRM/CBMRM initiatives. Some authors have noted that these principles may be somewhat incomplete (Cox et al., 2010). However, they remain essential to designing and implementing community focused development and conservation in many communities.

The eight fundamental principles include:

1. Defining clear group boundaries;

2. Matching rules governing use of common goods to local needs and conditions;

3. Ensuring that those affected by the rules can participate in modifying the rules; 
4. Making sure the rule-making rights of community members are respected by outside authorities;

5. Developing a system, carried out by community members, for monitoring members' behaviour;

6. Applying graduated sanctions for rule violators;

7. Providing accessible, low-cost means for dispute resolution;

8. Building responsibility for governing the common resource in nested tiers from the lowest level up to the entire interconnected system.

Milupi et.al., (2017) reviewed 21 case studies from different countries using the above set of design principles and concluded that successful CBNRM programmes work when resource users are motivated to take care of their resources. Unmotivated users result in unsustainable use of resources and consequently failure of CBNRM initiatives. The authors suggest that key common resource principles such as equity, rights and empowerment, collective choice, and conflict resolution mechanisms should be promoted to achieve social and livelihood sustainability

In another comprehensive review, Gruber (2010), identified 12 broad organisational principles and associated key characteristics of effective and successful CBNRM initiatives. He analysed more than 20 casestudies involving CBNRM approaches in various countries. While expanding Ostrom's eight design principles, he included adaptive leadership and co-management, communication and information sharing, and research and information development to the list.

Cox et al., (2010) also provide a systematic analysis of Ostrom's design principle and suggest reformulation of three of the eight principles. Specifically, the authors call for redefining principle 1), defining explicit user and resource boundaries, principle 2), congruence with local social and environmental conditions and appropriation and provision based on user input, and principle 4), monitoring should be split between users and resources. The authors suggest that principles $3,5,6,7$, and 8 are adequate to address common pool resource management as they currently stand.

Having considered the basic premises of CBNRM principles and how they have been adopted and adapted over time through the various reviews, the next section looks at how Pacific Islands have long adopted such principles within the marine and coastal resource management sector. 


\subsection{Renaissance of community based marine resource management}

Johannes (1998) described the demise of traditional marine management in Oceania. Using historical and anthropological information, Johannes demonstrated that Pacific Island countries had already been practising forms of marine resource management well before the introduction and implementation of western science and management concepts. However, these traditional forms of marine management are under threat from developments in markets and cash based economies expanding within rural areas, rapid uptake of sophisticated fishing gear such as mechanised boats and engines, improved fishing lines and hooks, and the gradual erosion of traditional leadership and governance mechanisms that haven't been able to keep traditional forms of marine management intact (Ruddle, 1998; Veitayaki, 1998; Johannes, 2002).

Contrary to Johannes' predictions and concern regarding the loss of traditional marine management concepts, CBMRM has re-emerged in the past three decades (Johannes, 2002). CBMRM is contributing to revitalising threatened and over-exploited marine areas in the Pacific and offers many Pacific Island nations a chance to reclaim Indigenous rights over traditionally or customarily owned marine areas (Veitayaki,1998; Johannes, 2002). Muehlig-Hofman et al., (2004) note that CBMRM is practiced in many Pacific Island countries to pursue their traditional Indigenous interests that also could enhance contemporary CBMRM efforts. Current CBMRM initiatives in the Pacific integrate and build upon traditional/customary resource management values and contemporary resource management mechanisms (Berkes, 2004; Veitayaki, 1998). Veitayaki et al., (2018) suggest that such customary fishing rights and resource use practices form the basis of a "community-based dual system" of resource management in Fiji.

Traditional marine resource management, through a western science perspective, was often viewed as insufficient and not fit-for-purpose to sustainably manage marine resources (Veitayaki, 1997). However, Veitayaki (1997) states that if appropriately modified and sanctioned, CBMRM systems could be suitable for saving depleted stocks and preventing further degradation of the marine environment. In a rapidly changing socioeconomic, political, and technological environment, a contemporary management approach, combining traditional forms of marine management with western scientific analysis might be beneficial (Veitayaki, 1997, 1998; Veitayaki et al., 2018). A recent 
review by Veitayaki et al., (2018) looked at the approaches that two CBMRM projects took to make them more effective, identified the challenges they faced and proposed suggestions to improve CBMRM in Fiji. The authors found that the ability of evolving and dynamic CBMRM systems were "easier to introduce, cheaper and more relevant to the attainment of local people's aspirations to improve their living conditions" (Veitayaki et al., 2018, p.384).

One way of implementing many community-based management projects is through the setup of locally managed marine areas in the Pacific and in Fiji. These low-tech, low cost management efforts have proliferated in Fiji over the last three decades and is now a rolemodel for how local marine management efforts are set-up (Govan, Tawake, Tabunakawai, Jenkins, Lasgorceix, Schwarz \& Afzal, 2009).

\subsubsection{Locally managed marine areas within communities}

Locally Managed Marine Areas (LMMAs) have gained wide attention and popularity across many coastal communities in world (Govan, 2009). LMMA's employ a range of management techniques including species-specific reserves, permanent or periodic closures, gear restrictions, and fully protected areas. Their central focus is sustainable management of marine resources rather than biodiversity protection per se (Rocliffe, Peabody, Samoilys \& Hawkins, 2014). Govan (2009) also suggests that in addition to the ecological functions of LMMAs, there are also significant logistical and cost benefits associated with implementing the approach.

According to Govan et al., (2009), LMMAs are generally thought to be a complementary and sometimes more culturally appropriate approach to marine management in the Pacific. In the Pacific where customary forms of marine management such as tabu's that existed pre-colonisation, contemporary marine resource management initiatives such as LMMA's were quickly adopted in response to food security concerns, threats to biodiversity, and the impacts of climate change in the region (Johannes, 2002; Govan, 2009; Jupiter et al., 2014). The definition ${ }^{12}$ for an LMMA

\footnotetext{
12 Based on Govan (2009), the definition of an LMMA was collectively agreed in two meetings in Fiji and in the Philippines in 2000, attended by more than 100 marine conservation practitioners (including professional resource managers, landowning community leaders, and government representatives) from 12 countries across Southeast Asia and the Pacific.
} 
provided by Govan (2009) is:

an area of nearshore waters and coastal resources that is largely or wholly managed at a local level by the coastal communities, land-owning groups, partner organisations, and/or collaborative government representatives who reside or are based in the immediate area. (p. 21).

LMMA approaches were developed to build on existing customary tenure and resource access mechanisms, the region's unique bio-physical and ecological features, and combining existing traditional knowledge and governance mechanisms (Govan et al., 2008; Govan et al., 2009; Govan, 2009). The primary focus is to maintain and/or improve social and ecological benefits from initiation, as well as achieve conservation and fisheries management outcomes within the region (Jupiter et al., 2014).

Despite its widespread applicability and uptake in the Pacific, Jupiter et al., (2014) and Cohen, Jupiter, Weeks, Tawake \& Govan (2014) argue that there are limited documentation and critical evaluation of many LMMA's. The empirical lack of evidence makes it difficult to ascertain the true nature of successful LMMAs. The authors note that only a few empirical cases describe how management tools are negotiated, reported, and outcome tested against project objectives. Given the unprecedented attention and effort put towards LMMA approaches by conservation NGO's and local communities, Jupiter et al., (2014) call for ongoing research and transparent reporting towards setting and achieving LMMA objectives, management measures, outcomes, and limitations. The authors highlight that LMMAs as a form of CBMRM often serve multiple objectives and are achieved through a multitude of strategies. However, they also add that it is not always clear whose objectives and outcomes are being met in multi-stakeholder, multi-governance CBMRM projects.

To assist in our understanding of this, it would be useful to review some basic concepts of community, given that they are most often the focus of CBMRM efforts. In this next section, I review the basic notions of what constitutes a "community". 


\subsubsection{Community definitions in natural resource management}

This section reviews literature on understanding and defining community in relation to CBNRM. Most literature reviewed for this purpose (and across various disciplines) highlights the complexity and ambiguity in concisely defining the term (Agrawal \& Gibson, 1999; Head, 2007; Mannarini \& Fedi, 2009; Kumar, 2005; Stone \& Nyaupane, 2014). Community has multiple definitions depending on its place and space dimensions in relation to resource management (Stone \& Nyaupane, 2014). Some scholars promote communities as small spatial units, with homogenous social structures and shared norms (Agrawal \& Gibson, 1999). One definition of community offered by MacQueen, McLellan, Metzger, Kegeles, Strauss, Scotti \& Trotter (2001) is, a "group of people with diverse characteristics who are linked by social ties, share common perspectives and engage in joint action in geographical locations or settings" (p. 21).

However, as argued by Agrawal and Gibson (1999), Brosius et al., (1998), and Kumar (2005), this viewpoint is often overly simplified and poorly defined. The presumption that community implies undifferentiated identity, emphasises unity instead of diversity, spontaneity instead of mediation, emotions instead of reasoning, cohesion instead of conflict, and stability instead of change is anything but a common reality within resource management (Agrawal \& Gibson, 1999; McMillan \& Chavis, 1986). Berkes (2004) posits, "Community" in community-based conservation as a gloss for more complex social-ecological issues within communities. Communities as social groups are dynamic and constantly evolving (Blaikie, 2006).

Several authors suggest rethinking the generalised use of community in communitybased development and conservation (Brosius et al., 1998; Berkes, 2004). Mannarini and Fedi (2009) suggest that the complexity of narratives within community mean meanings cannot be reduced to simple, unidimensional models and propose that such constructs of community need to be made within culturally situated discussions. Communities are multidimensional, cross-scale, social-political units or networks evolving through time. Expanding this notion, some authors propose shifting the focus on institutions and processes that shape and govern them rather than on community or its members (Agrawal \& Gibson, 1999; Berkes, 2004). 
Consequently, Agrawal and Gibson (1999) argue that in the context of conservation, community must be relooked at through the multiple actors and their interests within the community, the influence of these actors on governance and decision-making, and through external and internal institutions that influence those decisions. Community based conservation and management are more likely to succeed where community differences are recognised and valued, and where relationships with external stakeholders and institutions are transparent and follow good governance principles (Agrawal \& Gibson, 1999; Berkes, 2004; Ostrom 2000).

\subsubsection{The dilemma of community in post-colonial natural resource management}

This section highlights the complexity between two socioculturally different communities within an overarching community network, based upon their socioeconomic, sociopolitical, and socio-ecological reliance on coastal resources.

This study recognises customary fishing rights ( $i$ - qoliqoli) owners as one set of community and Indo-Fijian fisheries users as another. The distinctive difference in resource use and ownership rights determine access and participation in coastal fisheries in Fijian communities. Exclusion principles are often used in common pool resource management initiatives to limit the number of people accessing resources and ensuring long-term sustainability of such resources (Cox et al., 2010). Usually, exclusion is based upon characteristics of ethnicity, resource rights/ownership status, gender, culture, and/or social and economic relations (Cox et al., 2010. In some cases, more than one of these characteristics determine who gets to participate in resource use and management (Hollup, 2000; Sherif, 2013; Lokuge \& Hilhorst, 2017). On most occasions the ability to participate and access resources have created an environment of conflict, inequity, and social exclusions in colonised countries (Hollup, 2000; Sherif, 2013).

Most scholars have only recently turned their attention to issues of racialised conflicts between Indigenous people and other colonised groups (Kobayashi \& de Leeuw, 2010). Essentially, this refers to a situation where colonialism has influenced both Indigenous and non-Indigenous groups of people over space, time and resources. Much less is known about Indigenous people and other groups in the 
community and their relationships over natural resource use and management (Amungwa, 2011). As I discuss earlier in the chapter, postcoloniality has in many instances made issues of space, cultures, resource use, and governance more problematic (Gupta \& Ferguson, 1992; Escobar, 2006). Gupta and Ferguson argue that cultural and social changes within post-colonial communities are locations of interconnected spaces. Investigating the formation of such hybrid communities must occur through acknowledging each cultural difference rather than seeking commonality as a goal (Gupta \& Ferguson, 1992). Escobar (2006) questions the relationship between community differences and suggests that equality could be only achieved while respecting differences.

\subsection{The research gap and contribution to knowledge.}

This review has outlined the broad principles, characteristics, and complexity of CBNRM as a tool and concept to support conservation and development initiatives across communities. I have also outlined the complexity of understanding 'who' constitutes community and the role of community in CBNRM/CBMRM efforts. Communities are not homogenous, simplistic entities but rather a conglomeration of multiple perspectives, identities, ethnicities, and cultures within complex sociocultural settings. Colonialism and postcolonial influences have put communities of different cultural, ethnic, class, and gender backgrounds into complex relationships with one another. Such relationships are made even more problematic in relation to access to and participation in natural resource use and management.

This review indicates several gaps in our knowledge of postcolonial natural resource management, in particular within Fiji's CBNRM context. Firstly, very little data has been captured on the dependency of Indo-Fijians on coastal marine resources at subsistence level. The Fisheries Ministry collects data on commercial licensed fishers. However, there is no overall or comprehensive database detailing the other actors within the seafood market supply chain. This includes Indo-Fijians who are fish retailers and middlemen. Adequately determining the amount and intensity of Indo- Fijians' dependency on the seafood sector may improve policies aimed at strengthening the food security and livelihoods of this group of people. Secondly, little is understood and documented about the way Indo-Fijians establish and 
maintain socioeconomic and sociopolitical relationships between customary iTaukei fishing rights owners. Having a better understanding of how such relationships are negotiated would be useful in reducing nature/people conflicts and promoting better sociocultural relationships between stakeholder groups in Fiji. Thirdly, given the focus on community-based resource management in this research, this study hopes to complement existing CBNRM initiatives in the country by understanding the role and participation of Indo- Fijians within the broader context of coastal and marine resource management in Fiji.

The next chapter presents my research methodology including epistemology, conceptual framework, and research methods used. 


\section{Chapter 4: Methodology}

This chapter explains the methodology adopted to conduct this research and discusses why I chose an over-arching political ecology framework informed by postcolonial and decolonial theories. I discuss how my methods are aligned to a constructivist epistemology informed through my Pacifica origins. I describe the research methods used to collect, organise and analyse my data. Finally, I explain the ethical, health and safety considerations in this research before concluding the chapter with a summary.

\subsection{Constructivist epistemology}

Constructivist epistemology is based on the idea that there is no one universal truth. Applying this epistemology produces knowledge that is constructed based on the positionality and interactions of the research and research participants. In conducting this research, I position myself as a Pacifica woman and acknowledge my role as a cocreator of knowledge alongside my research participants. In doing so, I also view my role as that of a "vessel" or a means of transporting and transferring knowledge. As such, I extend the constructivist epistemology to not only being integral to producing new knowledge, but that of carrying through and disseminating the knowledge as demonstrated through some Indigenous Pacific epistemologies ${ }^{13}$. To illustrate this, I construct my understanding and interpretation of this research in the form of a traditional vaka or canoe (Figure 5).

In the illustration, I position myself as the canoe in the centre, to collate, store knowledge whose role is to transport and transfer knowledge. In this case, the knowledge I construct and transport, the voices I speak and the text I write is construed between my research contributors and myself. The canoe which rides the crest of two waves, represents my articulation of the theoretical frameworks; the political ecology and postcolonial and decolonial theories that informs this study.

\footnotetext{
${ }^{13}$ Indigenous epistemologies for example the Vanua Research Framework (VRF) (Nabobo-Baba, 2008) would have been essential if solely conducting research with Taukei people. Given the target community, I acknowledge that the VRF was influential in my analysis and interpretation of results, however, not fully appropriate for working with Indo-Fijian people.
} 


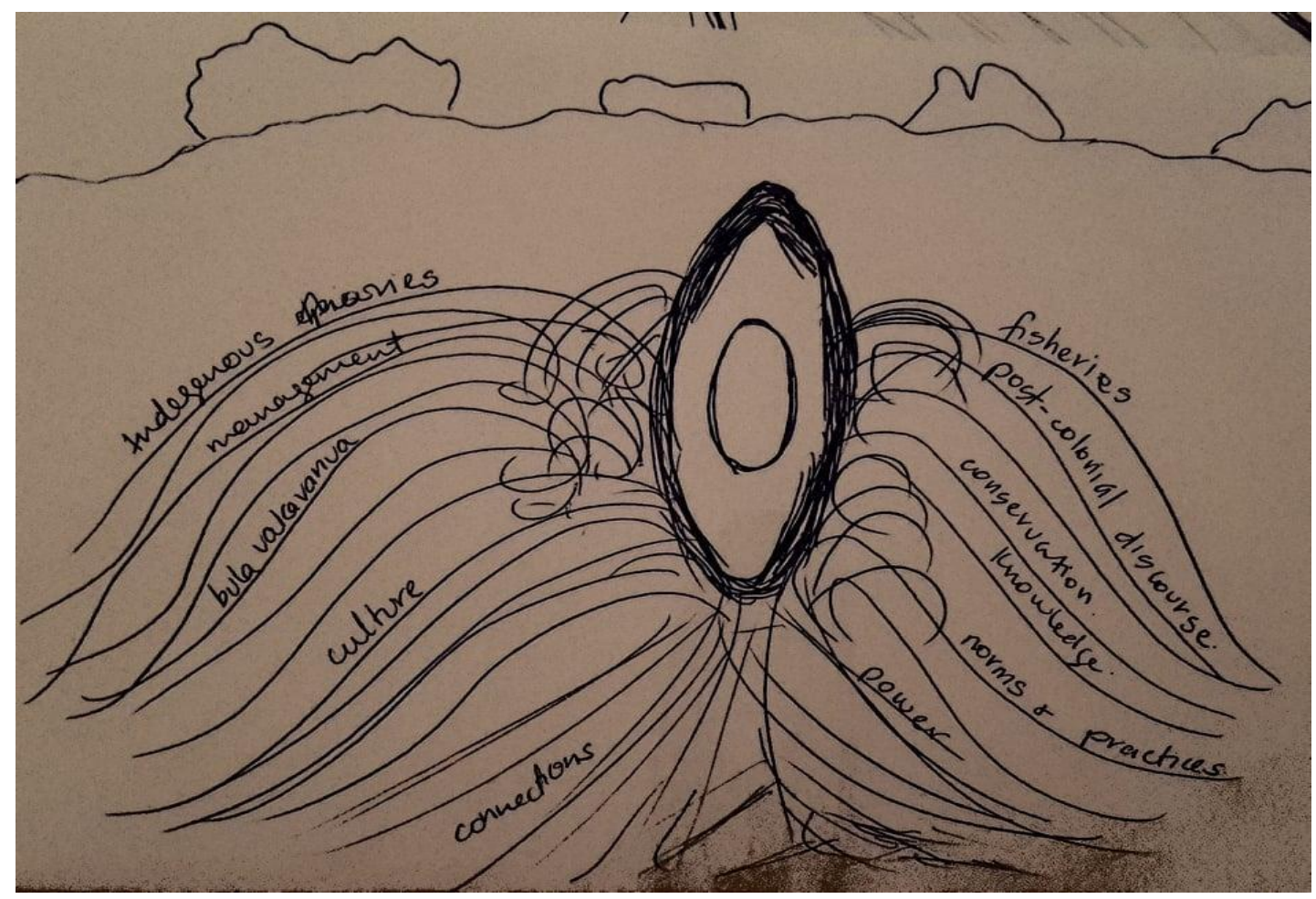

Figure 5: Epistemological canoe riding the waves of Indigenous, Postcolonial and Decolonial approaches. Source: Chinnamma Reddy.

In adopting a constructivist approach, Ultanir (2012) proposes that "individuals create or construct their own new understandings or knowledge through the interaction of what they already believe and the ideas, events, and activities with which they come into contact" (p.127). Holstein and Gubrium (2011) state that social, political and cultural contexts shape individuals' perceptions and how they create knowledge and meaning around them. Thus, people interpret and understand things differently based on social, historical and cultural contexts. As Thaman (2003) suggests:

While much has been written about the impact of colonialism on Pacific economies, environments, politics, and social structures, little attention has been focused on its impact on people's minds, particularly on their ways of knowing, their views of who and what they are, and what they consider worthwhile to teach and to learn ... I think we can perhaps try to read and write more critically. (p.2).

In extending a constructivist approach of co-creating knowledge, I also aim to reflect critically on my positionality as a woman, scholar, and novice researcher from the 
Pacific. The Massey University's Pacific Research: Guidelines and Protocols [PRGP] (Massey University, 2017) handbook provided useful considerations for undertaking research in the Pacific. It states that, "the identification of Pacific informed principles and values is paramount in understanding the distinct approach to research in the Pacific or with Pasifika communities" (Massey University, 2017, p.13). Pacific scholars such as Konai Helu Thaman, Unaisi Nabobo-Baba, Vijay Naidu, Teresia Teiawa and Epeli Hau'ofa have all inspired and influenced me in the ways I understand my positionality in this research. Based on shared values and principles across the Pacific, the PRGP proposes four key guidelines for Pacifica researchers. These are respect, reciprocity, holism and prioritising the common good for all Pacific Peoples $^{14}$ (Massey University, 2017, p.12).

\subsection{Situating myself within this research}

\section{Negotiating positionality}

My inspiration for conducting research in this topic stems from my personal and professional interest in the space. I was never quite sure if I should or would attempt to write about Indigenous fisheries management and governance processes in the same vein as user rights and equal participation of non-Indigenous resource users in Fiji. At one end of the spectrum is my appreciation and acknowledgement of traditional/ customary resource owners and their methods, efforts, and experiences of management, distribution, and access to their marine resources. On the other end, I feel a sense of responsibility to pay tribute to my heritage, ancestry, and the plight of the many Indentured labourers who sought a new beginning, in a place only known to them as $\operatorname{tapu}^{15}$.

\footnotetext{
${ }^{14}$ In the Pacific Research Guidelines and Protocol handbook, Pacific people is the recommended term used in Aotearoa/New Zealand which includes seven ethnic groups namely; Samoa, Tonga, Cook Islands, Tokelau, Niue, Fiji and Tuvalu. Other definitions for Pacific Peoples include reference to 'a broad category encompassing a variety of Pacific Island nations and communities who are linguistically, culturally and geographically distinct from each other' (Health Research Council, 2014 p. 2-3). Pacific Islanders, Pacificans, Tagata Pasefika, Pasefika and Pasifika have also been interchangly used (PRGP,2017).

15 "Tapu" or "dweep" is the Hindi term for an island. Many Indo-Fijians no longer use this word and prefer to use island.
} 
Working in the marine conservation field for the past decade, I have often mused with my Indo-Fijian colleagues over the non-representation of Indo-Fijians in the fisheries management and conservation sector. As if they (we) did not exist. Yet at the same time, I was sitting through workshops and meetings with NGO partners, donors and government departments discussing how to make fisheries more sustainable for Fijians. I was concerned with that fact that despite various local and grass-roots conservation and management efforts with Taukei communities, fish catches continued to decline, fish prices continued to rise, and Indigenous and traditional norms and forms of management challenged.

Given that Indo-Fijians' role in the coastal fisheries space is becoming more pronounced yet remains visibly hidden, I conceded that the opportunities for having these conversations now is necessary and urgent. Kobayashi (1994) highlights that such "situation establishes a starting point for analysing the politics of involvement and representation" (p. 76). Thus, this research is an effort toward involving and representing the concerns, interests and voices of the many Indo-Fijian people who rely on the fisheries sector. I hope that my representation as an Indo-Fijian female, and novice researcher, would encourage disempowered and often marginalized members of the Indo-Fijian fishing community to participate and contribute towards contemporary fisheries management efforts in the country.

However, doing this comes with its own set of challenges. Coming from a science background, I struggled with integrating various themes and discipline areas. Integrating my knowledge on natural resource management, conservation and marine science together with social sciences included building an understanding and acknowledging different worldviews and perspectives. In addition, given our country's colonial experiences and on-going socio-political tension, I had to carefully consider, navigate and negotiate with what/how knowledge and information was shared/presented. As Sultana (2007) suggests “conducting international fieldwork involves being attentive to histories of colonialism, development, globalization and local realities, to avoid exploitative research or perpetuation of relations of domination and control" (p.375). In my perspective, this research has been an ongoing process of negotiating ethical considerations, planning and re-planning the entire research process.

To counter such challenges, I aimed to adopt a stance of mutual respect, sharing 
responsibility, valuing differences, and recognising non-hierarchical ways of achieving ends (Kobayashi, 1994). In doing so, I acknowledge that my research was shaped by my preconceptions, values and belief systems (although these have, in turn, been also shaped by this research). As such, my involvement with research contributors cannot be considered value-neutral (Kobayashi, 1994) as I entered the research domain with the "researcher baggage" (Glesne, 2016) as described below.

The researcher baggage: what I carried through in this process.

Conducting sound ethical research involves negotiating multiple spaces and practices of reflexivity (Sultana, 2007; Kobayashi, 1994). I identify as an Indo-Fijian female from a small island Town in Fiji living amongst a predominantly Indigenous Taukei community. I attended a multi-cultural public school and learnt to speak and write in English and the Taukei language. I spoke Fiji-Hindi at home and understand Hindi but did not grow up learning to read or write in the language. Speaking in English was emphasised in school and I remember getting reprimanded for speaking in the vernacular (Taukei or Hindi) language.

I also acknowledge my professional role as a mid-career social-ecologist. My undergraduate degree in Marine Sciences from the University of the South Pacific, and subsequent work experience in the environment/conservation field shape my knowledge and understanding of the marine environment and how communities work to protect and manage them. As the lead researcher, studying and living in Aotearoa New Zealand for the last two years, with a background in marine/environmental science, I was aware of how such layers of privilege around my education and professional background might have shaped the way other people understood my research and my positionality within the research. Consequently, all throughout this research I remained cognizant of my positionality and how it may have shaped the interview process and subsequent analysis of my interviews (Sultana, 2007; Massey University, 2017).

While negotiating these "tricky spaces" (Sultana, 2007), I was also navigating between my role as the researcher and of being an "insider" as well as an "outsider" throughout the research. For the research contributors I knew, I emailed to arrange for a meeting. Being prior acquaintances puts me in the insider category, however, within my role as the independent researcher studying overseas, I sometimes felt a degree of otherness as 
well since I had been away from Fiji for a while. As an Indo-Fijian woman, I found gaining access to most rural Indo-Fijian homes easy due the hospitable nature of these people towards strangers or outsiders. I was always welcomed with a drink and even offered food most times. However, as I was unfamiliar with the study area and did not have any social or personal connections to these people, I always sensed a degree of hesitancy, especially when asked about inter-community relationships. These oftenmasqueraded interactions have nonetheless shaped the interview process and subsequent analysis and interpretation of my research findings.

\subsection{Research Methods}

To enable collection of a range of views and perspectives on relationship between IndoFijian and Taukei community members in relation to coastal fisheries, a qualitative research approach was considered most suitable. This research approach is open and emergent allowing the researcher to unfold the manifold of nuanced, intricate details embedded within the research process (Glesne, 2016). As Glesne explains, "the openness allows the researcher to approach the inherent intricacies of social interaction, to honour complexity, and to respect it in its own right" (p. 25).

Thus, I aimed to gather a broad and diverse range of contributions from the 'field'. In order to appropriately acknowledge the role of participants in my study, I have chosen to represent them as "contributors" and co-creators of knowledge in this study rather than just being a participant, a subject or a source of information within the study. In and through negotiating these roles in the study, I feel that this recognition as knowledge co-creators allows me to honour the people's intellectual contributions to this study. The research contributors included representatives from academia, conservation practitioners, customary fisheries managers, and individuals. Research contributors shared personal insights and views in relation to community-based fisheries management, social relations and current issues and challenges facing the fisheries sector.

\subsubsection{Pre-field preparation, participant recruitment, access and consent}

Approval for conducting this research was sought from Victoria University of Wellington's Human Ethics Committee on the $30^{\text {th }}$ April 2018 and granted on the 29th 
May 2018. In-field days were from the $04^{\text {th }}$ June to $19^{\text {th }}$ July 2018 in Fiji. I spent most time in Suva, the capital city, and up to two weeks toward the end of my research, at the study sites in $\mathrm{Ba}$. Although I would have preferred to have spent longer at the study sites, I had not anticipated the length of time to coordinate, prepare and organise myself (and relevant institutions) before beginning the actual field visit (Glesne, 2016).

Retrospectively, I realised that while being in Wellington, even for such a short amount of time, Ihad become accustomed to everything happening at once, on time, as planned. With a little bit of self-reflection and allowing myself to settle in once again with the idea of being home in Fiji, I accepted that plans and processes would have to 'go with the flow'. In doing so I acknowledge that research of this nature demands my respect and humility while building trustworthy relationships with the people (Sultana, 2007; Massey University, 2017).

Prior to the start of my research as well as in my human ethics application, I had proposed to carry out interviews and observations at two sites outside of Suva, in Ba and Rewa Provinces. However, following consultations with the primary supervisor and staff of conservation organisations, I realised that access to Rewa Province would require a longer time to set-up and negotiate, since neither myself nor the conservation organisations I consulted were actively working in the area. Given the time and resource limitations I had, I decided against conducting research in Rewa and instead focus solely on $\mathrm{Ba}$. I discussed this step with both supervisors who supported me with the decision. While in Suva for the first few weeks, I conducted additional literature reviews at the University of the South Pacific (USP) libraries and consulted with my secondary supervisor to formulate a research plan. I also organised various meetings to introduce my research and gather feedback from staff of various conservation organisations and USP. During my consultations with conservation NGO's, the World Wildlife Fund (WWF) Fiji office offered to support me by providing transportation to the site and assisting with pre-interview introductions with at least two people involved in CBMRM at the study sites. I was glad to accept this offer. Glesne (2011) suggests that such types of research are conveniently termed, "backyard" research, where a researcher chooses to work with familiar institutions and people. She suggests a few reasons for a novice researcher to attempt this approach, such as ease of accessibility to study sites, the fact that groundwork for building rapport with participants is already established, that the 
research is useful for future personal and professional careers, and that it can considerably reduce costs towards the field work. However, she cautions that researchers must be fully aware of the possible problems generated through this involvement.

As a former WWF employee, I was fully aware of engaging with former colleagues and the possibility of introducing bias within my research. For example, interviewing participants pre-selected by the organisation or being directed to interview only certain groups of people. To reduce any such bias within my research and to avoid any potential conflict with research contributors, myself, and WWF, a field terms of reference was drawn up between myself and WWF. This covered both our responsibilities and expectations from each other. In addition, as my research covered mainly Indo-Fijian communities and WWF's field sites were within largely Taukei communities, the possibility of pre-determined research contributors was minimised. The only liaising they carried out was between me and a fisheries committee representative in a village. I was left to recruit other contributors after making initial contact with this gatekeeper. As an outsider to the area, negotiating access into communities can be a tricky process. In particular where one has to be mindful of cultural norms and expectations of outsiders and in particular of women. In the Taukei (Vanua) context women are expected to show respect by remaining quiet, speaking when appropriate, and follow appropriate channels of communication to discuss or present something. Thus, as an Indo-Fijian female and researcher I was mindful of remaining vigilant of these protocols when talking to elders and people of authority within my research.

Accessibility into many of the Indo-Fijian fishing communities was a major consideration. Most sites involved travelling on dirt roads and across sugar-cane tram- lines. The uneven terrain would have been a major obstacle had WWF not generously provided a 4-wheel drive vehicle and a field assistant to accompany me during the field visit. Having reliable transport meant that I was able to reach into rural communities and having a male field officer travel with me to remote places offered security and support when needed.

While planning for my interviews and thinking about how I would conduct them, such as setting, location and so forth, I realised that I was going to be interviewing most of my community research contributors in their homes. Most Indo-Fijians are not socially 
structured as in within Taukei villages but live in either Townships or informal rural settlements outside the Towns. As most fisherfolks operate their businesses from their homes it made sense to seek them out as individual homes. What I had not considered was the setting of these interviews within individual homes and the involvement of other family members during the interview. As a middle-aged Indo-Fijian female, interviewing an Indo-Fijian male is not uncommon, however, it would be considered inappropriate if $\mathrm{I}$ had requested to conduct this interview in a private space within the house. Thus, it was more comfortable and appropriate for me and my research contributors to conduct the interview in a communal space such as the family lounge or veranda. Where other family members were present, either wife or a relative, they too were informed of the research and invited to contribute to the interview. Children were not involved in the research. In most cases, they were either away at school or played outside while interviews were held.

Seeking consent of my research contributors was an important and interesting process in my field interviews. I provided each participant with a research information sheet at the beginning of our interview. Not all participants read this straightaway, with most opting to hear me explain the research. I went over the research objectives with them and offered to answer any questions before beginning. I also explained the research consent process emphasising that they could withdraw at any point during the interview or within the time prescribed in the information sheet. After my first two interviews, I realised that some research contributors appeared uneasy when asked to sign the consent form, either at the beginning of or even after the interview. While initially concerned, I realised that this was going to be the reality of how I would be recording data. I noted this in my field note-book and decided that it seemed more appropriate to seek verbal consent in this case rather than making my research contributors uncomfortable. Sultana (2007) notes that concerns of such nature "are not captured in the 'good' ethical guidelines of institutional paperwork but have to be negotiated and grappled with on a daily basis in the field" (p.379).

The issue of obtaining appropriate "signed consent" is always problematic across communities; especially those who are not used to speaking or writing in English or usually are cautious about signing things in the presence of strangers (PRGP, 2017). Even where translated versions of the research consent were provided to research contributors, some brushed it aside, more comfortable with just being given the 
opportunity to be heard. I still offered the choice in each case where individuals could either sign if comfortable or provide verbal consent for the research. All interviews were audio-recorded with consent from the research contributors.

Fiji was preparing for a general election in November 2018. Preparations for the elections had begun months earlier. It was interesting to note but also as expected that government officials were highly vigilant of anything that required official signoff and of participating in research activities which posed risks to their jobs at the time. Seeking official clearance for the officers to speak with me required a rigorous and lengthy bureaucratic approval process which I did not have enough time to fulfil. As one government officer commented, "You may as well wait for anything to be signed off until after the elections, it will be a long process if you want anything done now" (Government Officer, personal communication, 2018). This required consideration of the fact that, as Sultana (2017) "the political and temporal instability of issues in Global South contexts may result in certain issues being interpreted or told in certain ways and producing silences in others” (pp. 382-383). Thus, I acknowledge that this research does not sufficiently include the government voice, which I had hoped to capture. Retrospectively, I am aware that the knowledge I have generated through this research is partial and produced within the context of my inter-subjectivities and the specific time and place that I occupied during the research process (Sultana, 2007). Ethical considerations such as this required me to pay critical attention to my positionality, reflexivity, the knowledge created and the power relations inherent in this research. However, once I had ensured that all research contributors were fully aware and informed of the research and its implications and only after receiving this consent, either written or verbal, I only then proceeded with the research process.

Having considered such concerns through careful negotiation and navigation of my positionality, I felt confident that I had gathered sufficient data to allow me to produce a reasonable analysis and understanding of my topic. The interview timings worked in my favour as well. Unsettled weather conditions during the field visit made fishing trips unfavourable for the fisherfolks thus allowing me the opportunity to speak with them. Some fisherfolks were unable to go out as they were waiting for their fishing licenses to be renewed. 


\subsubsection{Semi-structured interview, snow-ball technique, convenience sampling}

Using the snow-ball and convenience sampling techniques, I conducted a total of 19 semi-structured interviews with people of various professions, connected through their engagement with community-based management and coastal fisheries practices. The snow-ball technique, also known as chain referral sampling is widely used in qualitative studies (Biernacki \& Waldorf, 1981). It relies on social connections between participants and others who may be involved in a project. Normally an initial respondent will provide the name of a second respondent, who then provides the name of the third respondent and so on (Atkinson \& Flint, 2001). The technique is useful when the researcher has no prior contacts in the area and needs to look for research participants. In addition, this technique is often useful in uncovering hidden aspects of social experience from the researcher and the layperson's point of view. It usually seeks to include the contributions of marginal, excluded groups (Biernacki \& Waldorf, 1981; Atkinson \& Flint, 2001). This technique was useful in this study as it allowed me to recruit unknown Indo-Fijians fisherfolk who were part of the coastal fisheries sector in $\mathrm{Ba}$. Given that I had no prior connections in the area, I relied on the initial referral of the first research contributor to then recruit further contributors at other sites. I also used convenience sampling alongside the snow-ball technique to recruit research contributors.

Convenience sampling (also referred as haphazard or accidental sampling) is a nonrandom technique of selecting members within a target population that meet certain criteria (Etikan, Musa \& Alkassim, 2016). This could include ease of accessibility, geographical proximity, availability and willingness to participate in the research. Given that I had a limited time within which to complete the field research, using the convenience sampling technique allowed me to interview people who were available at home or offices when I arrived, and mostly no pre-arrangements were done in this case. I spent four days, being driven around and visiting each study site with the help of a field research assistant. Research contributors were given the option to reschedule the interviews or decline, however, most agreed to be interviewed at the time I met them.

I conducted fourteen semi-structured interviews in three Indo-Fijian settlements and one Taukei village. Since this research addressed a significant area of relationships and access to livelihoods and livelihood resources and given that inter-ethnic relations are 
evolving and fraught with possibilities of tension and danger in such small communities, I assigned alphabetical characters to names of villages and settlements in Tavua and $\mathrm{Ba}$ districts within the Ba Province. For respondents, they were assigned pseudonyms as well, usually common last names in Fiji that would make research contributors least identifiable. While most participants were willing to use their real names in the research, I opted to keep them confidential. However, participants were made aware that due to the nature of study within a small geographic area, people very familiar with the area may be able to deduce who they are.

Such approaches are essential to maintaining the 'do no harm' ethical consideration for my research contributors. Furthermore, such approaches are regularly used in qualitative research to protect participant's confidentiality. Site A was in Tavua, B and $\mathrm{C}$ in $\mathrm{Ba}$ and only one Taukei village, $\mathrm{D}$, were used as study sites. Five interviews were conducted with academic and conservation staff based in Suva. Within the settings, semi-structured interviews allowed me to engage in structured but open dialogue with my research contributors. While I had prepared an interview schedule for the interviews, the semi-structured approach allowed the conversations to flow in the direction taken by the contributor thus adding depth and nuances to the responses.

\subsubsection{Observations and field notes}

At each stage of the field research process, I made careful observations and kept a field diary in which I recorded 'things of interest'. I also recorded behaviour or attitudes that research contributors made while being interviewed, informally sitting around in participants home or at the interview site.

Writing down my thoughts, experiences and opinions helped deconstruct my knowledge and understanding of the topic. The scribbles on the page margins, the mind maps and doodles all later allowed me to grow and understand my role as a researcher, a student, a contributor into my own research. I hope that through this process I was able to make "the messiness of the research process visible" (Ortlipp, 2008) to my readers, signalling that this research and the final product, this thesis, is an outcome of such "organised chaos" (p.704). 


\subsubsection{Data analysis, interpretation and management}

I was able to transcribe a few audio recordings while in Fiji, but most were completed upon returning back to Wellington in July 2018. Interviews were transcribed onto a word document and later manually coded to look for themes through each of the interviews. Coding involved looking for repetitive responses or ideas within the interview. Each idea or theme was then categorised and built into a finding's matrix. Each subsequent idea was then appropriately placed under a broader heading. For example, 'responses on interactions with community members' was placed under 'community relations', and so forth until I condensed the key findings to three overarching themes. I opted to use thematic analysis (Braun \& Clarke, 2006; Maguire \& Delahunt, 2017; Nowell, Norris, White \& Moule, 2017) as a tool to interpret my data.

Thematic analysis is useful for examining the perspectives of different research participants, comparing and contrasting similarities and differences as well as generating unanticipated insights in the research data (Nowell et al., 2017). Additionally, thematic analysis as a method is not confined to one particular epistemology or theory, but rather its adaptability and flexibility makes it a useful core skill for novice researchers (Maguire \& Delahunt, 2017; Braun \& Clarke, 2006).

All audio recordings are labelled, filed and saved in a portable electronic device. Access to this file is limited to myself and my supervisor(s) as stated in my human ethics application. The audio files will be kept for three years, after which the files will be permanently deleted from all records. Transcribed word files, consent sheets and other related research materials will be also held for three years after which they will be permanently deleted. Research contributors were informed of their choices in participating in the research prior to the interviews. Research contributors had up to three months from the date of interviews to fully withdraw from the research. While I had indicated in my ethics application that a research summary would be shared via email with all participants, this proved to be a challenge for research contributors in the rural areas. Many of them did not have access to an email account and consequently, we agreed upon sharing and presenting the full research findings with each participant upon my return to Fiji in March 2019. I am aware that this eliminates a potentially important avenue for research contributors to provide feedback on the transcripts of their interviews, it illustrates the messiness of fieldwork and in such situation, it wasn't 
feasible to do this aspect of incorporating feedback within my research. Research contributors with email access were sent transcript summaries.

\subsubsection{Ethical considerations, health and safety}

Maintaining a high ethical standard is an important consideration in qualitative research. As researchers, there is duty of care and responsibility towards research participants/contributors who often share personal and sensitive information with us. Thus, ethics is about maintaining privacy, transparency and taking responsibility for research findings (Maylor \& Blackmon, 2005). Ethical considerations arising during the field-research must be respected and participants should be given the right to withdraw any information they share at any time. Massey University (2017) emphasises that

notions of service and prioritising the common good in the research process means ensuring that the wellbeing of Pacific Peoples and their environment is of central importance in how research is conducted, produced and disseminated. In sum, accountability to participants and communities prioritises the impact of research on communities. (p.12).

The approved human ethics application for this research is attached as Appendix A.

During this research, I was aware of sharing sensitive information with participants, in particular, on questions surrounding inter-community relations, household income and whether participants were in breach of any fishing regulations. As someone who plans to return to this community for future research and work, I intend to maintain the level of trust and confidence that my research contributors expected from me. Throughout the field research process, I followed a strict health and safety protocol to safeguard my research contributors and myself. This involved not conducting interviews at night or alone, and where the interviews were held at a participant's house, another field assistant accompanied me. In other cases, interviews were held in public places or within institutional offices. I shared my field plans with my supervisors and family members in Suva. 


\subsection{Summary}

This chapter has highlighted the research methods I undertook to carry out my field research. It informs the reader of my epistemology and then discusses how I gained the knowledge and understanding of my data in relation to theoretical frameworks that I applied to this research; political ecology and postcolonialism. I acknowledge the people involved in this research as contributors, honouring their wisdom and willingness to engage in the study. I explain how my positionality and reflexivity affects knowledge production, analysis and interpretation of the data generated in the study. To end this chapter, I discuss how ethical considerations were negotiated and managed. In the next chapter, I present my research findings. 


\section{Chapter 5: Findings}

\subsection{Introduction}

This chapter discusses the two key thematic findings from my research. These are related to: multiple translations and interpretation of community, and levels of dependency and interdependency between communities in relation to marine resource use. The findings suggest that there are many informal yet complex relationships characterised by friendship, mutual aid, and at times conflicts between the two ethnic groups in Fiji; the traditional Taukei fishing rights (qoliqoli) owners and Indo-Fijian resource users. Furthermore, it highlights the multi-faceted yet nuanced dependency on and interdependency with marine resources and between community members. The lesser-known involvement of Indo-Fijian women as either heads of fishing households, entrepreneurs, and as fishers themselves also deserves acknowledgement within my study. These findings have important implications for contemporary CBMRM in the country.

Nineteen semi-structured interviews were conducted with fishers, middlemen/women, resource custodians, boat owners, academics and fisheries/conservation management practitioners involved in coastal and inshore fisheries in the $\mathrm{Ba}$ Province. $\mathrm{My}$ observations, field notes, interpretation, and understanding of these, together with the interviews sought to explore the nature of contemporary CBMRM efforts. In doing so, this study looked to explore 'community' definition and relationships with Taukei communities engaged in CBMRM at the study site. As this research suggests, such "hybrid" communities are shaped and defined through intricate socio-economic and socio-political relationships, which have an effect on social-ecological systems.

\subsection{Summary of interviews}

Table 1a (next page) provides information on contributors to this study; their role, age, number of years fishing (if applicable) and key concerns that affected them at the time of study. Table $1 b$ (p.70) then summarises information on contributors whose roles have been identified as fishers. It includes information on gear type, type of fish caught and fishing arrangements in place. This sex-disaggregated data helps me understand the complexities of the coastal fishing sector and reliance on the marine environment by various members of the community. 
Table 1a: Research contributors' information

\begin{tabular}{|c|c|c|c|c|c|c|c|}
\hline No & $\begin{array}{c}\text { Pseudo- } \\
\text { nym }\end{array}$ & Gender & Role & Age & $\begin{array}{l}\text { No. of years } \\
\text { fishing }\end{array}$ & Location & Key concerns \\
\hline 1 & Lal & Male & Fisherman & 42 & 25 & $\mathrm{~B}, \mathrm{Ba}$ & Support for boat repairs, decline in catch \\
\hline 2 & Kumar & Male & Fisherman & 72 & $>30$ & $\mathrm{~B}, \mathrm{Ba}$ & $\begin{array}{l}\text { Declining fish stocks, management } \\
\text { efforts and license issues }\end{array}$ \\
\hline 3 & Pratap & Male & $\begin{array}{l}\text { Fisherman/boat } \\
\text { owner }\end{array}$ & 40 & 18 & A, Tavua & $\begin{array}{l}\text { Consent and license management, ice } \\
\text { supplies in Tavua, cost of fuel and other } \\
\text { expenses. }\end{array}$ \\
\hline 4 & Joji & Male & $\begin{array}{l}\text { Qoliqoli } \\
\text { committee } \\
\text { member }\end{array}$ & 64 & - & $\mathrm{D}$, Tavua & $\begin{array}{l}\text { Vanua and Taukei pressures on } \\
\text { resources, mis-managed resources }\end{array}$ \\
\hline 5 & Chand & Male & Middleman & $>20$ & 2 & $\mathrm{C}, \mathrm{Ba}$ & $\begin{array}{l}\text { Lack of support re fish sales, rising food } \\
\text { costs }\end{array}$ \\
\hline 6 & Daku & Female & Fisherwoman & 53 & $>20$ & $\mathrm{D}$, Tavua & $\begin{array}{l}\text { Boat repair support, access to markets for } \\
\text { mud-crabs }\end{array}$ \\
\hline 7 & Sauturu & Male & Fisherman & 41 & 14 & D, Tavua & Access to fishing equipment \\
\hline 8 & Deo & Male & Fisherman & 42 & $>20$ & $\mathrm{C}, \mathrm{Ba}$ & Fuel costs, weather affecting fishing \\
\hline$\overline{9}$ & Priya & Female & Fish retailer & 38 & 10 & $\mathrm{~B}, \mathrm{Ba}$ & $\begin{array}{l}\text { Training staff who leave after being } \\
\text { trained. Debts owed to her business }\end{array}$ \\
\hline 10 & Manjesh & Male & Fisherman & 51 & $>30$ & $\mathrm{C}, \mathrm{Ba}$ & Unpredictable weather conditions \\
\hline
\end{tabular}




\begin{tabular}{|c|c|c|c|c|c|c|c|}
\hline No & $\begin{array}{l}\text { Pseudo- } \\
\text { Nym }\end{array}$ & Gender & Role & Age & $\begin{array}{l}\text { No. of years } \\
\text { Fishing }\end{array}$ & Location & Key concerns \\
\hline 11 & Munir & Male & Middleman & 30 & 2 & $\mathrm{~B}, \mathrm{Ba}$ & Inconsistency in fish supplies \\
\hline 12 & Prasad & Male & $\begin{array}{l}\text { Boat owner, } \\
\text { mechanic }\end{array}$ & 34 & $>10$ & $\mathrm{~B}, \mathrm{Ba}$ & $\begin{array}{l}\text { Unsure about safety requirements by the } \\
\text { Marine services authority (FIMSA) }\end{array}$ \\
\hline 13 & Seema & Female & Middlewoman & 32 & 6 & $\mathrm{~B}, \mathrm{Ba}$ & $\begin{array}{l}\text { Weather affecting fishing activities, high } \\
\text { cost of fuel, license concerns }\end{array}$ \\
\hline 14 & Ilisapeci & Female & $\begin{array}{l}\text { Fisheries } \\
\text { Manager }\end{array}$ & - & - & $\begin{array}{l}\text { Tertiary } \\
\text { Institute, } \\
\text { Suva }\end{array}$ & $\begin{array}{l}\text { Participation of Indo-Fijians in coastal } \\
\text { fisheries has been neglected for a long time } \\
\text { and needs to be addressed }\end{array}$ \\
\hline 15 & Jane & Female & $\begin{array}{l}\text { Fisheries } \\
\text { Manager }\end{array}$ & - & - & $\begin{array}{c}\text { Tertiary } \\
\text { Institute, } \\
\text { Suva }\end{array}$ & $\begin{array}{l}\text { How to engage Indo-Fijians in fisheries } \\
\text { Management }\end{array}$ \\
\hline 16 & Moses & Male & Academic & - & - & $\begin{array}{l}\text { Tertiary } \\
\text { Institute, } \\
\text { Suva }\end{array}$ & $\begin{array}{l}\text { CBMRM cannot be effective unless all } \\
\text { stakeholders are involved including Indo- Fijians } \\
\text { who are part of community }\end{array}$ \\
\hline 18 & Anthony & $\bar{M}$ & $\begin{array}{l}\text { Fisheries } \\
\text { Manager }\end{array}$ & - & - & $\begin{array}{l}\text { NGO, } \\
\text { Suva }\end{array}$ & $\begin{array}{l}\text { Lack of clarity on how Indo-Fijian } \\
\text { communities are structured to allow for } \\
\text { engagement }\end{array}$ \\
\hline 19 & Samuela & $\bar{M}$ & $\begin{array}{l}\text { Fisheries } \\
\text { Manager }\end{array}$ & $>60$ & - & - & $\begin{array}{l}\text { Taukei relationships over resource } \\
\text { management, lack of leadership, eroding } \\
\text { customary values, Indo-Fijians are sometime } \\
\text { unfairly treated by Taukei }\end{array}$ \\
\hline
\end{tabular}




\subsubsection{Commentary on data in Table 1a}

The data reflects a range of experiences and roles within community fisheries in the area. Most men interviewed had been fishing all their adult life. Two participants had just started selling fish as middlemen (less than a year) while two boat owners employed other fishermen to fish for them. The youngest participant was a 32-year old Indo-Fijian female who sold fish from her home (middle-woman) and the oldest was a 72-year-old Indo-Fijian male who was still actively fishing. More men than women were interviewed. This is reflective of the nature of participation between the different gender groups, i.e. more men are in the sector than women.

The data suggests that Indo-Fijian women are more likely to be involved as fish traders/retailers (middlemen/women) than as actual fishers. Only one active IndoFijian fisher woman was interviewed. Anecdotal reports of Indo-Fijian women involved in capturing mud-crabs (Scylla serrata), freshwater prawns (Macrobracium spp.) and mussels (Batissa violacea) for subsistence and semicommercial sales are occasionally reported by the media. However, this study did not have a specific focus to include Indo-Fijian women involved in these other types of fisheries.

For most fishers, the key concern affecting them at the time of study were unfavourable weather conditions and increasing uncertainty in renewing fishing licenses. One fisherman commented on the lack of support provided by the national government towards his boat repairs following severe flooding earlier in the year. Cost of transport, ice- supplies for storage and rising fuel costs were also common concerns among those involved in the fisheries sector. People representing NGO's and academics highlighted that participation of Indo-Fijians in conservation and fisheries management activities was important and had been neglected.

Table $1 \mathrm{~b}$ below summarises fisherfolks assets, type of fishing activity, fishing duration and key concerns or issues affecting them at the time of the interview in July 2018. 
Table 1b: Summary of participants involved fishing activity, gear types and fishing arrangements.

\begin{tabular}{|c|c|c|c|c|c|c|}
\hline \multirow[t]{2}{*}{ Pseudonym } & \multirow{2}{*}{$\begin{array}{l}\text { Fishing assets } \\
\text { observed / } \\
\text { noted }\end{array}$} & \multirow{2}{*}{$\begin{array}{l}\text { Type of fishing } \\
\text { Activity }\end{array}$} & \multicolumn{3}{|c|}{ Fishing arrangement } & \multirow[t]{2}{*}{ Comments / Notes } \\
\hline & & & $\begin{array}{l}\text { Av. \# of days } \\
\text { at sea / week }\end{array}$ & $\begin{array}{l}\text { \# of crew } \\
\text { members }\end{array}$ & $\begin{array}{l}\text { Expenses } \\
\text { / trip }(\$)\end{array}$ & \\
\hline Samuel & $\begin{array}{l}\text { Outboard } \\
\text { engine, fishing } \\
\text { boat under } \\
\text { repair } \\
\end{array}$ & $\begin{array}{l}\text { Coastal pelagic, } \\
\text { Reef species }\end{array}$ & 5 & 3 & $\begin{array}{l}500- \\
600\end{array}$ & $\begin{array}{l}\text { Did not go fishing in past } 2 \text { months due to } \\
\text { boat being damaged. Sells catch to } \\
\text { middlemen. }\end{array}$ \\
\hline Kumar & $\begin{array}{l}2 \text { outboard } \\
\text { engines, } 1 \\
\text { working boat }\end{array}$ & Coastal pelagic & 4 & 3 & $\begin{array}{ll}600 & - \\
700\end{array}$ & $\begin{array}{l}\text { Currently sick, has not gone fishing in past } \\
\text { month. Sells catch to middlemen. }\end{array}$ \\
\hline Pratap & $\begin{array}{c}\text { Outboard } \\
\text { engines, } 2 \text { boats } \\
\text { out at sea } \\
\end{array}$ & Coastal pelagic & 5 & 5 & 800 & $\begin{array}{l}\text { Operates } 2 \text { boats, also pays access fees to } \\
\text { fish in Ra waters. Supplies hotels and } \\
\text { markets along Lautoka and Nadi. }\end{array}$ \\
\hline Vijay & $\begin{array}{c}\text { Roving } \\
\text { middlemen, was } \\
\text { not interviewed } \\
\text { at residence or } \\
\text { place of work. }\end{array}$ & $\begin{array}{c}\text { Coastal pelagic } \\
\text { Reef species } \\
\text { Estuarine species }\end{array}$ & - & - & 400 & $\begin{array}{l}\text { Buys on credit from other middlemen then } \\
\text { moves around the area to sell the fish. } \\
\text { Repays the middlemen once all fish sold. }\end{array}$ \\
\hline Isaiya & $\begin{array}{l}\text { Does not own } \\
\text { boat, fishes in } \\
\text { "share" using } \\
\text { Indo-Fijian } \\
\text { boats in the area }\end{array}$ & $\begin{array}{l}\text { Coastal pelagic } \\
\text { Reef species }\end{array}$ & 5 & 3 & - & $\begin{array}{l}\text { Does not have any initial expenses, as fuel } \\
\text { and food paid by boat owner, expenses are } \\
\text { deducted at the end of fishing trip. }\end{array}$ \\
\hline
\end{tabular}




\begin{tabular}{|c|c|c|c|c|c|c|}
\hline \multirow[t]{2}{*}{ Pseudonym } & \multirow{2}{*}{$\begin{array}{l}\text { Fishing assets } \\
\text { observed / } \\
\text { noted }\end{array}$} & Type of fishing & \multicolumn{3}{|c|}{ Fishing arrangement } & \multirow[t]{2}{*}{ Comments / Notes } \\
\hline & & & $\begin{array}{l}\text { Av. \# of days } \\
\text { at sea / week }\end{array}$ & $\begin{array}{l}\# \text { of crew } \\
\text { members }\end{array}$ & $\begin{array}{l}\text { Expenses } \\
\text { / trip }(\$)\end{array}$ & \\
\hline Makereta & $\begin{array}{l}\text { Own boat, } \\
\text { currently not in } \\
\text { use }\end{array}$ & $\begin{array}{l}\text { Reef gleaning } \\
\text { Mud crabs } \\
\text { Handline fishing }\end{array}$ & 1 & 1 & 150 & $\begin{array}{l}\text { Her boat has been damanged since Cyclone } \\
\text { Winston, she hasn't received any } \\
\text { assistance for repairing it }\end{array}$ \\
\hline Shalen & $\begin{array}{l}\text { Outboard } \\
\text { engine, fishing } \\
\text { boat }\end{array}$ & $\begin{array}{l}\text { Coastal pelagics, } \\
\text { reef spp. }\end{array}$ & 5 & 3 & 500 & $\begin{array}{l}\text { Used to sell fuel from his home before but } \\
\text { fuel company has stopped supplying fuel in } \\
\text { his area }\end{array}$ \\
\hline Manjesh & $\begin{array}{l}\text { Outboard } \\
\text { engine, fishing } \\
\text { boat. }\end{array}$ & $\begin{array}{l}\text { Net fishing, daily } \\
\text { fishing trips. }\end{array}$ & 1 & 2 & 200 & Wife assists with net fishing activities. \\
\hline Munir & $\begin{array}{l}\text { Roving } \\
\text { middlemen }\end{array}$ & & - & - & 250 & $\begin{array}{l}\text { Renting on main road, waiting to build } \\
\text { house for his family }\end{array}$ \\
\hline Dinesh & $\begin{array}{l}\text { Outboard } \\
\text { engines, fishing } \\
\text { boat. }\end{array}$ & Coastal pelagics & - & - & 600 & Provides boat for fishing \\
\hline Seema & Deep freezer & Coastal pelagics, & - & - & 500 & Provides boat for fishing \\
\hline
\end{tabular}




\subsubsection{Commentary on data in Table $1 b$.}

From the data gathered, Indo-Fijian fishing practises could generally be classified in two major categories; i) commercial operators which typically involved a boat owner, a licensed boat captain, and several crew members, and ii) smaller artisanal fishers with their own boats, fishing for themselves and occasionally involving one or two other crew members.

\subsubsection{Commercial operators}

Generally, boat owners who had fisherman fishing for them had more than one boat, often with bigger engine sizes that were between $100 \mathrm{Hp}^{16}$ and $300 \mathrm{Hp}$, and usually more than ten meters in length. These bigger vessels had a licensed boat captain/master and carried between three and six crew members, at least two large ice storage chests/freezers, and food supplies and equipment for up-to seven days. Commercial fishers typically travel further out to sea, targeting deep-water fish species and occasional reef fish species and fish mostly at night. These operators typically supply hotels, resorts and restaurants around Nadi, Lautoka and Rakiraki. A typical fishing trip lasts between three to six days depending on weather conditions and catch levels. Fishing can sometimes be disrupted during periods of strong wind, rain and currents. Weather forecasts are usually checked for up to seven days out at sea, but quite often fishers experience unexpected weather changes, which can adversely affect their fishing trip resulting in loss.

Both Indo-Fijian and Taukei men are contracted by mainly Indo-Fijian boat owners for commercial fishing purposes. A typical boat crew would have both ethnicities. In most cases no formal employment contracts are held between the boat owner and fishermen. These work relationships are maintained through mutual trust and verbal consensus between the two parties. However, this arrangement often raises concerns for both the fishermen and boat owners.

An average 5-day trip costs around $\$ 700$ with fuel being the largest share of expense. Other common expenses include food for the week (typically root-crops, potatoes, spices, noodles and some vegetables), ice for storing fish (2-3 bags depending on distance to fishing ground), fishing bait (sometimes this is caught live at sea and

\footnotetext{
${ }^{16} \mathrm{Hp}$ - Horse power is typically used to classify boat engine sizes.
} 
sometimes purchased from shops) and transport costs (supplies to jetty and back). All fishers noted that rising fuel costs and inadequate ice supplies were their biggest concerns.

Profit is shared on an equal catch-share basis. This means that profit is shared equally amongst everyone involved in that fishing trip. Usually, the boat owner who forks out expenses for the fishing trip deducts the fishing expenses (for example fuel, ice, food, bait, transport) and a boat fee before allocating the profit made. Commercial fishers usually target a considerable profit however, not all fishing trips are successful. Some trips are referred to as 'bounce-trips' where the fishers end up incurring debt when no profit is made. On some fishing trips, fishers and boat owners are only able to breakeven.

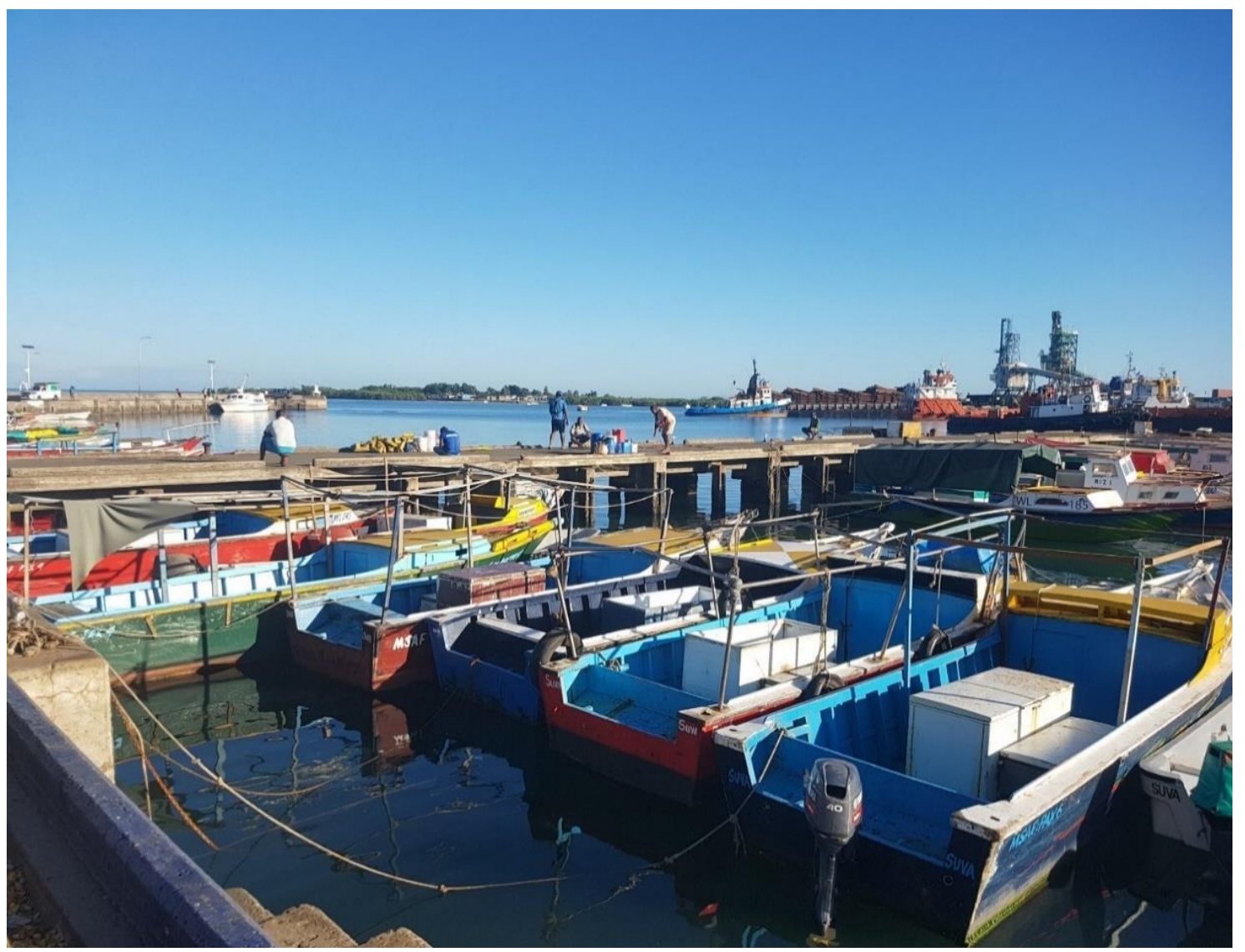

Figure 6: Commercial fishing boat operators docked at Lautoka wharf.

Photo: Chinnamma Reddy. 


\subsubsection{Small-scale artisan fishers}

Small-scale artisan fisherfolk generally do a one day or overnight fishing trip, usually with nets or handlines near river-mouths, mangrove deltas, and in the inshore shallow waters around the main islands. The boats used are typically aluminium or fibreglass punts or half-cabin medium sized skiffs (boats), about seven meters in length. These can usually accommodate up to three people and a small ice-box/chest freezer for storage. These fishers typically supply the local fish market in $\mathrm{Ba}$, Lautoka, Tavua and Rakiraki as well as to individual/households around their area.
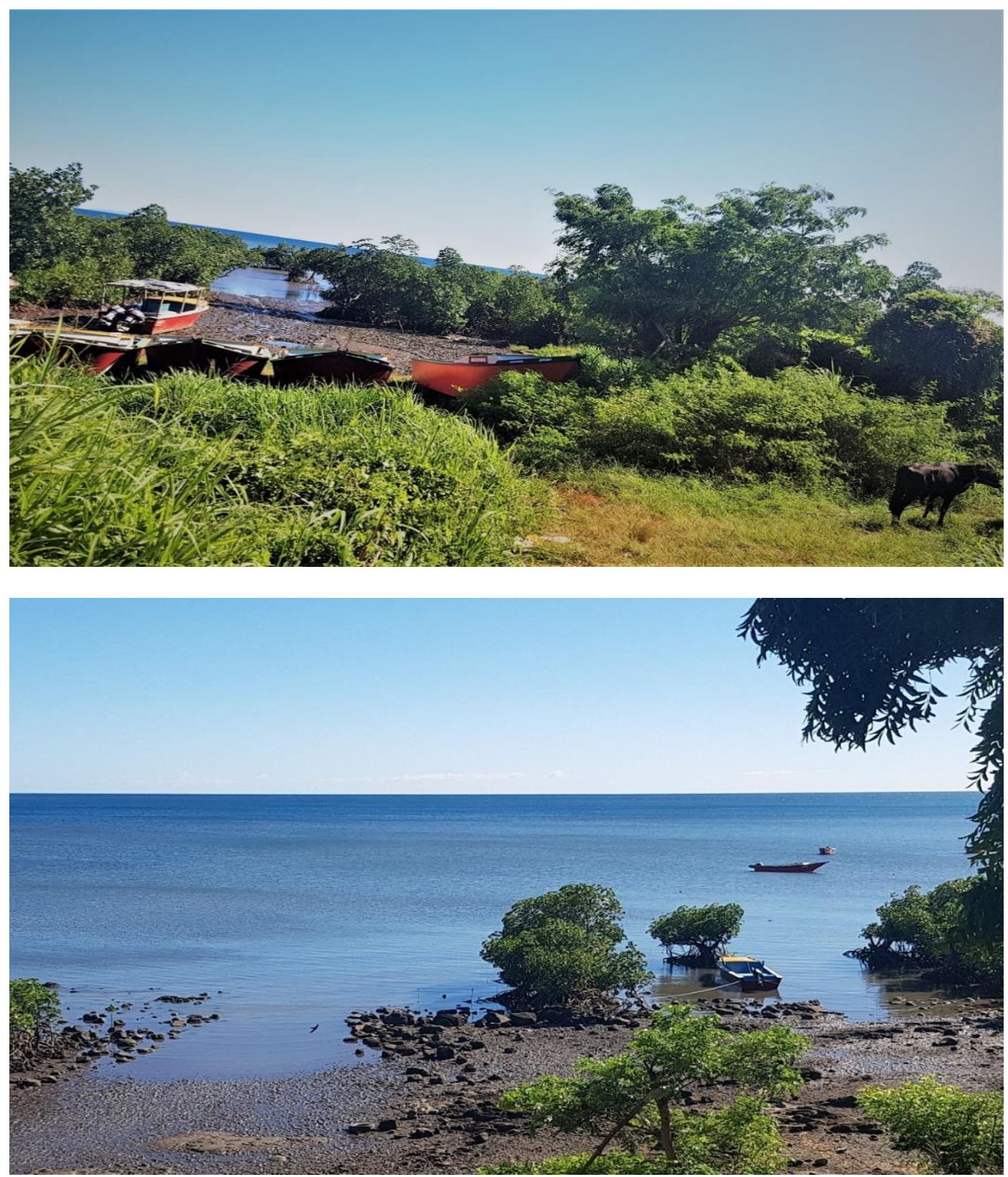

Figure 7: Fishing boats tied-up within mangrove stands in $\mathrm{Ba}$ (top) and boats out at sea (bottom). Photo: Chinnamma Reddy. 

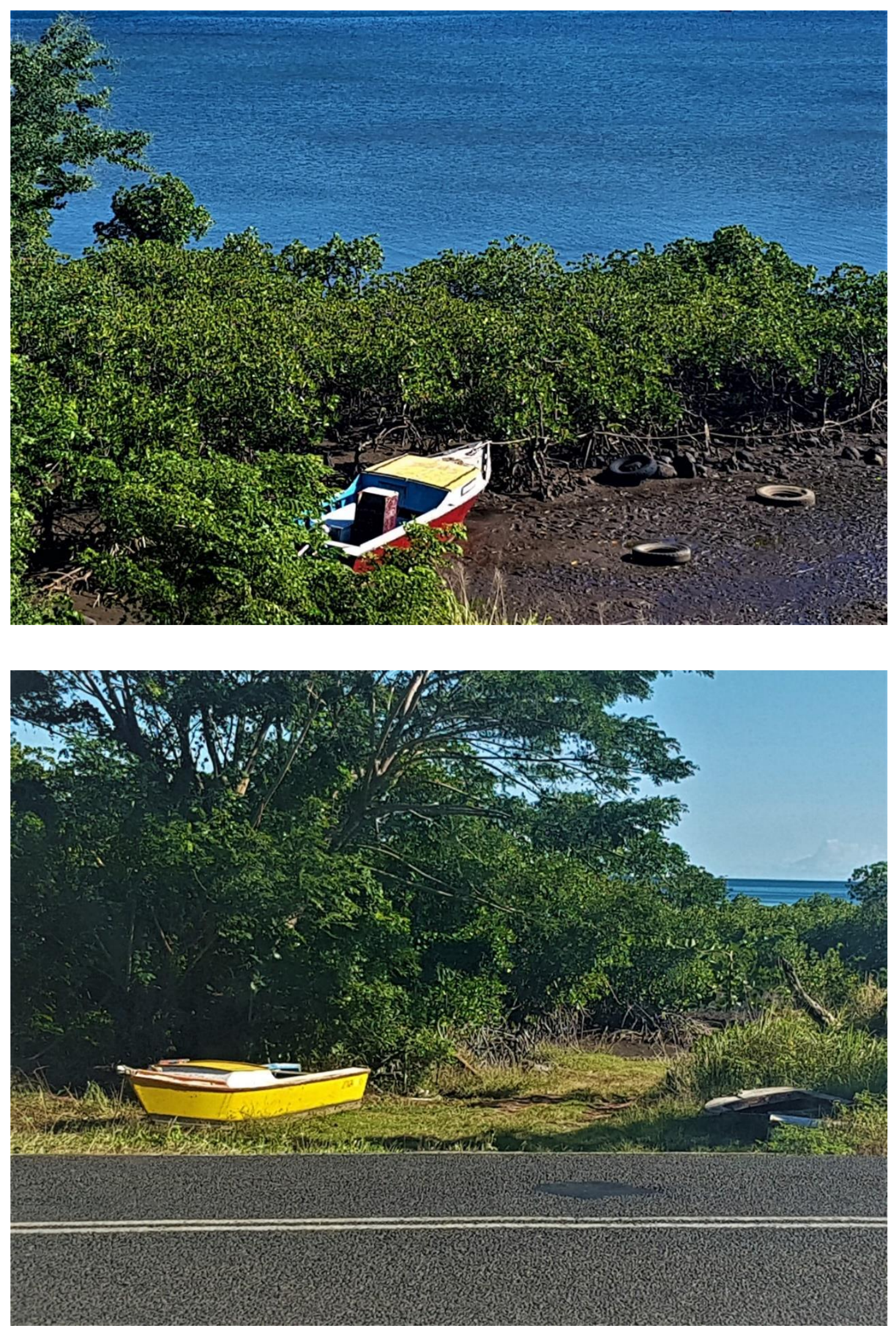

Figure 8: Typical half-cabin boats (top and bottom pictures) sheltered within mangrove patches in Ba. Photo: Chinnamma Reddy. 


\subsection{Representation, translation and interpretation of community}

The interviews I conducted in the fishing communities, conversations with research contributors, personal reflections, and my field notes have shaped what and how I understand the nature of social interactions between Indo-Fijians and Taukei communities. Everyday lived experiences such as meeting and greeting each other in the native language, participating in each other's cultural or traditional events, and the informal and formal processes of seeking permission to access and use marine resources form part of a broader fishing community in $\mathrm{Ba}$. In order to understand how these everyday interactions' play out in a multi-user group, complex and situational fishing community, it is important to reflect on peoples' experiences and interpretations of performing community. In doing so, people are provided an opportunity to narrate their own 'realities' of living and belonging to a community. To protect the authenticity of people's realities, I have presented the interview responses in their original form, either in Taukei or Fiji-Hindi language. Their English translation is provided below the original text.

\subsubsection{Representation and identity}

All research contributors unanimously agreed that Indo-Fijians play a critical role as resource users in Fiji's coastal fisheries space and that inclusion in management activities which impact them, and resource owners are long overdue. As Anthony, an NGO fisheries manager remarked:

The issue of non-resource owners in Fiji has been long neglected, even ignored and is an area needing investment if sustainable fisheries is going to work. As users of the resource I consider their role also integral to the sustainable management of the resource. They like iTaukei's will be affected by the loss of fisheries for both income and food. Personally, I think they should have a mechanism to channel their concerns to the management by both the resource owners and fisheries [officials]. This does not exist fully aside from issues around licensing. Management should ideally have a means for non-indigenous individuals to bring concerns to the table and likewise be used as conduits to channel decisions and awareness issues from the resource owners.

(Email correspondence, 12 August 2018)

During my interviews I asked participants to describe how these social interactions were performed and maintained with each other and as part of a wider fishing community in the Ba Province. In particular, I was interested in documenting the 
consent and access process that allowed other non-resource custodians to participate in commercial fisheries at the study site.

Overall, the findings suggest that for the most part socio-cultural differences amongst the two major ethnic groups have become less profound over-time with an improvement in inter-ethnic relationships. However, some Indo-Fijians felt that the socio-political and economic relationships have become estranged and difficult particularly in recent times. More Indo-Fijian fishers were comfortable identifying themselves as Fijians, however said that cultural and religious differences would remain for the time being. Some research contributors noted that inter-marriages were becoming more common and may help with strengthening relationships and reducing conflicts between the two ethnic groups.

\subsubsection{Two sides of a coin-multiple or conflicting perspectives}

I had the opportunity to speak with a fishing committee (qoliqoli) representative in one village. Joji is a senior member within the fishing committee and an advisor to the chief of the village which gave him certain authority over marine management and decision making in his community. In essence, his role was to act as the gatekeeper to commercial fishing in the area. Most Indo-Fijian commercial fishers in the area liaised with him to gain fishing consent and access to the village's fishing waters. I asked him to describe how he felt about the present social relationship with Indo-Fijians in the nearby IndoFijian settlement. Speaking in Taukei language, he said:

O ira na wekada kei ira na Taukei sara vaka edua na vuvale (Joji, interview, 04 July 2018)

Our relatives, referring to Indo-Fijians and the iTaukei, are just like one family.

Joji went on to add that in the past they would not openly talk to Indo-Fijian women without the presence of their husbands, but now they treat each other as brother and sister and maintain that respect for each other. He adds that they are now invited to IndoFijian functions and religious gatherings and similarly Indo-Fijians get invited to Taukei social and cultural gatherings. He added that their relationships have persisted through times and they are in a new era of forming united identity and communities, as Fijians. 
Joji's views were reinforced in my interview with Munir, an Indo-Fijian fisherman living in a Indo-Fijian settlement in Ba. Munir feels that the relationship between the two ethnic groups is generally good and has improved. When requested to elaborate, he remarked:

Hiyan ke kaibiti log bahut acha hain, aur bahut madhat bhi karde hain, pahile ke rakam nahi hoye abh (Munir, interview, 05 July 2018)

The Taukei people in this community are very good, they are helpful and its unlike in the past.

Munir explains that the Kaibiti ${ }^{17}$ or Taukei community in his area have good relationships and are also helpful in times of need. He said that it's unlike the past where once he recalled how Taukei men would sometimes forcefully take away the days catch from his father and uncle's boat. He spoke cautiously as he explained how on one occasion, six Taukei men took out bundled fish from the ice-bins and started distributing them amongst themselves while his father and uncles stood-by and watched on, powerless as they feared for their safety and backlash had they attempted to stop the men. As a child he remembered how traumatic such experiences were. With the catch taken, the family had to compromise meals and basic necessities until his father could go back to catch more fish.

I sensed that Munir was not comfortable elaborating on this experience, so I asked if the situation had changed since then. His tone changed when he quickly went on to say that those experiences were well in the past, and that relationships had surely improved in recent times. He then explained how grateful he felt for living in Fiji after witnessing how quickly the community acted after the January 2018 floods in $\mathrm{Ba}$. He said people from all walks of life came together to help clean up $\mathrm{Ba}$ Town, and the cooperation and support amongst everyone renewed his hope in the country. Munir's experience of how inter-community relations have changed isn't isolated. However, where he thought that things had improved considerably, Pratap, a boat owner in an Indo-Fijian settlement in Tavua experienced inter-ethnic relations differently.

\footnotetext{
${ }^{17}$ Kaibiti is a colloquial term used by Indo-Fijians to refer to Taukei people. It literally translates as people of Kai Viti or the people of Viti or Fiji.
} 
Following my interview with Joji, I informed him that I also intended to visit IndoFijian fishers in the area to talk about their fishing experiences and concerns affecting them. Joji offered to introduce me to Pratap who lived a short distance from where Joji and I conducted our interview. After our formal introductions, Joji was invited for tea at a neighbour's place, and I proceeded to prepare myself for the interview.

Before commencing the interview with Pratap, I described to him the purpose of my visit and the research topic and specifically added that I was seeking Indo-Fijian fishers' perspectives on fishing and relationships with Taukei qoliqoli owners. Without hesitating, Pratap added that one of his biggest concerns with the qoliqoli owners/committee, was the constant harassment for money from the committee members. He confided with me that he did not particularly like Joji, as Joji would often come around demanding for money. However, his dislike of Joji was not made obvious during our introductions:

Khabi khabi to hum log bahut tang hoi jata paisa dehte dehte elog ke, kam karke ke liye. (Pratap, interview, 05 July 2018).

We often get stressed and fed-up of giving money each time in order to do any work. Pratap added that he felt that they had to constantly give in order to live, survive and work in his settlement. He went on to explain how one Taukei landowner continued to harass him for money over access to a fish landing area that cuts through the Taukei gentleman's property. The landing site is only used to access and transport fish, gear and supplies through the river out to open sea. Pratap's father built a small jetty many years ago with consent from the village chief and before the Taukei man had moved in to build his home across the landing site. In the initial years, the family did not ask for any compensation until the chief's death in 2015. Pratap was unexpectedly stopped from accessing the jetty one day and the family made demands for cash and shares in the catch every week.

Following weeks of negotiation with the fishing committee and other villagers, an informal working solution was found, and Pratap was able to retain the jetty. He was required to compensate the family for the loss of their fishing area in the river. While a one-off compensation payment was agreed to between them, Pratap was expected to provide a bundle of fish from each fishing trip to the family. This is in 
addition to monetary loans requested by the Taukei man every so often, with the promise that they would be returned. Pratap seemed distressed as he described this situation to me as he mentioned that the money had never been returned. However, he also could not stop himself each time there was a new request, due to fears that he would lose access to the jetty and consequently would have to travel further away to access the sea.

Pratap's experiences and concerns were reflected by another research contributor from Ba. Samuela worked at the Fisheries Department for over 30 years until his retirement a year ago. He was engaged as a consultant for an NGO at the time of our interview. As a retired officer, concerned with the state of fisheries affairs in the country, Samuela was grateful to be able to share his views and opinions openly without having to be worried about his former role as a government employee. Being a Taukei, he stated that he was appalled at how Indo-Fijian fishermen were treated by Taukei communities in some areas:

The way Fijians treat the racial divide; kai dia, kai viti, even harassment, even demanding fish and even after paying consent fees, and getting license. The chiefly people issue the consent, but the village people have no ideait's a problem within the Kai viti unit. The money the chief obtains often is not shared resulting in internal conflict. (Samuela, interview, 06 July 2018)

When asked to explain the factors that maybe lead to preferential treatment of some fishermen and boat owners over other fisherman, he said:

Demand is the main factor. Some people give chance for part-payment, some custodians demand cash, some small fishing grounds demand so much. When you talk to fishermen, their full-time job is fishing - the main factor there is the demand. It is a good will payment, and that should be any amount but when they put an amount, $\$ 1000$,

\$3000. Some fishermen they cannot afford. Only big fishermen, they can put that money down. Because in Ba, there are boat owners and the fishermen. In some cases, they are on the good side because the big business man owns the boat. But for individual boat owners, it's hard. (Samuela, interview 06 July 2018).

Samuela's responses, based on his years of experience in the fisheries sector and being a Taukei man, suggests deep concerns over resource management, access, participation and equity over those resources. His concerns highlight the lack of 
transparent governance over marine resources, especially the role of village chiefs who did not disclose the amount of goodwill payment they receive from commercial fishers. This, he suggests, resulted in inequitable resource benefit distribution between common Taukei people, despite their recognition as customary owners under the Vola ni kawa bula (VKB) and the Native Fisheries Commission.

Fishing ground belongs to the Vanua. Vanua'o Votua - all people listed in the $V K B$ should be consulted for fishing license, but problem is that chiefs are themselves making decisions - causing tension and bickering amongst villagers. But if chiefs liaise properly with villagers, some issues facing fisheries is because of internal bickering amongst the community members. (Samuela, interview 06 July 2018)

Additionally, Samuela's response reflects the inequity over affordability in paying consent payment by commercial and individual small-scale artesian fishers in Ba. Reflecting on the issue of fishing consent and access, Munir explained how he'd had to pay multiple qoliqoli owners for access and passage to fishing grounds between $\mathrm{Ba}$ and the Yasawa Islands, further west of the main island and also a prime fishing area: Aur ek issue hain, hum log ke pata nahi ke kaun qoliqoli kiske hain. Votua la people batayein ulong ke hain aur Yasawa le batayein ke ulog hain. Hum log ke fisheries ke baghal se koi map nahi mila. (Munir, interview 05 July 2018)

There is one other issue, it is the confusion over which qoliqoli belong to whom, we haven't received any maps to show boundary that marks which area belongs to who and even out at sea it's hard to know which qoliqoli that we are fishing in as there are no markers.

Munir added that since the Government was overseeing the license process (refer 2.2.2) the situation had improved, while in the past Taukei had been known to confiscate fish catch, harass fishers, and claim ownership over different areas. $\mathrm{He}$ added that fishers should be given maps that demarcated the different areas so that there was no confusion and conflicts could be avoided when they were confronted by the Taukei qoliqoli owners out at sea. In sharing his thoughts Munir added:

Hum log ke sange bhit gayais hain. Votua ke people demand karis ke humlog ulong ke jaada paise deo khaski boat cross kare ulog ke paani se. (Munir, interview, 05 July 2018) 
We have had a few issues in the past; Votua community came and said that we are accessing the fishing ground through their waters, so we must pay them more.

Another fisherman, 72-year-old Kumar also mentioned about the fishing area dispute by Vatoa villagers. According to him, his dad who used to fish some fifty years ago never paid the so-called consent and access fees to the villagers. However, he personally felt that the resource owners needed to be compensated and internal disputes over ownership needs to be resolved amicably. Unfortunately, the fisherman were the ones that suffered, he added.

I followed up this concern with the Fisheries Officer in Ba later that day where the officer explained that fishermen are normally provided with such maps, however, some fishing grounds in the areas such as Votua were being contested, therefore fisherman were receiving contradictory information on the qoliqoli boundaries and its ownership.

These three contrasting interviews in the same area prompted me to think of what and how community is performed and perceived in these locations. The lack of trust and transparency between people and their leader's resulted in disputes, not only internally but also externally outside of community that involves other stakeholders. The lack of clarity between people over qoliqoli boundaries are reflective of poorly planned colonial remnants affecting people in the present day. As such, these findings suggest that communities are performing and maintained through these intricate and complex socio-cultural, economic, and political processes embedded within layers of social relationships. I note that these findings are situated appropriately within the postcolonial and political ecology discourses, which I will comment on further on in the next chapter.

\subsubsection{Hidden figures: community linkages - roles of women in and within} fishing spaces

Learning how Indo-Fijian women participated in their family fishing businesses was an unexpected finding in this research. This research had a particular focus on the relationships between Indo-Fijian fishers and Taukei resource owners, positions typically occupied by men. It became clear, however, that women played several critical roles including as heads of household while the men were away fishing, as businesswomen involved in the fish trade, as fishers themselves and as co-workers 
in the trade. Additionally, the role of women in Fiji, and especially Indo-Fijian women in the fisheries sector, is under-researched. Little is understood in terms of their participation, contribution to household income and decision-making in resource management in the country. In the following section, I present the multiple and important roles that Indo-Fijian women perform within the coastal fisheries sector at the study site.

Priya is the daughter-in-law in a family run business in Ba. She was married into the family 13 years ago and now manages the general grocery store which also sells locally caught fresh and frozen seafood. The family also own a fishing boat and a fishing business which she manages. I asked Priya to explain how their fish business operated hoping to gain further insights into the fish retail side of fisheries in the area. Priya fell into the owner/operator and middlemen (or women in this case) category of the business. In this situation, Priya provided the appropriate resources such as the boat, fishing gear, bait, food, and other necessary supplies to fish while the men (mostly Taukei, some Indo-Fijians) were tasked with fishing and bringing the catch to her. Priya explained that the business operated through an informal labour scheme that was underpinned by trust rather than a formal job agreement or contracts.

I asked her to elaborate on how this trust and mutual agreement scheme worked and was maintained between parties:

Crew ke family ke bhi soche ke pare, chota chota ladkan hain saab ke paas. Hum log ke pas dui boat hain. Crew leke jawe boat somar ke aur hapta bhar machari mar ke leke awe. Usme se hum log panch share karta, expenses nikhal ke. Dui share hume mile because hum boat aur khana, ice supply karta, bacha teen share crew ke jawe. Hum log ke share hum yahi dukhan se bechleta. Kuch kuch crew ke hum log ke dukhan me account bhi hain. Hapta mein agar uske ghar me kuch sauda mange to hum log credit pe deta, phir jab crew machari leke awe, tab apan share me se phir credit kateh. Aise mein hum log ke bhi chale aur ulong ke bhi chal jawe. (Priya, interview, 04 July 2018). 
I have to think about the families of my fishing crew as well, they have small children. We have two boats which are crew-operated through the week, beginning on Monday until they can return with enough catch either on Friday or Saturday. We usually allocate five shares; I take two of those. One for the boat expenses and one for food and other fishing supplies. The remaining three is then divided between the crew members. I normally sell my share of fish from our family-owned retail shop. Some crew members take groceries on credit from the shop and have an account. Usually the wife is able to take food items on credit for the week, while the husband is away fishing. The husband then repays the weeks debt after getting his share from the fishing trip. In this way, I also benefit, and the crew member and his family also benefit).

Most fishers got paid upon return from their fishing trips, some took an advance on the money they would have earned from their contractors. In some cases, the amount taken was more than what they earned from fishing, often due to the variability in fish catch numbers and price of fish. Inevitably, these fishers got caught in a debt cycle, as they constantly tried to balance everyday living costs (bills, travel, medical expenses) with their income. Most times there was not enough cash to last the week and some fishers set up informal credit arrangements with local business operators that allow a fishers family to buy necessary food items on credit during the week. This arrangement involves trust and accountability in repaying debts between the fishers and business owners.

Priya explained that the system they had allowed her business to continue while the fisherman was also able to support his family. Although Priya benefited from this informal system, she also saw it as being open to abuse or disloyalty when workers went elsewhere. One requirement of obtaining a fisheries license is that the boat is manned by a licensed boat captain. In order to maintain a regularly operating fishing business, Priya paid to upskill and train three crew members to obtain boat masters training with the Maritime School in Fiji. In addition, she also supported her crew members in paying for insurance that covers search and rescue in case of a tragedy at sea. However, when asked if the crew were considered employees, she stated that it was difficult to employ fishers on a permanent basis as fishing activity is seasonal and weather dependent and had becoming increasingly unpredictable. Thus, fishers could be considered to be working for her 
but without any formal agreements.

At times, due to the uncertain work conditions and disruptive weather conditions which hindered fishing activities, fishing crew left her fishing business to look for permanent jobs elsewhere or fish for someone else. For Priya and her business this was not favourable, as she had to constantly spend money paying for training. However, she still would not employ the fishers as staff to eliminate this concern. Such informal work relations highlight the vulnerability of people involved in the fisheries sector in the area. In the absence of formal employment contracts and inaccessibility to other opportunities provided by waged labour, the fishing business is considered highly risky and volatile. As Munir shared:

Machari wala business me kaam bahut mehanat hain, garam, thanda sahe ke pare aur u saab proper kapara bhi bahut managa hain. Hum log samundar me eke eke hapta bhitaye deta. Aur ab age bhi jaye hain. (Munir, interview, 05 July 2018)

Fishing is physically tiring, we have to endure so much, the heat and the cold, and we go through this and cannot afford proper gear to combat the weather. We have to endure this in old age and we stay out for up to a week in those unfavourable conditions.

Seema shared similar sentiments to Priya, in relation to her views on supporting fisherman and their families in particular the wives and children. She explained:

Machari wala business mein paisa nahin hain. Kabhi profit ban jawe toh ban jawe. Weather bhi etna karab rewe. Naito hum log to kahli isme roll karta hain. Kuch hum log ke bhi chal jawe aur machawa log ke family ke bhi chala jawe. (Seema, interview, 04 July 2018)

There isn't much money in the fishing business. We hardly ever make profit, especially these days when the weather conditions are so unpredictable, we are mostly just "rolling" in this business. Well, however it is, the business is able to support myself, fishers and their families.

In this quote Seema says that the money made from fishing is on a rolling basis, explaining that the income received often equaled the expenses incurred. Seema supports her husband by running a fish shop from their family home. Normally she just bought fish off the fisherman that went fishing on her husband's boat. She added "not many people are able to make any profit from this business, yet 
we are still in this as I see it as a form of support for me and the fishers and their families" (Seema, interview 04 July 2018).

Another woman, Naz, is a fisherwoman herself and lives in an Indo-Fijian settlement in $\mathrm{Ba}$. She and her husband were preparing to go out for their routine Saturday shopping when I approached them for an interview at their home. Initially requesting thirty minutes for the interview, we ended up talking for more than an hour. I had started talking to her husband who is also a daytime net fisherman when he mentioned that Naz was his crew member. Naz was quite happy to share her fishing tales as she hardly had anyone inquire about that before. I was of course very interested and told her it was unusual to hear of Indo-Fijian women engaged in commercial fishing. While she laughed at this remark, Naz was equally serious when she replied that this is what she had to do to support her husband and family.

Apart from saving costs on paying for an extra deck hand, Naz mentioned that fishing kept her active and fit. She added that just as women helped their men work the farm, plant vegetables, harvest, and then sell, it was the same way she saw herself going out to sea to fish, clean the fish, and prepare to sell to middlemen. Her usual routine would be to accompany her husband and a crew member for day-fishing, using either a hand- line or net. They spent five to seven hours out at sea, sometimes longer depending on the amount of catch they had. The one thing she mentioned which was similar to the many others I spoke to was that if they went out they must make sure to come back with catch to sell. The costs they incur prior to a fishing trip must be recovered and when possible a profit helps them with other needs of their household.

These are just three of the women who are inextricably linked to coastal fishing practices in the area. Their roles across the fisheries sector were important in supporting businesses and families. The particular experiences of women in such a male dominated industry would be a fruitful area for further research. 


\subsection{Dependency and interdependency}

The second key theme emerging from this research highlights the complex inter and intra socio-economic and socio-political relationships between the two ethnic groups. Such relationships are formed, navigated, and maintained through highly fluid interactions between resource owners and users. This section highlights the dependency between people and the interdependency of fishers on marine resources, their vulnerability to disasters, impacts on livelihoods and the lack of institutional support for fishers in this community.

\subsubsection{Resource dependency, vulnerability, volatility}

The coastal fishing business was described as highly risky, volatile, seasonal and a laborious industry. However, men who continued to engage in the sector said that it was the only profession they knew. Five out of the fourteen fisherfolks who participated in this study stated that fishing was their only source of income. Samuel, an Indo-Fijian fisher was busy with boat repairs when I requested for an interview at his family home. He explained that following the severe flooding events earlier in the year, he hadn't been able to return back to his fishing business due to his damaged boat. He also did not receive any government support for fixing his boat, which was his only source of income, despite several requests to various government departments. In June 2018, he was offered a $\$ 1000$ grant which was being provided to all flood-affected victims in his area. While he had other urgent concerns to look at, Samuel chose to use the money to rebuild his boat as a priority. He was deeply affected by the lack of support from Government regarding his requests for funding to repair his boat. He added that had he received a loan or grant from the repairs he would have been able to support his family better with the $\$ 1000$ provided. But now with very little help, and no other source of income, he was compelled to use the grant money for urgent repairs to his boat so that he could start earning an income.

Government's lack of support for Indo-Fijians fishers involved in coastal fisheries was also highlighted by Munir. Following the recent flood event, Munir commented that government agencies only took stock of damage on land caused by flooding, hurricane, or strong winds. However, the agencies did not appear to account for the 
damage caused to the ocean:

Hum log ke main problem konchi hoijao ki Government maybe sayth Government samajh nahi pat hoi ke jab disaster ao u long deke khayn flood aise, tufan damage karis hain hala ke tufan samundar itna damage kar dewe. Hum log kabhi kabhi ek maina se upar samundar me kam nahi kar pata. Tufan ke bhad samundar ke pani mita hoijawe, aur itna mahile rah eke machari milte nahin. (Munir, interview, 05 July 2018)

Our main problem is that Government does not account for, or perhaps they cannot see, that when we have natural disaster events, they (officials) only assess damage on land from flooding or hurricane. However, what they don't account for is the damage caused at sea from the flooding and pollution. We cannot go out fishing for up to a month after these events as the water becomes sweet and dirty and we are not able to find any fish.

In the above quote, Munir describes his despair with government agencies over lack of attention over damage and loss to marine resources following natural disasters. He explains that he was unable to go out fishing for up to a month after such disasters, as "sometimes the ocean water became too murky and polluted to find fish” (Munir, interview, 05 July 2018).

He further added that when visited by government officials for damage assessments, he often did not meet the eligibility criteria for compensations as his home does not get flooded or had suffered minimal wind damage. He added that sadly government documents did not attempt to take stock of damage caused to their livelihoods, i.e., the sea.Continuing his discussion, Munir added that his other major concern was the lack of formal recognition of fisherman within the formal waged sector in the country. Consequently, fisherman like him had limited access to financial support from banks, commercial retailers, and other financial institutions. He added that fisherman were some of the poorest in the society and yet nothing much had been done to improve or support their livelihoods. He recently bought a Yamaha boat engine on hire purchase from Courts, a large department store in Fiji. He explained how he juggled making repayments for his engine and meeting his family's needs:

Agar tuma pass bholo $\$ 200-\$ 300$ ke kam karliye, aur tum pass bacha aur kuch le mangta le liya, lekin bank nahi sako kuch. Aur agar payment pe kuch le liya 
toh phir agar 2-3 maina kham nahi be to phir payment toroh payment ulong roki. Jaise courts ulog I bhat nahi jana, ke tuma boat chale ken ahi chale, ulog to paisa mainga...I sab chij ke piche humlog bahit musibhat khata. (Munir, interview, 05 July 2018)

Let's say if I earn $\$ 200$ to $\$ 300$ today, and after meeting all expenses, I get what I want to, there is hardly any money left to save. And if you have something bought on hire purchase then payment for that becomes a priority. Even if you don't work for two to three months, they (hire purchase companies) will not consider that, they require monthly repayments. Companies like Courts don't care if you tell them that my boat was damaged and I have been unable to go fishing, at the end of day, they only want their repayments. It is because of these financial burdens that we sometimes suffer so much.

Munir added that because of the highly unpredictable weather events recently, he had been struggling to go out fishing every week. Therefore, between managing his families' needs and meeting repayment obligations, there was no way he could afford to save on an average $\$ 200$ a week income. Additionally, without any contribution to insurance or superannuation schemes, Munir expressed his concern for his family in case of an inevitable accident or even his death out at sea.

Hum log ke paas kohi asara nahi hain, nato government ke bagal se aur naito FNPF me kuch paisa hain ki nikhal ke boat repair kar dai (Munir, interview, 06 July 2018).

We have very little support from anywhere, either Government or FNPF who could assist with boat repairs or where we could take money from to do them ourselves.

Concerns over changing weather patterns was also a key concern for all people that I interviewed. Having suffered huge losses during the devastating 2016 Cyclone Winston, followed by several damaging flooding events, most fishers commented that the unpredictable weather conditions made fishing unviable. Weather conditions were highlighted as one of the biggest variables in the fishing business, and one that fishers had no control over.

These findings have highlighted that although Indo-Fijian fishers are heavily dependent on marine resources for their livelihoods, they face increasing socioeconomic and socio-political disparity due to their vulnerability within the informal, 
volatile, and risky fishing industry. This situation is being further exacerbated by extreme weather conditions over which these people have little control and receive minimal support through existing institutional structures.

\subsubsection{Socio-political and livelihoods dependency between resource owners and users}

As highlighted above in Priya's case, I was informed on multiple occasions that most Indo-Fijian boat owners themselves do not go out fishing. Instead, most operate though ad-hoc fishing arrangements based on trust and reciprocity between the parties. These socioeconomic relationships are carefully negotiated and maintained over periods of time between and within ethnic groups. In one situation, Sauturu, a resource custodian and a fisherman in Tavua village worked as a crew member on Pratap's fishing boat. I interviewed Sauturu at his family home in the village and asked him to describe how the social and financial relationships were carried out between him and Pratap. Speaking in Taukei language, here is what he explained:

O au sa siwa tiko vei na waqa ni Pratap sa baki dua tiko oqo. Au marau ni rawa kina noqu sede mai na noqu cakacaka ni siwa. Ia au sa cakacaka tiko me dua talega na noqu waqa enidini meu qai lai siwa me noqu. O bhaiya sa veivuke tiko me rawa na noqu naki qo (Sauturu, interview, 05 July 2018)

I have been fishing for Pratap for the past year. I am happy that I am able to earn money from the fishing business. Now, I am working towards saving enough money to buy my own motor boat so I can fish for myself. Brother [Pratap], is helping me to achieve this goal.

Sauturu explains that he worked for Pratap in his fishing business. He aspires to own his fishing boat one day. Referring to Pratap as bhaiya (or brother), Sauturu acknowledged his gratitude towards Pratap for offering him employment through which he may be able to own his boat someday. Similarly, when I spoke with Pratap earlier, he mentioned that he was grateful of the local village support, which had helped him through dealing with a difficult situation with the village fishing committee. He was likely referring to the issue of jetty excess discussed earlier in 5.2. This mutual appreciation comes through trust and reciprocity which are critical values in building social capital between the two groups. 
These socio-economic and political relationships are further explained by Joji, the village fishing committee representative. Joji mentioned that he hoped that the positive relationship between the Taukei and Indo-Fijians would bring about mutual benefits for each other. When describing the process of granting consent and access to Tavua fishing waters, Joji explained that he always encouraged commercial Indo-Fijian fishers in his area to support local village initiatives. Commenting in Taukei he explained:

Na veisemati vei ira na Taukei kei na wekadraa, na kaidia na qoli, sara cicivaka tiko na qoli o ira na Taukei. Vagataka tiko na waqa ni ira nai Kaidia me ra lai qoli kina. Dua na veisamati qo sa on. Oi ra talega na kaidia sara lai cakava va vinaka na vale ni Taukei, so na Taukei ra sega tiko nodra vale sara lai veivale sara. Na deal au sa cakava tiko qo me vaqo - iko na Taukei ni yaya, ia mo qarava sara va vinaka na lewe ni Taukei koya qarava tiko na nomu cakacaka ni qoli. Me soli na sede ni qoli mo qai veuvuke taki koya talega me caka vale, se vavinaka taka na nodra vale sa tara oti tu (Joji, interview, 05 July 2018)

The connection between us Taukei and the Indo-Fijians is through the sea. The Taukei's are today operating Indo-Fijian owned boats to go out fishing. This is a unique relationship and its working. The Indo-Fijians in return are helping Taukei men to build their homes. Those that didn't have homes in the village now have decent homes now. As fishing committee representative, I am encouraging this type of working relationship where each group have responsibility toward one another. For Indo-Fijians who own the boats and gear, they have a responsibility to uplift the living standards of Taukei men who work for them.

Joji described an important socio-economic and political relationship in regard to Taukei people contracted for fishing by Indo-Fijian boat owners. He explained that nowadays a lot of Taukei men were fishing for Indo-Fijians and according to him, Indo- Fijians had certain responsibilities to look out for the welfare of these Taukei men. He added that in the current consent and access process, he was striking deals with Indo- Fijian boat owners to assist Taukei fishermen in building their houses or renovating them as conditions for granting fishing consent in his area. This situation fits within a political ecology perspective which examines unequal socioeconomic power relations and distribution of the power within the communities. Thus, it describes an interesting example of how power shifts between different people and groups at different times. 
In order to understand how power affects socio-economic relationships between people and how this impacts livelihoods, I describe another scenario to help understand this. Anil is a roving fish middleman who buys fish from local fisherman to sell from his truck. At the time of our meeting, Anil had just returned from one of his purchasing trips. Not wanting to disrupt his work schedule, I asked if I could observe him while he worked and, in the process, ask him some questions. He agreed. This gave me an opportunity to gather useful insights into the financial arrangements between fishers and middlemen in the area.

As he worked, I noticed he was opening and re-bundling fish from an already bundled fish. When asked why he was doing this, he explained that he buys fish bundles directly from fishermen around $\mathrm{Ba}$. He paid up to $\$ 30$ for a A-grade bundles of fish and between $\$ 5$ and $\$ 10$ for the other types. He also mentioned that fish are often "auctioned" off at the fish landing site, where the middleman who bids the highest gets the fish. Most times he re-bundled fish to make them into two or three separate bundles. This re- distribution depended on the fish grade and quality, and on market demand. He said if fish supply was less, he would make as many bundles as he could to meet the demand, as well as maximising his profit. He was reluctant to talk about how much profit he made but added that he did not end up making profit all the time.

He explained that on most occasions he got fish from the fishers on credit and then hoped to sell all of them to make any money. It was difficult to repay back the debt sometimes if he wasn't able to sell all his fish, or if they become spoilt if not stored properly. He added that sometimes his customers, who were both Taukei and IndoFijians, also did not have enough cash. So, he gave them fish on credit or in exchange for other commodities such as root crops, mud crabs, or prawns. He either sold these products in Ba Town or kept it for himself. "I am not the only middleman in the area though", he added:

There are bigger operators in the area, who buy fish from a wider area, even as far as Site land Rakiraki. They are probably making more money and own boats. As for me, I just own this truck and hope that I am able to make some money for my family (Anil, interview, 05 July 2018 
When talking to fisherman, Munir, I asked him why he did not sell his catch at the local market. He explained that after spending four to five days out at sea, the one thing he longs for is a warm bed and sleep. Thus, he found it easier to sell his catch to middlemen who can collect fish from his home rather than worry about spending another day at the market to sell them. However, as Anil revealed, middleman often buy fish at a cheaper price to re-bundle them and sell on for a bigger profit. Such intricate financial arrangements reveal a complex market-supply chain relationship which is currently poorly understood. How these relationships are formed, negotiated, and maintained between parties is an important future study in this area if we are to ensure equitable benefit sharing between all stakeholders.

\subsection{Summary of Findings}

The findings in this chapter have highlighted the multi-layered and nuanced relationships that exist between resource custodians and users at the study site. The findings suggest that access to and participation in coastal fisheries are developed, negotiated and maintained through complex, often informal relationships that are based on trust, reciprocity and a sense of responsibility to others. The informal nature of such relationships can sometimes lead to disagreement, disloyalty, conflicting expectations, and feelings of harassment in some communities. Such intricate experiences are often cognisant of uneven power relations between people that determine who gains accessibility and who is able to participate in coastal fisheries in the area.

In the next chapter I will discuss some of these complexities in relation to my theoretical understanding of community, principles of CBMRM, and the findings presented here. I connect these concepts and findings to the applicable theoretical frameworks; political ecology, postcolonialism and decolonial theories - to understand the role that Indo-Fijians' play within the coastal fisheries sector in $\mathrm{Ba}$ Province. 


\section{Chapter 6: Discussion}

\subsection{Introduction}

This chapter discusses the findings of my research in relation to the literature reviewed. Two key themes have emerged from this research. First, community in relation to coastal fisheries is a broad term for a complex, intertwined, and informal network. Community has multiple meanings depending on everyday socioeconomic, sociocultural, and socio-political activities between Taukei and Indo-Fijian people. Second, people within these communities are dependent and interdependent on each other and on coastal marine resources for their livelihoods. Understanding these linkages is crucial for understanding coastal fisheries management in Fiji. I discuss how these two findings are important considerations when implementing community based or led projects in diverse, multi-user communities (Berkes \& Nayak, 2018)

Based on my findings, I discuss how people within the coastal fisheries space in the study site function within a cycle of reciprocal aid and informal financial arrangements while having a sense of responsibility and expectation toward and from each other. I also discuss how such arrangements and relationships are fostering a sense of diverse community economies in relation to marine resource management. Finally, I discuss how recent socioeco/political initiatives may be applied and extended to support contemporary community based marine resource management in Ba Province.

Figure 9 (next page) shows the intertwined, complex relationship between both communities who find the common space in coastal fisheries that forms and sustains a complex inter and intra relationship between people. 


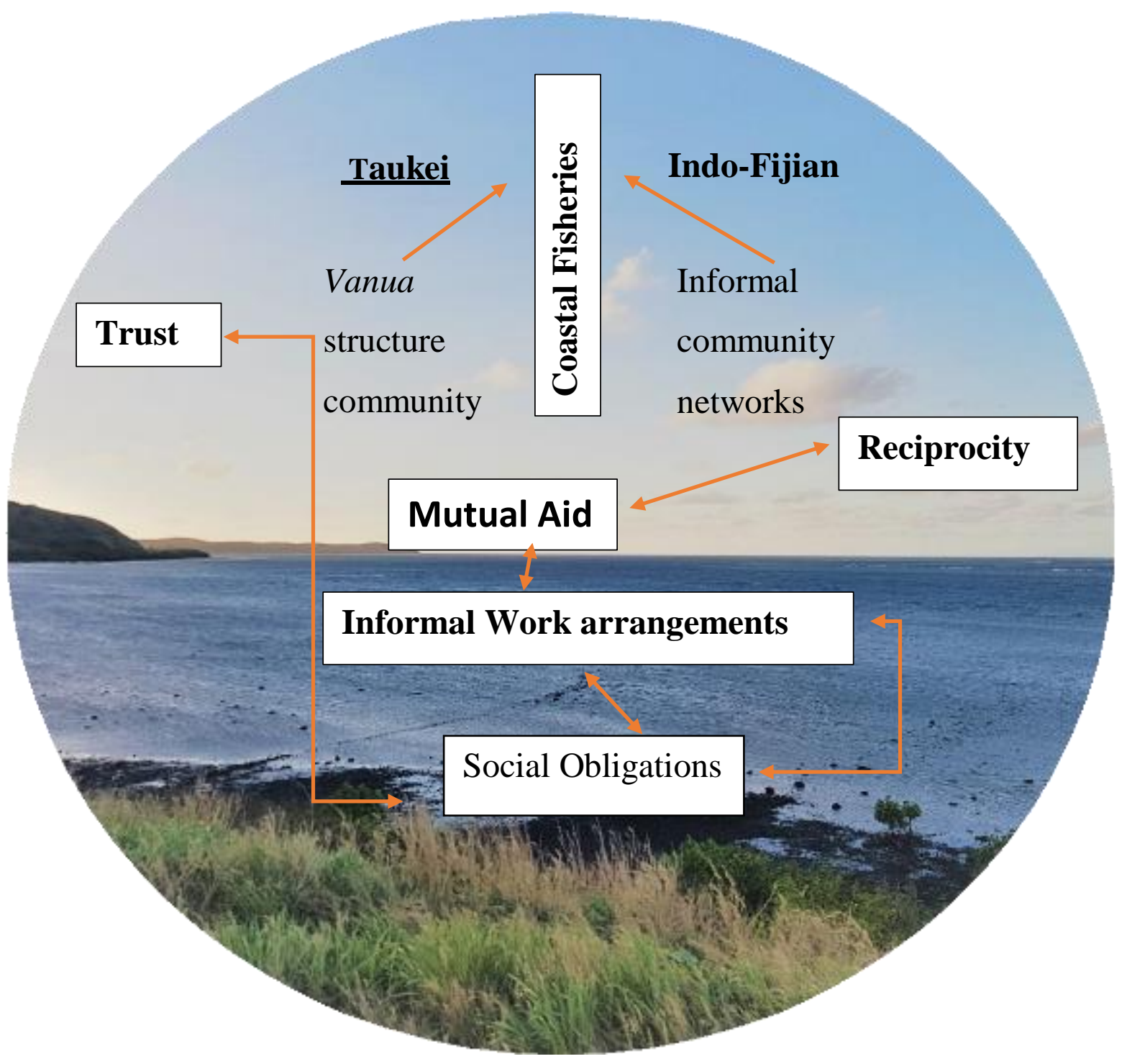

Figure 9: Conceptual overlays of social relationships in coastal fisheries in Ba. 


\subsection{Performing communities}

Communities are dynamic, fluid groupings that perform according to the multiple everyday lived experiences of people (Gupta \& Ferguson, 1992; Brosius et al., 1998; Levine \& Richmond, 2014). This study employs current and emerging definitions of community that recognise the heterogeneous, diverse nature of communities, as understanding this nature is vital to understanding the importance of communities in fisheries management (Jentoft, 2000; Berkes \& Nayak, 2018). This study has found that communities are formed and performed spatially and temporally through complex socioeconomic, sociocultural and sociopolitical processes, all of which may have consequences for coastal social-ecological systems. That is, human relationships and actions inherently impact natural environmental services and functions usually with catastrophic, irreversible consequences.

This study identifies a few ways in which such human/nature and human/human relationships are sustained in communities. Firstly, community members navigate and negotiate informal work and financial arrangements between members of different ethnic groups such as Taukei resource (qoliqoli) owners and Indo-Fijian fishers, middleman or boat owner(s), and between members of the same ethnic group such as in the case of an Indo-Fijian boat owner or middleman and an IndoFijian fisher. Secondly, most actors within the coastal fisheries space in Ba operate under a sense of mutual aid, responsibility, and expectation between and from each other. How these social arrangements and relationship make community and its implications for contemporary CBMRM are discussed below.

\subsubsection{Navigating and negotiating community}

There are multiple instances in this study where various research contributors have highlighted or shared how they developed, navigated, and negotiated relationships between each other within the coastal fisheries space. For example: social relationships between Taukei resource custodians and Indo-Fijian fishers and middlemen; Indo- Fijian boat owners and Taukei fishers, and Indo-Fijian businesses and either Taukei or Indo-Fijian fishers and their families. These arrangements are negotiated at various points depending on the needs of the 
individual as a single fisher or communally as in a customary village fishing committee and based on the needs of their families. In most cases, the basis of negotiation and maintaining relationships are trust and reciprocity but also at times on basis of coercion and compulsion (refer Pratap's example) (field notes, July 06 2018). These interactions reinforce the multiple and diverse notions of community that current literature are supporting (Berkes \& Nayak, 2018).

Jentoft (2000) argues that community is a critical missing link within fisheries management, often ignored and overlooked or even considered a drag on fisheries management. Findings from this study support Jentoft's (2000) argument that "viable fisheries stock require viable fisheries communities" (p. 56). Recent expansion of Jentoft's work by Berkes and Nayak (2018) argues that shared values are important in creating viable communities and maintaining viable fish stocks. Community values such as trust and reciprocity are usually embedded within the social capital between members of different ethnic groups and of the same ethnic group. Consequently, these social relations affect power relations and power distribution between groups (Quimby \& Levine, 2018).

\subsubsection{Dependencies and interdependencies}

Communities display dependency and interdependencies between them and on natural resources they have access to for their livelihoods (Béné, 2006). One such example was documented between Sauturu, a Taukei fisherman 'working' for Pratap, an Indo-Fijian boat owner and between Pratap and Joji. Pratap negotiated with Joji for access to fishing grounds by paying a certain amount in consent fees. While the practice of paying consent/access fees is currently prohibited in Fiji, Joji explained that consent fees were important towards meeting certain sociocultural obligations within the traditional Vanua system. Consequently, despite there being a ban, Pratap was expected to pay some amount to the village fishing committee to ensure that he can continue his fishing business.

While negotiating access to the fishing ground, Joji also asserted his authority as a leader and representative of the fishing committee, over Pratap, by tying in an element of mutual aid within the negotiation process. In this case, as part of the consent granted, Pratap was expected to informally contribute towards helping 
Sauturu, a member of the Taukei village, towards Sauturu's aspiration of buying his own boat or building his house in the nearby settlement. Concurrently, Pratap was also negotiating with Sauturu to fish for him, through an informal work arrangement often on a catch-share basis. Without Sauturu's help, Pratap would not have been able to sustain his business of supplying fish to nearby hotels, restaurants and local markets. While Sauturu relied on Pratap to provide him with financial security when needed, Pratap also relied on Sauturu to fish for him. This example of a three-way interaction is important in our understanding of the levels of dependency between different ethnic groups; Indo-Fijian and Taukei (Pratap and Joji, Pratap and Sauturu) and between members of the same ethnic group (Joji and Sauturu). Sauturu relied on Joji to take appropriate actions within the consent or access agreement with Pratap that would also be mutually beneficial to Sauturu. This study highlights that community relations are built and negotiated based on informal arrangements between people. Within these social relationships, power is constantly shifting (Ballet et al., 2007; Levine \& Richmond, 2014) between resource custodians and fishers depending on the current socioeconomic and sociopolitical situation in the community. Various studies have examined the role and importance of social network relationships (Bodin \& Prell, 2011; Turner, Polunin \& Stead, 2014) and social capital (Nenadovic \& Epstein, 2016) in relation to coastal fisheries management. Ostrom (1994) recognises social capital as "the shared knowledge, understandings, norms, rules, and expectations about patterns of interactions that groups of individuals bring to a recurrent activity" (p.176).

Ballet et al., (2007) suggest that consideration of cultural capital such as norms, values, trust and cooperative behaviour is essential within natural resource management, writing that "the combination of social and cultural capital therefore helps to understand the underlying power relationships (or symbolic capital) that shape individuals' interactions in a social structure" (p. 367). For example, when negotiating access to fishing grounds, Indo-Fijian fishers normally approach individuals that they already have connections with in the community or may have aided in the past, which is recognised as bridging capital by scholars (Nenadovic \& Epstein, 2016). Similarly, Taukei members would request assistance from IndoFijian boat owners, middleman, or retailers with whom they have an established relationship. 
However, the frequency of how often aid and assistance is requested can also lead to feelings of harassment and resentment within the groups. In the study, Pratap who is a boat owner and fisher in Yasiyasi settlement shared in his interview $\left(04^{\text {th }}\right.$ July) how he felt compelled and harassed by Joji, the fishing committee representative, who frequently requested financial donations on the basis of getting continued access to fishing grounds. Pratap shared that most times he did not have a choice but to give in to these demands, as he feared that non-compliance would result in losing access to the fishing grounds on which he relied for his livelihood. In contrast to this view, I noted that when we arrived at Pratap's house together with Joji, they greeted each other amicably and there were no visible differences in their relationship (Field notes, July04 2018).

Ostrom $(1993,1994)$ argues that in order to avoid common problems of excludability and subtractability, resource users must work cooperatively. Extending this argument, Sano (2008) further suggests that resource users need to share norms and understand institutional rules regarding resource use embedded in social capital and social relationships between groups. Findings from this study suggest that social relations between community actors are entrenched within complex underlying socioeconomic relationships. As discussed above, resource custodians play an important role in regulating access and consent to participate in fisheries activities, while Indo-Fijians play an instrumental role in exploiting, marketing, and brokering fish resources. The analysis of this study finds that while Taukei and Indo-Fijians display mutual reciprocity amongst each other, there is also occasional mistrust within the community characterised by feelings of harassment and unwarranted expectations experienced by Indo-Fijians in the coastal fisheries space in Ba. Sano (2008) suggests developing bridging social capital as one way to build trust between a group of people. According to Sano, bridging social capital usually facilitates information and knowledge sharing, opportunities, and technology that a group normally does not possess.

Thus, findings from this study suggest a need for building "bridging" social capital between the two ethnic groups. One that would promote sharing information and knowledge regarding marine resource use and its management, of social and economic opportunities not usually available to each other and technology that 
assist with more sustainable forms of fishing and fisheries management. As reported by Sano (2008):

rural Fijians are increasingly under pressure to participate in a global economy, thus bringing pressure on local natural resources. These changes in the lives of Fijian people require higher levels of bridging social capital for the purpose of coastal management. This allows people in a small community to obtain the new ideas, technology and funds that are necessary to improve the status of natural resources. To improve marine resource management at the village level, the challenge is to identify a strategy for building bridging social capital that is consistent with the bonding ties that already exist. (p. 31).

In saying that Indo-Fijians perceive a general lack of trust and have feelings of harassment and unwarranted expectations from Taukei communities and institutions, I acknowledge my positionality as an Indo-Fijian women and IndoFijian researcher. Given that Pratap, who is also an Indo-Fijian, chose to share his sentiments with me does not necessarily warrant that the same sentiments would be shared by other Indo- Fijians across this community and more widely in Fiji. I also cannot at this stage speak of the Taukei perspective, as both Joji and Sauturu were optimistic of the positive relationship between the two ethnic groups. Jojis' sentiments that he considered the Indo-Fijians in the community as his family and Sauturu's grateful response in appreciating Pratap's help in giving him a job and contributing towards owning his own boat is reflective of the more emphasised cultural values of trust and reciprocity in Taukei people. (Interviews and Field notes, July 05 2018). However, again, my positionality as an Indo-Fijian woman, an outsider speaking to Taukei men, may inherently contribute to my interpretations of community relations at the study site (Sultana, 2007).

While a social network analysis (Bodin \& Crona 2009; Turner et al., 2014) was not conducted as part of this research, future research to investigate and map these social relationships would be useful in understanding the intricate, complex, and interconnected network of actors and relationships within the coastal fisheries space in Fiji. The complexity of relationships that highlight diversity of community within coastal fisheries sector in $\mathrm{Ba}$ is discussed below. 


\subsubsection{Informal economies, patron-client relationships}

The role of the informal economy in sustaining coastal-fisheries dependant households is important (Béné, 2006) yet receives little attention (Ruddle, 2011). One such relationship is that of patron/client relationships (Ferrol-Schulte, Ferse \& Glaser, 2014) or fisher/middleman (Crona, Nyström, Folke \& Jiddawi, 2010) as is more commonly known in Pacific communities. Multiple studies have documented the existence of such relationships (Ferrol-Schulte et al., 2014; Veitayaki, 1998; Dacks, Ticktin, Jupiter \& Friedlander, 2018). Foster (1983) describes patron-client relationships as dyadic ${ }^{18}$ contracts that "are based on the principle of, and are validated by, reciprocal obligations expressed in the exchange of goods and services between people of different socioeconomic status (or order of power)" (p.1281). Within such informal relationships, each partner expects to receive something from the other partner under varying socioeconomic conditions, and in return the partner acknowledges their obligation to give something in exchange for the particular goods or services mutually agreed upon (Foster, 1983). FerrolSchulte et al., (2014) adds that another feature of the patron client relationship is its multifaceted or multi-stranded character in contrast to single-issue relations, such as for employment, credit, or trade.

According to Crona et al., (2010) middlemen, "refers to the group of intermediaries in direct contact with fishermen at the landing sites" and could also be commissioned as agents for larger fish retailers (p.761). The role of middlemen within coastal social- ecological systems is also important in understanding the links between social drivers and ecological issues in many tropical, coastal dependent communities (Crona et al., 2010; Dacks et al., 2018). In their study looking at patron/client relationships in the coastal communities of Zanzibar, Crona et al., (2010) found that middlemen had a potentially important function in natural resource management and poverty alleviation and were therefore crucial for mitigating vulnerability and driving effective coastal governance in coastal communities.

In another case study looking at the role of rural credit schemes in Vietnam,

\footnotetext{
${ }^{18}$ Dyadic contracts refer to principles of reciprocal obligations expressed in the exchange of goods and services (Foster, 1983).
} 
Ruddle (2011) investigated the nature of 'formal' and 'informal' credit and lending arrangements between Vietnamese boat owners, fishers, money-lenders and middlemen to understand how various social arrangements were performed in the industry. In his findings, Ruddle noted that households often have a variety of strategies for borrowing and saving and that "financial decisions are influenced by a range of sociocultural, economic, and ecological factors" (p.224). Furthermore, Ruddle argues that "a continuum of institutions and individuals are involved" (p.224), in understanding and appreciating the rural credit systems which often goes unnoticed in formal financial arrangements.

The majority of interactions described to me during the study were based on some form of mutual social/financial arrangements between resource owners, fishers, boat owners, and retailers or middlemen (patron/client relationships as identified in the literature) (Crona et al., 2010). Patron/client relationships are important links within coastal social-ecological systems (Dacks et al., 2018) as they 'informally' regulate market supply and demand of fish in local communities. Thus, recognising and understanding this relationship within local contexts may contribute toward more sustainable forms of fisheries.

In one example, Naz, a supermarket owner and a fish retailer, provided the boat, equipment, and supplies for fishing to a group of fishers. In return the fishers were expected to give the catch to Naz on their return. After deducting the relevant expenses, Naz then allocated the profit to be shared between the fishers. Usually, Naz would also have provided goods on credit to the fisher's families while the fishers were out at sea. In other research, middlemen, rather than encouraging fishers to pay off their loans or credit, further perpetuated a cycle of dependency, thus capturing the fisher in an endless debt cycle (Ruddle, 2011; Crona et al., 2010) In another example, Anil, who was a roving middleman, engaged with fishers and his buyers in a two-way credit system. As an intermediary, he obtained fish on credit from fishers and then sold this on to other clients who also sometimes exchanged the fish for other commodities which Anil could sell. One key factor identified here was the advantage Anil had by having access to his own transport which he used to get to fishers in rural areas and to travel to markets in the Town. As Crona et al., (2010) highlight, middlemen also provide essential access and links to external markets, greatly reducing the time and investments needed by 
coastal fishers to market their goods, especially highly perishable commodities such as fish.

Another research contributor, Munir, also provided similar reasoning for selling to middlemen. He explained that after being out at sea for up to five days in a week, he preferred that a middleman buy the fish from his landing site to "avoid the hassle of finding transport to the market as well get much needed rest before his next trip out to sea" (Munir, interview, July 05 2018).

Apart from being crucial informal mechanisms of sustaining rural economies, patron/client relationships (or middleman/fisher) relations are important in sustaining communities through times of need and low catch seasons in communities. The lack of alternative livelihood opportunities, access to financial support and advice, in addition to poor or limited government support systems further perpetuates a cycle of debt, credits, and loans in many coastal communities (Crona et al., 2010). While there are often negative connotations associated with many of these informal socioeconomic relationships, further studies and analysis of these interactions would allow for a more nuanced understanding of drivers of illegal over-fishing and unregulated fishing in many communities. Crona et al., (2010) highlight that middlemen involved in small- scale artisanal fisheries are both part of the problem in fisheries management and could also be potential solutions in management of complex social-ecological systems. Middlemen regulate crucial feedback links as knowledge, operating as information brokers between market supply and fish demands in many social-ecological systems (Crona et al., 2010) Therefore, ignoring the importance of such links could lead to incomplete conclusions and recommendations in environmental and coastal management policies (Crona et al., 2010; Ferrol-Schulte et al., 2014). Findings from this study reflect on calls for further studies in this domain to improve understanding of patron/client (middlemen/fisher) relationships within coastal communities.

\subsubsection{Role of women in coastal fisheries}

Women's dominant presence in inshore fishing either for subsistence or semicommercial fisheries has become a growing focus for research recently, as evident 
in literature highlighting the role of women in coastal fisheries by Harper, Zeller, Hauzer, Pauly, \& Sumaila (2013) and Harper, Grubb, Stiles \& Sumaila (2017). In the Pacific, Vunisea (1997) notes that women also play an active role in post-harvest activities, including marketing and distribution marine products from source to market. This trend has not changed much in the past few decades, as women continue to dominate inshore fishing activities such as gleaning, processing, and marketing. However, with new technology and a raising awareness of the role of women in fisheries, the reported numbers of women involved in fisheries activities may be higher (Vunisea, 1997).

Harper et al., (2013) estimates "that in the Pacific, women account for $56 \%$ of annual small-scale catches, and resulting in an economic impact of 363 million USD" (p.56). According to Narsey (2007), as quoted in Vunisea (2016), "in the fisheries sector, the contribution of women is lost in enumeration, through the exclusion or underestimation of household work and unpaid family work" (p.20). Harper et al., (2013) strongly recommend recognising and quantifying the role of women in fisheries so as to influence better management, poverty alleviation, and development policies in the region. While sex disaggregated data collection and reporting are becoming a norm in fisheries management studies, much of the data presented, represents only certain activities and often just one community or region (Harper et al., 2013). Findings in this study supports the argument that other groups, or communities, are rarely reflected in national data provisions. This study support's Vunisea's (2005) proposal for identifying and documenting participation of other ethnic groups in establishing ethnic participation in other aspects of the fisheries sector, such as value-adding or selling marine resources in Fiji. This study has found that not only do Indo-Fijian women play a role in the patron/client relationship (described in 5.3.3 and 5.4.1), they also play a role in supporting fishers' livelihoods and their families through their continued support for men involved in coastal fisheries activities.

In one such scenario, interactions between $\mathrm{Naz}$ and local fishermen, while predominantly reflecting the patron/client (or middlemen/retailer and fisher) relationship, also reflects a social relationship of concern and empathy towards fishers and their families. Naz took business risks in training crew members as boat captains, who could take up the opportunity to fish for other boat owners or move 
on to other employment opportunities. Despite this, she maintained a credit account for her fishers' families who took food items during the week while the fishers were out at sea. The social relationship described was that of concern and care for the fishers' livelihoods. Similarly, Seema who bought fish directly from fishers commented that, "despite the fact that there is hardly any money made in in the fishing business, I continue to do it as it keeps our livelihoods rolling" (Seema, interview, 05 July 2018).

While only one Indo-Fijian fisherwoman was interviewed as part of this study, anecdotal reports received from other areas in the country, mainly Vanua Levu, suggests that more Indo-Fijian women are involved in direct coastal fisheries activities such as mud-crabbing and net-fishing or as processors and retailers. As Nisha, the Indo- Fijian fisherwoman commented, she was involved in the fisheries business so as to reduce labour costs and to support her husband. Even more IndoFijian women would be involved in marketing seafood; as fish vendors in local markets and seafood retailing shops, in aquaculture, and in processing factories where ethnically disaggregated data is often not reported (Field notes, July 062018 ) Further studies in looking at the role of women from other ethnic groups and their participation in coastal fisheries is suggested through this study. Local and context specific interactions are essential in understanding women's role in the sector. These could be either through supporting local fisherman with negotiating informal credit arrangements, reciprocity or as just as employees in the sector. Such analysis and research would enable a better and more nuanced understanding of women's roles in Fiji's contemporary coastal fisheries sector.

\subsubsection{Vulnerability, people, and poverty}

Adger (2006) describes vulnerability as "the state of susceptibility to harm from exposure to stress associated with environmental and social change and from the absence of capacity to act" (p.268). Béné (2009) notes that vulnerability to environmental change varies for different groups of people (for example the poor or migrants) and across spatial and temporal scales. Berkes and Nayak (2018) view vulnerability as "a multidimensional, complex, highly dynamic, and a relative concept" (p.245), the study of which needs to be inter- and transdisciplinary. A 
combination of bio-physical and socioeconomic factors determine the vulnerability of coastal communities and climate change is noted to further exacerbate the situation (Cinner, Folke, Daw \& Hicks, 2011). Across many natural resource dependent communities, extreme weather events such as drought and cyclones are increasing people's vulnerability and their reducing their coping mechanisms, making them less resilient to shocks in the natural environment (Adger, 2006). A political ecology perspective is therefore useful in understanding the potential impacts of climate change and society's capacity to adapt. This would require an analysis of a combination of socio-economic, socio-political and socio-ecological conditions that determine vulnerability (Cinner et al., 2011) within communities.

The unpredictable nature of extreme weather events has caused extensive damages and loss in many coastal communities in the last decade. All contributors to this study commented on recent changing weather patterns as their biggest concern in coastal fisheries. This study demonstrates, through two of the research contributors, the vulnerabilities that fishers are exposed to in relation to coastal fisheries at the study site. Munir and Sanjay are both full time fishers, who shared their experiences of recent weather events on their livelihoods. Both contributors highlighted their inability to carry out any fishing activities due to a lack of technical and/or financial support following cyclones and flooding in the Ba area. Sanjay was the sole breadwinner in his family and whatever income he earned was used to support his wife, two children, and elderly parents. Fishing was his primary source of income and he supplemented that by growing cash crops to sell at the local market as well as for personal consumption. The devastating floods in February 2018, followed by two cyclones the same year, (RNZ, 2017) resulted in extensive damages to his boat and vegetable gardens, consequently affecting his income and livelihood. Sanjay had not gone out fishing in the past three months since his boat got damaged in April:

paisa bhi to mange maintenance ke, aab tum kayega gi maintenance kari, kayega ki maintenance karage, aur upar se humar paas dui ladhkan. Aur upar se tufan se ghar udh gera, u saab banaye ke ready kara toh badh chadhge. Sanjay, interview, 04 July 2018).

money is also needed for boat maintenance, how do I feed my family if I spend money on boat maintenance? I have two children. My house got blown away during 
the cyclone [Winston], by the time I fixed that, there was major flooding.

Despite seeking government assistance, he was unable to secure finances for repairing his boat. Sanjay and his family were left with little option but to survive on a meagre

$\$ 100$ government assistance grant that his parents received each month. Later, in July 2018, government provided all flood/cyclone affected victims a \$1000 grant to assist with house repairs for flood affected victims in the Ba area. Sanjay used most of the money to repair his boat. Repairs to the boat cost more than $\$ 1000$ and Sanjay had to borrow additional money from his friends to help fix the boat. He needed to pay that back once he started fishing in a few weeks. With lack of adequate support and assistance, many fishers like Sanjay become vulnerable to the negative impacts of climate related events.

Another research contributor, Munir spoke extensively of how extreme weather events such as the recent flooding had made the sea inaccessible for up to a month after the floods. Munir shared that "after a flooding or cyclone event, the ocean becomes really murky, visibility is horrible for days and fish are in hiding. The impacts of some cyclones are so bad that the whole reef topography is changed in some areas known to be good fishing spots" (Munir, interview, 05 July 2018). This observation is consistent with literature describing the impacts of tropical cyclone Winston on the Vatu-i-Ra seascape region in Fiji (Chaston Radway et al., 2016). Despite sustaining damages to his boat engine, Munir did not meet the criteria for government assistance since his home and contents were not damaged during the floods/cyclones therefore he was ineligible for the $\$ 1000$ grant.

It appears that national natural disaster assessments fail to adequately capture the damages to people's livelihoods, especially for those reliant on the marine environment. In 2016, following Cyclone Winston, various agencies including the Fisheries Department worked with the Wildlife Conservation Society, to provide the first post- disaster assessment of coastal fisheries including loss and damages to infrastructure, livelihoods and food security (Chaston Radway et al., 2016). The report estimated damages and losses to boats, engines, fishing and post-harvest gear, and fish aggregating devices between $\$ 205,578$ and $\$ 954,581$, and overall the affected areas sustained damages worth $\$ 2,964,139$. The report findings are limited though in that majority of the assessments were conducted in coastal Taukei villages 
and did not take into account other settlements or areas less occupied by Taukei people due to time and resource constraints (Chaston Radway et al., 2016). Losses and damages would have been far greater had fishers like Sanjay and Munir been included in the assessment.

With lack of access to financial and technical support following disasters, fishers become further marginalised and highly vulnerable to impoverished socioeconomic conditions, which often leads to further resource exploitation and non-compliance to management rules, and reduces community viability for sustainably managing fisheries stocks in coastal communities. Poverty in small-scale fisheries is gaining attention and has become a focus of research amongst scholars (Béné, 2003) seeking to identify poverty causes and links with overfishing, resource degradation and loss of societal values as threats to social-ecological resilience (Nayak, Oliveira \& Berkes et al., 2014). As Nayak et al., (2014) propose:

in small-scale fisheries, increased disparities in wealth and poverty are the meeting place of many interconnected and complex dynamics that stem from social, economic, political, institutional, and ecological structures and processes. The sources of poverty and socioeconomic disparities (drivers) cut across the boundaries between these structures and processes, further operating across scales. (p.73).

Nayak et al., (2014) following Béné (2003), provide an extended typology of factors that lead to impoverishment processes and poverty in small-scale fishery socialecological systems. Key factors identified by Béné include economic exclusion, social marginalisation, class exploitation, political disempowerment and extensions by Nayak et al., (2014) include factors such as environment change, ecological marginalisation, loss of identity and fishers' disconnection from resources and from other fishers.

Becker (2017) highlights that in two Indigenous Fijian communities, modernity as a way of development is rapidly transforming the social dynamics and communal disaster risk reduction strategies in communities. He adds that modernity impacts the most vulnerable people in often communities which may have higher access to financial and natural resource capital but which tend to have lower social capital. Thus, vulnerability has implications at both community and household levels and needs to be carefully considered if development projects are to be more meaningful and contribute towards a sustainable community (Becker, 2017). 
While vulnerability and poverty assessments were beyond the scope of this research, through responses received from research contributors and my observations, I gather that most people, particularly those involved in primary coastal fisheries production in the Ba Province, are vulnerable and experience some form of poverty along the chain. Experiencing one or more factors of vulnerability and or poverty as described above may be one of the reasons why the different ethnic groups, Taukei and Indo-Fijians, are so dependant and interdependent on each other and on coastal resources. Some approaches described below could be adapted and adopted at the local level in Fijian communities.

One such approach for analysing vulnerability and poverty is the sustainable livelihoods approach (SLA) (Allison and Ellis, 2001). The SLA evaluates livelihoods on the basis of wealth and assets, as well as surrounding contexts, in order to obtain a picture of the capacity within households to mitigate vulnerability. Another approach proposed by Adger (2000; 2006) assesses key dimensions of vulnerability such as exposure, sensitivity, and adaptive capacity of local communities. However, given the nature of the complex and intertwined reciprocal community relationships identified in this study, the SLA maybe insufficient to provide a clearer understanding of how communities could adapt to change and cope with threats to livelihoods.

An alternative approach, called the community economies approach, embraces the idea of diverse economic possibilities (Gibson-Graham, 2008). A diverse economy approach places equal value between market and non-market transactions, such as household duties carried out by women, like child-rearing, and other societal activities that are not captured in formal capitalist transactions. 


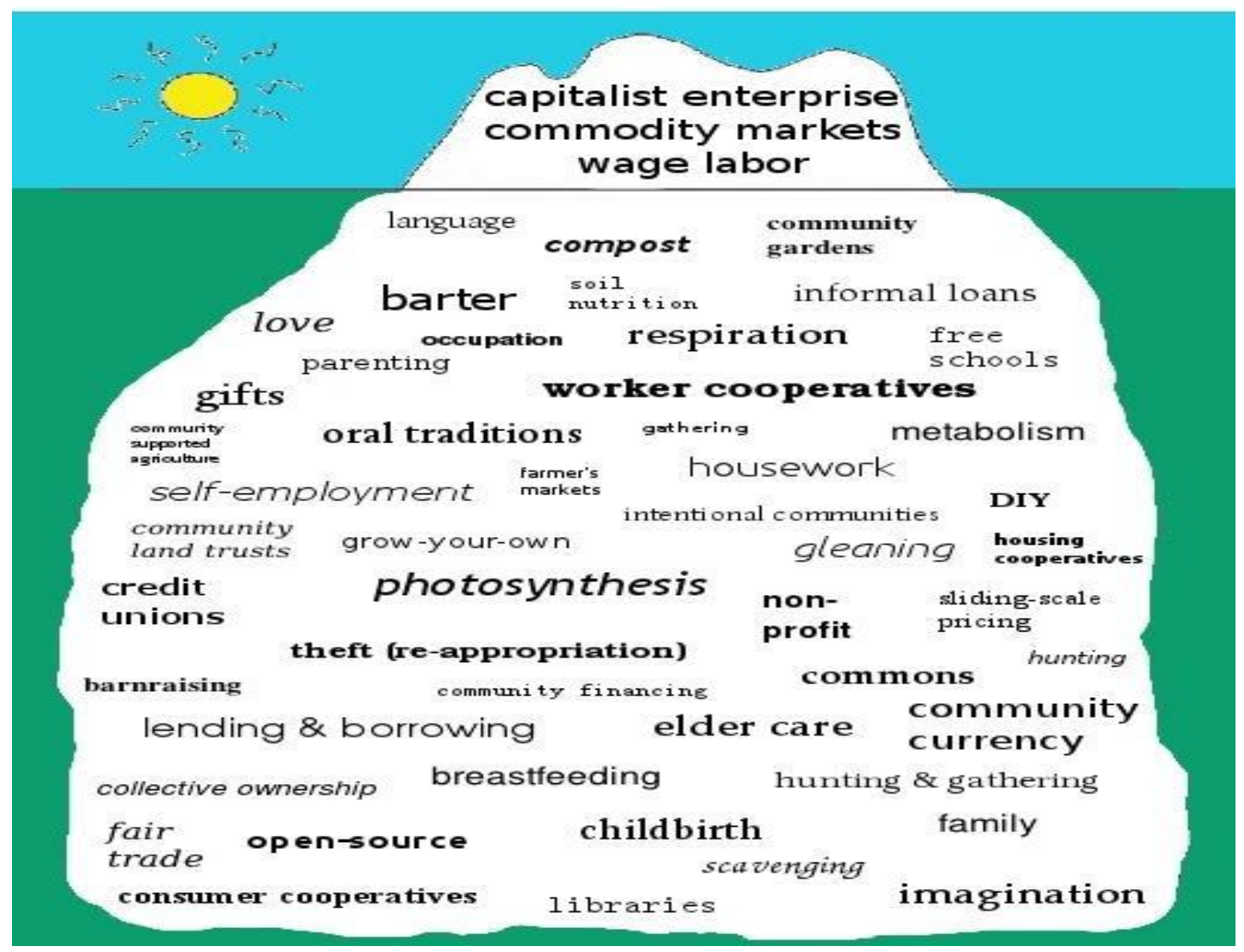

Figure 10: Diverse economies ice-berg. Source: Gibson-Graham (2013)

Gibson-Graham highlight that "the diverse economies research program is a performative ontological project - part of bringing new economies into being rather than a realist epistemological project of capturing and assessing existing objects" (p.616). The diverse economy iceberg (Figure 8) is just one way of representing the multiple economic practices that exist beyond traditional capitalist activities, which are only but the tip of how many Indigenous communities and societies operate.

Future research in identifying the diverse economies including social, cultural, political, and economic relationships that exist within multi-ethnic communities such as $\mathrm{Ba}$ would be beneficial to our understanding of complex social-ecological systems. This would also in turn identify vulnerable communities and identify ways that existing Indigenous structures and institutions such as the Vanua could support sustainable fisheries management in the area. Nonetheless, how such institutional structures and their roles in resource management is greatly affected by power and power relationships operating within communities. 


\subsection{Power dynamics in coastal fisheries}

Power appears to weave in and through every aspect of social interaction described in this research and has close links to understanding impoverishment and poverty within communities. Power between resource owners and fishers, fishers and boatowners, fishers and retailers, and at multiple points along the chain of authority depended on the nature of activity being negotiated and maintained. The importance of power relations are well recognized within community and natural resource management (Berkes \& Nayak, 2018) as well as in co-management applications (Quimby \& Levine, 2018). However, despite its wide recognition within these fields, power remains poorly understood, due to its multiple interpretations and our limited understanding of how power operates between complex social-ecological systems (Berkes \& Nayak, 2018; Quimby \& Levine, 2018). In complex social-ecological systems such as coastal fisheries, the role of power is especially salient, however, very few studies have been conducted to document what power means in these contexts and how it is manifested (Jentoft, 2007; Berkes \& Nayak, 2018). In other words, we know that power is important yet do not fully understand how it works through people and nature to influence management and governance of natural resources.

Power mechanisms within a community are often shaped by combinations of “inside" and "outside" perspectives (Jentoft, 2007, p. 426). Power refers to a certain authority gained through financial, social, cultural or political relationships between people. Power is often fluid, negotiated, navigated and maintained through complex social, political and economic processes depending on the demand and need for power. Nayak, Armitage \& Andrachuk (2016) raises a few important questions to this end: who should define power? Whose perspective matters? What are some of the key externalities influencing power? What implication does power have on management and governance structures and processes designed to respond to fisheries management challenges?

These questions have clear resonance with many issues over power and fisheries management in customary sea tenure systems. In such cases, traditional/customary powers of the Vanua over marine resources is increasingly in competition and in some cases being undermined by capitalist power structures. These capitalist factors include an increase in numbers of middlemen, increased demand for fish that 
consequently raises fish prices and making them unaffordable in urban areas. Recent literature in customary fisheries management in the Pacific and in Fiji, highlights the need for strengthening and supporting customary governance institutions such as the Vanua to achieve sustainable fisheries management (Cinner et al., 2011; Muelig-Hofman et al., 2004, Veitayaki et al., 2017). Berkes and Nayak (2018) argue that "a holistic treatment of power will then lead to facilitating healthy and viable fishing communities by creatively reducing vulnerabilities", stating that "issues of power are at the heart of creating viable communities" and that "viability requires, among others, reducing community vulnerability, with attention to well-being, access to capitals, and resilience" (p.249). Thus, recognising how power operates, weaves, and navigates through multiple social-ecological processes will be key to our understanding of future fisheries policies. As Berkes and Nayak assert, "fisheries governance cannot be isolated from greater societal issues and that it has no easy technical solution" (p.249).

While a more in-depth analysis of power was beyond the scope of this research, future studies in understanding power structures and relationships within coastal Fijian communities are recommended to understand the social-ecological drivers and forces contributing to over-fishing and stock depletion in these communities. Based on findings from this study and my understanding of various concepts of community, vulnerability, power, gender, and the various socioeconomic and sociopolitical relationships described in this study, I infer that current community based marine management processes in $\mathrm{Ba}$ is not inclusive of taking into account other users and that customary marine management institutions need strengthening and support from various NGOs and the national government in order to sustain long-term coastal fisheries (Jentoft, 2007; Berkes and Nayak, 2018), which could then lead to viable oceanic communities (Hau'ofa, 1993). 


\subsection{Summary}

This chapter has drawn together findings and literature to explore and understand the role of Indo-Fijians within the coastal fisheries space in Ba, Fiji. A political ecology approach, with supporting theories from post colonialism and decolonialisation, is useful in understanding the contemporary issues and challenges facing communitybased resource management in Fiji.

Beginning with my understanding and interpretation of community, I found that community relationships were embedded in complex, underlying socioeconomic and sociopolitical relationships, which were negotiated and navigated depending on the needs of particular groups and individuals. Thus, "community" has multiple interpretations and translations that depend on everyday lived experiences. Communities are not homogenous, simplistic entities but rather are conglomerations of multiple perspectives, identities, ethnicities and cultures within complex sociocultural settings. The role of particular actors such as women and patrons (middlemen) are also significant and found to have important links within the coastal social-ecological system.

This study highlights the vulnerability of fishers and resource owners to changing environmental, economic, and social conditions, which are influenced by power relations between the two ethnic groups. Unequitable power relationships and the lack of appropriate support marginalises people of both ethnicities. Inadequately recognising the present socioeconomic and sociopolitical relationships within such diverse communities would only have far more negative consequences for social-ecological systems in the area. As such, current CBMRM practices must be re-evaluated to identify the potential actors and drivers that are currently missing from the community of coastal fisheries and its management in Ba and more widely in Fiji. 


\section{Chapter 7: Conclusion}

This study was undertaken to explore and understand the role of Indo-Fijians within the coastal fisheries space in Ba Province, Fiji. The research was important for two reasons. First that the roles and participation of Indo-Fijians are yet to be adequately reflected in fisheries and conservation agendas in the country, despite their being the second largest ethnic group in Fiji (38\%) and having a strong influence on the fisheries market and supply chain in the county. Secondly, Fiji is experiencing rapid changes to its sociocultural, socioeconomic landscapes and risks losing cultural values and norms associated with customary fisheries management and governance. Consequently, current community-based management faces multiple challenges that pose risk to the viability of fisheries and communities.

Therefore, more work is needed to make current CBMRM initiatives robust, inclusive, and participatory. This includes building nuanced understandings of community, particularly between different ethnicities in post-colonial communities such as Fiji. In addition, there is scope for a more nuanced understanding of the fisheries economy and of the networks that feed into it. This includes the recognition and understanding of key actors, including women and middlemen who contribute to and influence coastal fisheries.

Findings from this study support recent studies in Fiji by Dacks et al., (2018), who argue that fine-scale social data is better at capturing variations of fishing practices and nuances of decision-making within communities. They suggest that such information improves our understanding of the implications of different management measures within the fisheries sector. I support and extend this argument by calling for a re- conceptualisation of contemporary CBMRM that would be fair, equitable, and just for both resource owners and resource users in the country.

The following section summarises the key findings in relation to this study. 


\subsection{Summary of findings}

This research has applied a political ecology and postcolonial/decolonial perspective to understanding the role and participation of Indo-Fijians in the coastal fisheries space in Ba Province, Fiji. As this research has shown, CBMRM is widely advocated for in Fiji and is one approach to fisheries management, recognizing the customary use rights of Indigenous Taukei communities in the country. Fiji's coastal resources are already facing multiple threats and ill-informed management practices can lead to negative social-ecological conditions for coastal dwellers in particular. Resource users can often exert considerable power over traditional marine management practices by driving capitalist, exploitative use of marine resources. Power relations are consistently negotiated and navigated between the two ethnic groups resulting in multiple interpretations and translations of community. As such, current CBMRM initiatives have not adequately addressed the role of resource users or non-Indigenous community groups in management and decision-making.

My findings reveal multiple complex, informal socioeconomic and sociocultural relationships between Taukei and Indo-Fijians. Community relationships are often characterised by positive social capital such as mutual aid, reciprocity, and care, however, at times also of coercion and compulsion. Both resource owners and users form dependant and interdependent relationships which makes them vulnerable to a range of environmental, economic, and social conditions. Current regulatory frameworks for inshore fisheries management is not conducive for supporting customary and traditional (Vanua) fishing rights in the country. This is causing disputes between Indigenous customary owners themselves and also between user-groups such as commercial Indo-Fijian fishers and business owners. Current fishing practices cannot be sustained, and it is pleasing to note that a revamped Ministry of Fisheries in Fiji are taking proactive steps to help manage and conserve fishery resources in the country. A few of these measures, as well as suggested ways forward, are discussed below. 


\subsection{Suggested ways forward for a contemporary CBMRM in Fiji}

This section draws on recent work by Berkes and Nayak (2018) in their paper "Role of communities in fisheries management: one would first need to imagine it" and Hau'ofa's "Vision for Oceania" in his 1993 Sea of Islands essay. Inspired by fisheries sociologist, Svein Jentoft's (2011) argument of imagining what viable fishing community might look like and how they could be maintained. Berkes and Nayak propose that "there are multiple images of communities, fisheries, and management; therefore, it is appropriate to pay attention to images of viable fishing communities and fisheries policies appropriate for such communities" (p.243). As such, these are personal suggestions for re-imagining contemporary CBMRM and what it may require towards making viable communities and viable fisheries in Fiji.

7.2.1 Engaging with and accepting the wider influences on Vanua structures and systems

As I have indicated earlier in this thesis, community based marine management is largely focussed on Indigenous Taukei communities in Fiji, owing to their customary rights over marine resources in the country. Most CBMRM initiatives are based around the Vапиа structure which defines a person's identity and affiliation based on their sociocultural, kin, and tribal relations with one another. The bula vakavanua is referred to as the Indigenous or Fijian way of life encompassing the cultural and social norms and values of the Vanua. More recently, the bula vakavanua has become increasingly under threat due to rapid developments within the sociocultural, economic, and political spaces of Fijian life. As suggested by Nainoca (2011) the appropriate integration and "realignment of norms, behaviour and practices in prevailing Fijian culture" is needed to adapt to changing environment and sustain the bula vakavanua (p.ii). Nainoca suggests that adaptations will have to occur across the bula vakavanua spectrum to make community-based management and conservation sustainable.

Further, Nainoca posits that traditional ecological knowledge and social capital which are embedded within kinship systems of the bula vakavanua are important. While kinship or veiwekani is usually established through birth or marriages, the recent adoption process of Indian descendants within the wider Vanua structure, may be one way towards creating viable communities through building social capital between the 
two ethnic groups. This in turn would be one way of preserving and maintaining the bula vakavanua way of life. The Ba Province has been the only other Province after Rewa, to recognise Indo-Fijians as the Luvedra na Ratu which gives it a huge opportunity to harness and secure socio-cultural capital including trust and reciprocity of this group. According to Veitayaki et al., (2018):

The core CBMRM values of commitment, teamwork, transparency, empowerment, respect, fun, and the belief that practitioners can make a difference ensure that people understand each other and trust each other to deliver on their responsibilities. These features of genuine partnership cannot be easily forged through legal contracts, but through a social commitment to doing better in terms of sustainable resource management and meeting the aspirations of communities. (p. 405).

Taukei and Indo-Fijian people are increasingly aware of their dependence and reliance on each other either through financial or social relations. There are many existing socioreciprocal interactions between Taukeis and Indo-Fijians which signify the good relations and acceptance of different cultural norms and values in Fiji. Increase in intercultural marriages between Taukei and Indo-Fijians in communities have, to some extent, also helped bridge differences and foster acceptance of each other's culture.

However, more work is needed to create stronger ties that build and maintain positive social capital between these groups of people. One way would be to re-imagine communities and contemporary CBMRM through a diverse economies perspective in order to identify the existing sociocultural capital between the two groups. Current marine management practices are mostly exclusive to Indigenous customary owners, which unfortunately only contributes to the issues of poaching, exploitation of local communities, and illegal fishing in coastal communities (Veitayaki et al., 2018). This is despite decades of NGO interventions, collaboration with scientific partners, and the often-limited support from national government.

Genuine partnerships with the key drivers (perpetrators) of illegal and unsustainable fishing (such as middlemen, fish retailers, exporters) cannot be achieved unless existing rules and regulations around fisheries management is improved. It is therefore critical that the national government genuinely attempts to get on-board with current management initiatives by allowing for the strengthening of customary practices. At the 
same time, the government should also be providing and creating an enabling platform for other resource users to share their issues and concerns regarding marine management. The adoption of a National Fisheries Policy, depending on its finalisation, is expected to strengthen community-based management initiatives but also contribute towards building stronger, diverse, and resilient communities.

The onus is on current community-based resource management committees, conservation partners, and relevant government ministries (fisheries, environment, Taukei Affairs) to act urgently on reconciling policies and creating inclusive participatory platforms that include resource users of all ethnic groups and representative bodies such as fish retailers, middlemen, and exporters. Customary, traditional management systems must be able to re-imagine (re-vision) what contemporary CBMRM would look like in the context of rapidly changing sociocultural and socioeconomic and sociopolitical landscapes. This is critical to restoring the socialecological balance synonymous with the Indigenous or bula vakavanua way of life.

\subsubsection{Facilitating participation within coastal fisheries}

As I have highlighted in this study, Indo-Fijians participate in coastal fisheries activities through either subsistence fishing, commercial licensed fishing, or both. A majority of Indo-Fijians are also involved as middlemen, retailers, and exporters of seafood. This study focussed mainly on Indo-Fijians engaged in primary subsistence or commercial fishing activities, but also included middlemen, research practitioners, academics, and conservation organisation representatives. There was no doubt that all research contributors unanimously agreed that Indo-Fijians play a critical role as resource users in Fiji's coastal fisheries space and thus need to be involved at some level of management in their local fishing communities or within qoliqoli's where they have commercial fishing licenses. Currently, Indo-Fijian fishers in $\mathrm{Ba}$ are not well organised and interact with the Ministry of Fisheries on an as needs basis, either when renewing fishing licenses or buying ice for fish storage. Most fishers expressed the need for a formal platform to raise and voice their concerns and carry out collective bargaining within coastal fisheries spaces with respect to access and consent fees, tabu areas, and enforcement. However, the lack of any formal organisational structure beyond the 
household level in Indo-Fijian communities would make representation challenging.

Establishing effective partnerships or co-management approaches based on elements of mutuality, trust, and concern between Taukei resource owners, resource users (including middlemen/retailers), government departments, conservation partners, and donors would be critical to advancing CBMRM in the country. According to Veitayaki et al. (2018), an integrated approach to coastal management is needed to ensure the sustainable development of coastal resources within complex environmental problems. Further, based on two of their case studies in Fiji, collaborative management, partnership, and replication are effective policies for CBMRM.

The pressing issue of regulating commercial fishing licenses through the Ministry of Fisheries must be urgently revisited and a working solution identified for both resource owners and fishing license holders. The illegality of taking goodwill payments have been enforced by the Ministry since January 2017, with the promise of an equitable, just, and fair system of accepting goodwill payments. However, to date, no formal mechanisms are in place to regulate consent fees. As noted in this study, certain qoliqoli owners continue to accept such fees that allow licensed fisherman to access their fishing grounds. While in some communities, reports of qoliqoli owners prohibiting licensed fishers to access fishing grounds were reported at the Fisheries office. While being subjected to abuse, qoliqoli consent fees were an important source of social funding within Taukei communities. Thus, national government while acting on the best interest of qoliqoli owners need to ensure that Taukei and Indo-Fijian communities are not further marginalised within the proposed regulating structure.

The ongoing support and role of conservation NGO's in the country place them in a neutral platform to facilitate conversation with and between the different user-groups and customary fishing rights owners. Recent work involving Indo-Fijians in a participatory community-based fisheries management approach, known as the Length Based Spawning Per Recruit method (LBSPR), by WWF in Macuata, and recently in $\mathrm{Ba}$, is a promising step. LBSPR combines local fisher knowledge with the appropriate science on fish length and maturity to inform management approaches for sustainable fisheries. The practical approach involves resource users as part of a broader and more 
complex coastal social-ecological system and the management of which requires integrated innovative approaches, such as the LBSPR. 


\subsection{Limitations}

This study has covered a broad range of themes in trying to understand the role and participation of Indo-Fijians in the coastal fisheries space in Fiji. There are many limitations to what a 12-month research period could produce of such a complex topic. In an attempt to provide a holistic picture of what and how community relations are formed and maintained in relation to coastal fisheries in the study, I acknowledge that many nuanced and intricate details had to be left out. In particular, this study has addressed very little climate change related impacts on fishers' livelihoods and daily sustenance due to its scope. Severe weather impacts such as flooding and cyclones in $\mathrm{Ba}$ have had detrimental consequences to the livelihoods of many Fijians in the past few years. Future research could look at the effects of climate change on coastal fisheries in Indo-Fijian settlements and how they impact livelihoods and contribute to ongoing issues of poaching or illegal fishing.

Other factors which limited this study were firstly, the field study period was only seven weeks due to family and financial constraints. Then, I had to reconsider doing two sites because of time constraints. As I had no previous connections with the Rewa Province, establishing a sound relationship would have not been possible in the amount of time I had. Research funding available through the New Zealand Scholarships grant was limited and WWF support was only available for the site in $\mathrm{Ba}$, therefore I decided to do just one site. This may have, to some extent limited the diversity of responses I got, however, I am confident that the responses I received from $\mathrm{Ba}$ were sufficient to allow me to conduct some analysis and interpretation of social relationships in the fishing community. 


\subsection{Final remarks}

This study found that Indo-Fijians participate in a range of fishery related activities and form complex and informal social relationships between themselves and Taukei resource owners. Indo-Fijians experience a range of vulnerabilities to environmental, social and economic factors with minimal technical and financial support toward their livelihoods. Consequently, some Indo-Fijians are likely to live in poverty and become further marginalised within society. According to Veitayaki et al. (2018), "the application and adaptation of old solutions to new management issues is a feature of the collaborative community-based resource management arrangement in Fiji” (p.406). Therefore, a robust, participatory and inclusive CBMRM approach that incorporates a diverse or community economies framework is needed to sustain coastal fisheries in the $\mathrm{Ba}$ Province.

This recognises the non-market, social and reciprocal relationships between people and acknowledges the role and place of customary (Vanua) based marine management while at the same time appreciating multiple perspectives, knowledge, and understanding of coastal fisheries by other users. More specifically it calls for a social- ecological systems approach to community fisheries management in Fiji that is centered around community and solidarity for sustainable fisheries in Fiji and other diverse, postcolonial communities in the world.

I am hopeful that this study provides us a good starting place to reimagine what some Pacific scholars such as Epeli Hau'ofa, Konai Helu-Thaman, and Teresia Teiawa have been calling for in relation to natural resource management and the Pacific people. This is parallel to what other fisheries academics and scholars such as Svein Jentoft and Fikret Berkes have been promoting recently. They propose that in order to understand the role of communities in fisheries, one would first need to imagine it. This study strongly recommends re-imagining the process from a diverse Oceania perspective, one which encompasses traditional, customary forms of management, yet is sufficiently flexible to allow for adaptation and adoption within the wider socioeconomic and sociocultural aspects of the country. To encompass this vision of a diverse, Oceanic approach to coastal fisheries management in postcolonial Fiji and the wider Pacific community, the below 
quote by Hau'ofa (1993) is apt:

Oceania is vast, Oceania is expanding, Oceania is hospitable and generous, Oceania is humanity rising from the depths of brine and regions of fire deeper still, Oceania is us. We are the sea, we are the ocean, we must wake up to this ancient truth and together use it to overturn all hegemonic views that aim ultimately to confine us again, physically and psychologically, in the tiny spaces which we have resisted accepting as our sole appointed place, and from which we have recently liberated ourselves. We must not allow anyone to belittle us again, and take away our freedom. (p.39).

This passage acknowledges that the Ocean (Pacific) is vast and hospitable (to accommodate, to sustain everyone), it allows for expansion (of ideas, thoughts, ways of doing) and calls for action to resist (colonial hegemonies) and liberate ourselves (as Pacifica people) from confined places and thoughts and towards finding new knowledge and ways of doing things, creating diverse economies and ways of managing resources. 


\section{Reference list:}

Adger, W. N. (2000). Social and ecological resilience: are they related? Progress in Human Geography, 24(3), 347-364.

Adger, W. N. (2006). Vulnerability. Global Environmental Change, 16(3), 268-281.

Agrawal, A., \& Gibson, C. C. (1999). Enchantment and disenchantment: the role of community in natural resource conservation. World Development, 27(4), 629649.

Ali. A. (1979). Girmit - The Indenture Experience in Fiji. Bulletin of the Fiji Museum, No. 5. Retrieved from http://girmit.org/?page_id=1152

Allison, E. H., \& Ellis, F. (2001). The livelihoods approach and management of small-scale fisheries. Marine Policy, 25(5), 377-388.

Amungwa, F. A. (2011). The evolution of conflicts related to natural resource management in Cameroon. Journal of Human Ecology, 35(1), 53-60.

Armitage, D. (2005). Adaptive capacity and community-based natural resource management. Environmental Management, 35(6), 703-715.

Atkinson, R., \& Flint, J. (2001). Accessing hidden and hard-to-reach populations: Snowball research strategies. Social Research Update, 33(1), 1-4.

Ballet, J., Sirven, N., \& Requiers-Desjardins, M. (2007). Social capital and natural resource management: a critical perspective. The Journal of Environment \& Development, 16(4), 355-374.

Becker, P. (2017). Dark side of development: Modernity, disaster risk and sustainable livelihoods in two coastal communities in Fiji. Sustainability, 9(12), 2315. 
Beddington, J. R., Agnew, D. J., \& Clark, C. W. (2007). Current problems in the management of marine fisheries. Science, 316 (5832), 1713-1716.

Bell, J. D., Kronen, M., Vunisea, A., Nash, W. J., Keeble, G., Demmke, A., \& Andréfouët, S. (2009). Planning the use of fish for food security in the Pacific. Marine Policy, 33(1), 64-76.

Béné, C. (2006). Small-scale fisheries: assessing their contribution to rural livelihoods in developing countries. FAO Fisheries Circular, FAO, Rome. 1008, 46.

Berkes, F. (2004). Rethinking community-based conservation. Conservation Biology, 18(3), 621-630.

Berkes, F., \& Nayak, P. K. (2018). Role of communities in fisheries management: “one would first need to imagine it”. Maritime Studies, 17(3), 241-251.

Bhabha, H. (1994). The Location of Culture. London and New York: Routledge.

Biernacki, P., \& Waldorf, D. (1981). Snowball sampling: Problems and techniques of chain referral sampling. Sociological Methods \& Research, 10(2), 141-163.

Blaikie, P. (2006). Is small really beautiful? Community-based natural resource management in Malawi and Botswana. World Development, 34(11), 1942-1957.

Bodin, Ö., \& Crona, B. I. (2009). The role of social networks in natural resource governance: What relational patterns make a difference? Global Environmental Change, 19(3), $366-374$.

Folke, C. (2011). Foreword. In: Bodin, Ö. and C. Prell (Eds.). Social Networks and Natural Resource Management: Uncovering the Social Fabric of Environmental Governance (pp. iv). Cambridge, United Kingdom: Cambridge University Press. 
Braun, V., \& Clarke, V. (2006). Using thematic analysis in psychology. Qualitative Research in Psychology, 3(2), 77-101.

Brosius, J. P., Tsing, A. L., \& Zerner, C. (1998). Representing communities: Histories and politics of community-based natural resource management. Society and Natural Resources, 11(2), 157-168.

Bryant, R. L. (1998). Power, knowledge and political ecology in the third world: a review. Progress in Physical Geography, 22(1), 79-94.

Castree, N., \& Braun, B. (1998). The construction of nature and the nature of construction: analytical and political tools for building survivable futures: Nature at the Millennium. In B. Braun, \& N. Castree (Eds.), Remaking Reality: Nature at the Millennium (pp. 3-42). London: Routledge.

Chand, G. (2017). Whose Story is it? Colonialism, Syria Ship Wreck, and Texting Race Relations in Fiji. Fijian Studies, 15(1), 63-92.

Chaston Radway, K., Manley, M., Mangubhai, S., Sokowaqanilotu, E., Lalavanua, W., Bogiva, A., \& Veibi, T. (2016). Impact of Tropical Cyclone Winston on fisheriesdependent communities in Fiji (03/16), 79. Suva, Fiji: Wildlife Conservation Society (WCS). Retrieved from https://fiji.wcs.org/Portals/82/reports/FinalImpact\%20of\%20TC\%20Winston\%2 0on\%20Mud\%20crabs_09012017_FINAL_APPENDICES.pdf?ver=2017-09-03175836-053

Cinner, J. E., \& Aswani, S. (2007). Integrating customary management into marine conservation. Biological Conservation, 140(3-4), 201-216.

Cinner, J. E., Folke, C., Daw, T., \& Hicks, C. C. (2011). Responding to change: using scenarios to understand how socioeconomic factors may influence amplifying or dampening exploitation feedbacks among Tanzanian fishers. Global Environmental Change, 21(1), 7-12. 
Cohen, P. J., Jupiter, S. D., Weeks, R., Tawake, A., \& Govan, H. (2014). Is community-based fisheries management realising multiple objectives? Examining evidence from the literature. Retrieved from http://agris.fao.org/agrissearch/search.do?recordID=QW2016000510

Cox, M., Arnold, G., \& Tomás, S. V. (2010). A review of design principles for communitybased natural resource management. Ecology and Society, 15(4).

Crona, B., Nyström, M., Folke, C., \& Jiddawi, N. (2010). Middlemen, a critical socialecological link in coastal communities of Kenya and Zanzibar. Marine Policy, 34(4), 761-771.

Dacks, R., Ticktin, T., Jupiter, S., \& Friedlander, A. (2018). Drivers of fishing at the household scale in Fiji. Ecology and Society, 23(1).

Escobar, A. (2006). Difference and conflict in the struggle over natural resources: a political ecology framework. Development, 49(3), 6-13.

Etikan, I., Musa, S. A., \& Alkassim, R. S. (2016). Comparison of convenience sampling and purposive sampling. American Journal of Theoretical and Applied Statistics, 5(1), $1-4$.

Fabricius, C. (2009). Community-Based Natural Resource Management. In Hudson, R.J. (Ed.), Management of Agricultural, Forestry, and Fisheries Enterprises (pp.3649). Oxford, United Kingdom: Eolss Publishers.

Ferrol-Schulte, D., Ferse, S. C., \& Glaser, M. (2014). Patron-client relationships, livelihoods and natural resource management in tropical coastal communities. Ocean \& Coastal Management, 100, 63-73.

Fiji Bureau of Statistics. (2018). 2017 Population and Housing Census Release. Retrieved from https://www.statsfiji.gov.fj/index.php/census-2018. 
Fiji Environmental Law Association (FELA) and EDO NSW. (2017). Regulating Fiji's Coastal Fisheries. Policy and Law Discussion Paper, (p. 45). Suva, Fiji: Fiji Environmental Law Association.

Foster, G. M. (1983). The Dyadic Contract in Tzintzuntzan, II: Patron-Client Relationship. American Anthropologist, 65(6), 1280-1294.

Gegeo, D. W. (2001). Cultural rupture and indigeneity: The challenge of (re) visioning" place" in the Pacific. The Contemporary Pacific, 13(2), 491-507.

Gegeo, D. W. (2017). Teaching and Conserving Pacific Languages: Theoretical and Methodological Considerations. Amerasia Journal, 43(1), 53-70.

Gibson-Graham, J. K. (2008). Diverse economies: performative practices for other worlds'. Progress in Human Geography, 32(5), 613-632.

Gillett, R. (2016). Fisheries in the economies of Pacific Island countries and territories. Manduloyong City, Philippines: Asian Development Bank.

Gillett, R., \& Tauati, M. I. (2018). Fisheries of the Pacific Islands: regional and national information. FAO Fisheries and Aquaculture Technical Paper. Rome, FAO (625), I-400.

Gillett, R., Lewis, A., \& Cartwright, I. (2014). Coastal Fisheries in Fiji. Resources, Issues, \& Enhancing Role of the Fisheries Department. Suva.

Gillion, K. L. (1977). The Fiji Indians - Challenge to European Dominance, 1920-46. Australian University National Press, Canberra.

Glesne, C. (2016). Becoming qualitative researchers: An Introduction. Pearson. One Lake Street, Upper Saddle River, New Jersey 07458. 
Gonzalez, R., Ram-Bidesi, V., Leport, G., Pascal, N., Brander, L., Fernandes, L., Salcone, J., Seidl, A. (2015). National marine ecosystem service valuation: Fiji. Retrieved from https://www.researchgate.net/publication/317168538_National_marine_ecosyste m_service_valuation_Fiji

Govan, H. (2009). Achieving the potential of locally managed marine areas in the South Pacific. SPC Traditional Marine Resource Management and Knowledge Information Bulletin, 25(July).

Govan, H., Tawake, A., Tabunakawai, K., Jenkins, A., Lasgorceix, A., Schwarz, A. M., \& Afzal, D. (2009). Status and Potential of Locally-managed Marine Areas in the South Pacific: Meeting Nature Conservation and Sustainable Livelihood Targets Through Wide-spread Implementation of LMMAs:

Govan, H., W. Aalbersberg, A. Tawake and J. Parks (2008). Locally-Managed Marine Areas: A guide for practitioners. Suva: The Locally-Managed Marine Area Network.

Green, K. E. (2016). A political ecology of scaling: Struggles over power, land and authority. Geoforum, 74, 88-97.

Gruber, J. S. (2010). Key principles of community-based natural resource management: a synthesis and interpretation of identified effective approaches for managing the commons. Environmental Management, 45(1), 52-66.

Gupta, A., \& Ferguson, J. (1992). Beyond "culture": Space, identity, and the politics of difference. Cultural Anthropology, 7(1), 6-23.

Harper, S., Zeller, D., Hauzer, M., Pauly, D., \& Sumaila, U. R. (2013). Women and fisheries: Contribution to food security and local economies. Marine Policy, 39, 56-63.

Harper, S., Grubb, C., Stiles, M., \& Sumaila, U. R. (2017). Contributions by women to fisheries economies: insights from five maritime countries. Coastal Management, 
45(2), 91-106.

Hau'Ofa, E. (1993). Our Sea of Islands. The Contemporary Pacific, 6 (1), 148-161.

Head, B. W. (2007). Community engagement: participation on whose terms? Australian Journal of Political Science, 42(3), 441-454.

Hill, B. (2017, October). Syria shipwreck rescue efforts of 1884 leads to communal reconciliation in Fiji. Pacific Beat. Retrieved from https://www.abc.net.au/news/2017-10-20/shipwreck-rescue-of-1884-communalreconciliation-fiji/9069014

Hollup, O. (2000). Structural and sociocultural constraints for user-group participation in fisheries management in Mauritius. Marine Policy, 24(5), 407-421.

Holstein, J. A., \& Gubrium, J. F. (Eds.). (2011). Varieties of Narrative Analysis. London: Sage Publications.

RNZ. (2018, April). Fiji floods a 'brutal reminder' of climate reality, says PM. https://www.radionz.co.nz/international/pacific-news/354103/fiji-floods-abrutal- reminder-of-climate-reality-says-pm

Jackson, M., \& Maracle, L. (2014). Nature, critique, ontology, and decolonial options: Problematizing 'the political'. The SAGE Handbook of Nature. London: SAGE, $1-25$.

Jentoft, S. (2000). The community: a missing link of fisheries management. Marine Policy, 24(1), 53-60.

Jentoft, S. (2007). In the power of power: The understated aspect of fisheries and coastal management. Human Organization, 1, 426-437. 
Johannes, R. E. (1998). The case for data-less marine resource management: Examples from tropical nearshore fin fisheries. Trends in Ecology \& Evolution, 13(6), 243-246.

Johannes, R. E. (2002). The renaissance of community-based marine resource management in Oceania. Annual review of Ecology and Systematics, 33(1), 317-340.

Jupiter, S. D., Cohen, P. J., Weeks, R., Tawake, A., \& Govan, H. (2014). Locally-managed marine areas: multiple objectives and diverse strategies. Pacific Conservation Biology, 20(2), 165-179.

Jupiter, S. D., Epstein, G., Ban, N. C., Mangubhai, S., Fox, M., \& Cox, M. (2017). A socialecological systems approach to assessing conservation and fisheries outcomes in Fijian locally managed marine areas. Society \& Natural Resources, 30(9), 10961111.

Kellert, S. R., Mehta, J. N., Ebbin, S. A., \& Lichtenfeld, L. L. (2000). Community natural resource management: promise, rhetoric, and reality. Society \& Natural Resources, 13(8), 705-715.

Kobayashi, A., \& de Leeuw, S. (2010). Colonialism and the tensioned landscapes of Indigeneity. The Sage handbook of Social Geographies, 118-138.

Kumar, C. (2005). Revisiting 'community' in community-based natural resource management. Community Development Journal, 40(3), 275-285.

Lal, B. (1999). Bound for the Colonies: A View of Indian Indentured Emigration in 1095. Journal of Pacific History, 34 (3), pp. 306-09.

Lal, B. (2015). "The World becomes Stranger, the Pattern More Complicated': Culture, Identity and the Indo-Fijian Experience', in P. Pratap Kumar (Ed.), Indian Diaspora: Socio- Cultural and Religious Worlds, Brill, Leiden Boston, pp. 52-72. 
Levine, A., \& Richmond, L. (2014). Examining enabling conditions for community-based fisheries comanagement: comparing efforts in Hawai 'i and American Samoa. Ecology and Society, 19(1).

Levine, A., \& Quimby, B. (2018). Participation, Power, and Equity: Examining Three Key Social Dimensions of Fisheries Comanagement. Sustainability, 10(9), 3324.

Lokuge, G., \& Hilhorst, D. (2017). Outside the net: Intersectionality and inequality in the fisheries of Trincomalee, Sri Lanka. Asian Journal of Women's Studies, 23(4), 473-497.

MacQueen, K. M., McLellan, E., Metzger, D. S., Kegeles, S., Strauss, R. P., Scotti, R., \& Trotter, R. T. (2001). What is community? An evidence-based definition for participatory public health. American Journal of Public Health, 91(12), 19291938.

Maguire, M., \& Delahunt, B. (2017). Doing a thematic analysis: A practical, step-by-step guide for learning and teaching scholars. The All Ireland Journal of Teaching and Learning in Higher Education, 9(3).

Mannarini, T., \& Fedi, A. (2009). Multiple senses of community: The experience and meaning of community. Journal of Community Psychology, 37(2), 211-227.

Massey University. (2017). Pacific Research Guidelines and Protocols. Pacific Research \& Policy Centre. New Zealand. Pp. 40.

Maylor, H., \& Blackmon, K. (2005). Chapter 5: Scientist or Ethnographer: Two models for designing and doing research. Researching Business and Management, 134-164.

Mayer, A.C. (1963). Indians in Fiji. Institute of Race Relations. Oxford University Press. London. pp. 142. 
McMillan, D. W., \& Chavis, D. M. (1986). Sense of community: A definition and theory. Journal of Community Psychology, 14(1), 6-23.

Milupi, I. D., Somers, M. J. \& Ferguson, W. (2017). A review of community-based natural resource management. Applied Ecology and Environmental Research. 15. 11211143.

Ministry of Fisheries. (2019). Annual Corporate Plan August 2017/July 2018. Place: Publishing organistion. Retrieved from: http://www.fisheries.gov.fj/images/Publications/MoF20172018ACP.pdf

Mishra, S. (1993). Haunted lines: postcolonial theory and the genealogy of racial formations in Fiji. Meanjin, 52(4), 623.

Muehlig-Hofmann, A., Veitayaki, J., Polunin, N. V., Stead, S., \& Graham, N. A. (2004). Community-based marine resource management in Fiji-from yesterday to tomorrow. Concepts of Tropical Coastal Management. Suva.

Nabobo-Baba, U. (2006). Knowing and learning: An indigenous Fijian approach. Suva. USP.

Naidu, V. (2017). From Indian Coolies to Fijians: Culture and Identity Change among IndoFijians. Fijian Studies, 15(1), 11-26.

Naidu, V., Matadradra, A., Sahib, M., \& Osborne, J. (2013). Fiji: the challenges and opportunities of diversity. Minority Rights Group International. London, 38pp.

Naidu, V. (n.d). The significance of the adoption of Girmitiya descendants by the Vanua of Rewa. Unpublished Manuscript.

Nainoca, W. U. (2011). The influence of the Fijian way of life (bula vakavanua) on community-based marine conservation (CBMC) in Fiji, with a focus on social capital and traditional ecological knowledge (TEK). (Doctoral dissertation, Massey University). 
Nair, V. (2003). Fiji Islands marine ecoregion: An overview of outstanding biodiversity, threats, opportunities and key stakeholders for conservation. Fiji Islands marine ecoregion: An overview of outstanding biodiversity, threats, opportunities and key stakeholders for conservation. World Wide Fund for Nature (WWF). Retrieved from https://www.sprep.org/att/IRC/eCOPIES/Countries/Fiji/56.pdf

Narsey, W. (2007). Gender issues in employment, underemployment and incomes in Fiji. Vanuavou Publications, Suva, Fiji. xiii, p. 149; $30 \mathrm{~cm}$.

Nayak, P. K., Armitage, D., \& Andrachuk, M. (2016). Power and politics of social-ecological regime shifts in the Chilika lagoon, India and Tam Giang lagoon, Vietnam. Regional Environmental Change, 16(2), 325-339.

Nayak, P., Oliveira, L., \& Berkes, F. (2014). Resource degradation, marginalization, and poverty in small-scale fisheries: threats to social-ecological resilience in India and Brazil. Ecology and Society, 19(2). P \#'s

Nenadovic, M., \& Epstein, G. (2016). The relationship of social capital and fishers' participation in multi-level governance arrangements. Environmental Science \& Policy, 61, 77-86.

Nowell, L. S., Norris, J. M., White, D. E., \& Moules, N. J. (2017). Thematic analysis: Striving to meet the trustworthiness criteria. International Journal of Qualitative Methods, $16(1)$.

Ortlipp, M. (2008). Keeping and using reflective journals in the qualitative research process. The Qualitative Report, 13(4), 695-705.

Ostrom, E. (1990). Governing the Commons. Cambridge University Press. New York.

Ostrom, E. (1993). Design principles in long-enduring irrigation institutions. Water Resources Research, 29(7), 1907-1912. 
Ostrom, E. (1994). Constituting Social Capital and Collective Action. Journal of Theoretical Politics, 6(4), 527-562.

Ostrom, E. (2000). Collective action and the evolution of social norms. Journal of Economic Perspectives, 14(3), 137-158.

Overton, J. (1999). Vakavanua, vakamatanitū: Discourses of development in Fiji. Asia Pacific Viewpoint, 40(2), 173-186.

Prasad, R. (2004). Tears in Paradise: A personal and historical journey, 1879-2004. Glade Publishers. Auckland.

Pomeroy, R. S., Pollnac, R. B., Predo, C. D., \& Katon, B. M. (1996). Impact evaluation of community-based coastal resource management projects in the Philippines. Naga, the ICLARM Quarterly, 19(4), 9-12.

Rai, S. C. (2010). In exile at home: a Fiji-Indian story. (Doctoral dissertation, The University of Western Sydney).

Round, S. (2016, May 19). To be or not to be "Fijian". RNZ International. Retrieved from https://www.radionz.co.nz/international/pacific-news/304216/to-be-or-not-to-befijian. Accessed 01 March 2019.

Ramesh, S. (2016). Colonial and post-colonial Ethnocracy in Fiji. Cosmopolitan Civil Societies: An Interdisciplinary Journal, 8(3), 115.

Ratuva, S. (2012). Coerced preferences: Affirmative action and horizontal inequality in Fiji. In E. T. Gomez \& R. Premdas (Eds.) Affirmative Action, Ethnicity and Conflict (pp. 109-139). Routledge.

Ravuvu, A. (1983). Vaka i Taukei: The Fijian way of life. Suva, Fiji: Institute of Pacific Studies of the University of the South Pacific. 
Rawlinson, N. J. F., Milton, D. A., Blaber, S. J. M., Sesewa, A., \& Sharma, S. P. (1995). A survey of the subsistence and artisanal fisheries in rural areas of Viti Levu, Fiji 435 2016-33690.

Robbins, P. (2011). Political Ecology: A critical introduction. 16: West Susses, John Wiley \& Sons.

Rocliffe, S., Peabody, S., Samoilys, M., \& Hawkins, J. P. (2014). Towards a network of locally managed marine areas (LMMAs) in the Western Indian Ocean. PloS one, 9(7).

Ruddle, K., Hviding, E., \& Johannes, R. E. (1992). Marine resources management in the context of customary tenure. Marine Resource Economics, 7(4), 249-273.

Ruddle, K. (1998). The context of policy design for existing community-based fisheries management systems in the Pacific Islands. Ocean \& Coastal Management, 40(23), 105-126.

Ruddle, K. (2011). "Informal" Credit Systems in Fishing Communities: Issues and Examples from Vietnam. Human Organization, 70(3), 224-232.

Rutz, H. J. (1995). Occupying the headwaters of tradition: Rhetorical strategies of nation making in Fiji. Nation making: Emergent identities in postcolonial Melanesia, 7193.

Said, E. W. (1978). Orientalism. Routledege and Kegan Paul Limited. 57p.

Salas, S., Chuenpagdee, R., Seijo, J. C., \& Charles, A. (2007). Challenges in the assessment and management of small-scale fisheries in Latin America and the Caribbean. Fisheries Research, 87(1), 5-16.

Samuela and Sloan. (2018). Fiji fisheries law: When is fishing activity illegal in Fiji's nearshore waters? Ocean Law Bulletins. Retrieved from http://www.sas.com.fj/ocean-law-bulletins/fiji-fisheries-law-when-is-fishing- 
activity-illegal.

Sano, Y. (2008). The role of social capital in a common property resource system in coastal areas: A case study of community-based coastal resource management in Fiji. SPC Traditional Marine Resource Management and Knowledge Information Bulletin, 24, 19-32.

Schafer, J., \& Bell, R. (2002). The state and community-based natural resource management: the case of the Moribane Forest Reserve, Mozambique. Journal of Southern African Studies, 28(2), 401-420.

Schulz, K. A. (2017). Decolonizing political ecology: ontology, technology and critical enchantment. Journal of Political Ecology, 24(1), 125-43.

Shackleton, S., Campbell, B., Wollenberg, E., \& Edmunds, D. (2002). Devolution and community-based natural resource management: creating space for local people to participate and Bénéfit. Natural Resource Perspectives, 76(1), 1-6.

Sherif, S. (2013). Negotiating Postcolonial Spaces: A Study of Indo-Sri Lankan Fishing Disputes. International Studies, 50(1-2), 145-164.

Singh J. (2008). The life of a fisherman: a socio-economic survey. Retrieved from https://fijisun.com.fj/2008/06/21/the-life-of-a-fisherman-a-socioeconomicsurvey/

Sloan, J., \& Chand, K. (2015). A review of near shore fisheries law \& governance in Fiji. Suva: David and Lucille Packard Foundation. 30p.

Smith, L.T. (2012). Decolonizing Methodologies: Research and indigenous peoples, second edition. Dunedin, New Zealand: Otago University.

South, G. R., \& Veitayaki, J. (1998). The Constitution and Indigenous Fisheries Management 
in Fiji 1. Ocean Yearbook 13(1): 452-466.

SPC (2015). New Song for Coastal Fisheries-Pathways to Change: The Noumea Strategy. Pacific Community, Noumea.

Spivak, G. C. (1988). Can the subaltern speak? Reflections on the history of an idea, 21-78.

Spriggs, M., \& Scarr, D. (Eds.). (2014). Degei's Descendants: Spirits, Place and People in Pre-Cession Fiji. 41. ANU E Press. 34 pp.

Stone, M. T., \& Nyaupane, G. (2014). Rethinking community in community-based natural resource management. Community Development, 45(1), 17-31.

Sultana, F. (2007). Reflexivity, positionality and participatory ethics: Negotiating fieldwork dilemmas in international research. ACME: An international E-journal for Critical Geographies, 6(3), 374-385.

Svarstad, H., Benjaminsen, T. A., \& Over, R. (2018). Power theories in political ecology. Journal of Political Ecology, 25(1), 350-363.

Tawake, A., Parks, J., Radikedike, P., Aalbersberg, B., Vuki, V., \& Salafsky, N. (2001). Harvesting clams and data involving local communities in monitoring can lead to conservation success in all sorts of unanticipated ways: a case in Fiji. Conservation in Practice, 2(4), 32-35.

Teaiwa, K. M. (2012). Choreographing difference: The (body) politics of Banaban dance. The Contemporary Pacific, 65-94.

Teh, L. C., Teh, L. S., Starkhouse, B., \& Sumaila, U. R. (2009). An overview of socioeconomic and ecological perspectives of Fiji's inshore reef fisheries. Marine Policy, 33(5), 807-817. 
Tetreault, D. (2017). Three forms of political ecology. Ethics and the Environment, 22(2), 123.

Thaman, K. H. (2003). Decolonizing Pacific studies: Indigenous perspectives, knowledge, and wisdom in higher education. The Contemporary Pacific, 15(1), 1-17.

Trnka, S. (2012). Cleanliness in a Caste-less Context: Collective Negotiations of Purity and Pollution among Indo-Fijian Hindus. Anthropological Forum, 22 (1), 25-43.

Turner, R. A., Polunin, N. V., \& Stead, S. M. (2014). Social networks and fishers' behavior: Exploring the links between information flow and fishing success in the Northumberland lobster fishery. Ecology and Society, 19(2):38.

Ültanir, E. (2012). An Epistemologic Glance at the Constructivist Approach: Constructivist Learning in Dewey, Piaget, and Montessori. London.

United Nations Sustainable Development. (2019). About the Sustainable Development Goals - United Nations Sustainable Development. Retrieved from https://www.un.org/sustainabledevelopment/sustainable-development-goals

Vandervord C., Fox M., Nand Y., Nalasi U., Veibi T., Mangubhai S (2016) Impact of Cyclone Winston on Mud Crab Fishers in Fiji. Wildlife Conservation Society. Report No. 04/16. Suva, Fiji. 23 pp.

Veitayaki, J. (1997). Traditional marine resource management practices used in the Pacific Islands: an agenda for change. Ocean \& Coastal Management, 37(1), 123-136.

Veitayaki, J. (1998). Traditional and community-based marine resources management system in Fiji: An evolving integrated process. Coastal Management, 26(1), 47-60.

Veitayaki, J. (2000). Fisheries resource-use culture in Fiji and its implications. Culture and Sustainable Development in the Pacific, 116-130. 
Veitayaki, J., Ledua, E., Nakoro, A., Hong, H. P., Han, D. P., Moon, S., \& Breckwoldt, A. (2018). Future Use of Past Practices: Policy Implications of Insights from Two Community-Based Marine Resource Management Initiatives in Fiji. Ocean Yearbook Online, 32(1), 376-405.

Vunisea, A. (1997). Women's fishing participation in Fiji. SPC Women in Fisheries Information Bulletin.1: 10-13.

Vunisea, A. (2005). Women's changing roles in the subsistence fishing sector in Fiji. Pacific voices-Equity and sustainability in Pacific Island fisheries. Suva, Fiji: Institute of Pacific Studies, USP, 89-106.

Vunisea A. (2016). The participation of women in fishing activities in Fiji. SPC Women in Fisheries Information Bulletin. 27:19-28.

Watts, M. (2000). Political Ecology. In E. S. Sheppard and T. J. Barnes (Eds.) (pp.\#), A Companion to Economic Geography: Oxford, UK; Malden, Mass., USA: Blackwell.

Young, I. M. (2002). Inclusion and democracy. London. Retrieved from Oxford University press on demand.

Young, R. J. (2016). Postcolonialism: An historical introduction. London: John Wiley \& Sons. 


\section{Appendices}

Appendix A: Ethics Approval

TE WHARE WÃNANGA O TE OPOKO O TE IKA A MÃUI

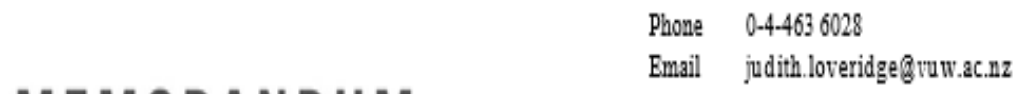

MEMORANDUM

Email judith.loveridge@ruw.ac.nz

\begin{tabular}{l|l}
\hline TO & Chinnamma Reddy \\
\hline FROM & Dr Judith Loveridge, Convenor, Human Ethics Committee \\
\hline DATE & 29 May 2018 \\
\hline PAGES & 1 \\
\hline & \multicolumn{2}{|l}{} \\
\hline SUBJECT & $\begin{array}{l}\text { Ethics Approval: 26127 } \\
\text { Reframing coastal fisheries management in Fiji: A case study of } \\
\text { two fishing communities in Nailaga and Naselai Districts }\end{array}$ \\
\hline
\end{tabular}

Thank you for your application for ethical approval, which has now been considered by the Human Ethics Committee.

Your application has been approved from the above date and this approval is valid for three years. If your data collection is not completed by this date you should apply to the Human Ethics Committee for an extension to this approval.

Best wishes with the research.

Kind regards

Judith Loveridge

Convenor, Victoria University Human Ethics Committee 
Appendix B: Information sheet

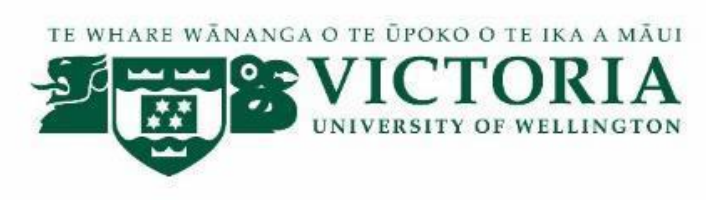

\section{Reframing coastal fisheries management in Fiji:}

INFORMATION SHEET FOR PARTICIPANTS (Interviews and observations)

You are invited to take part in this research. Please read this information before deciding whether or not to take part. If you decide to participate, thank you. If you decide not to participate, thank you for considering this request.

\section{Who am I?}

My name is Chinnamma Reddy and I am a Masters student in the Environment Studies programme at Victoria University of Wellington. This research project is work towards my thesis due to be completed in March 2019.

\section{What is the aim of the project?}

This project aims to provide an overview of how community groups are participating in coastal fisheries, its management and to what extent and how are they involved in the decision making or governance process. This research has been approved by the Victoria University of Wellington Human Ethics Committee Ref \#26127.

How can you help?

You have been invited to participate because of your involvement in coastal

fisheries as a (will be deleted as appropriate for the individual being interviewed. fishery user/manager/academic/researcher/local expert/other

- fishery user - fisherman or fisherwoman, middlemen or fish retailer

- manager - involved as part of a local management committee, an NGO representative or a Government official

- academic / researcher - involved in coastal fisheries management research at local or overseas institute, has contributions to fisheries research in Fiji or Pacific

- local expert - individual involved with local planning, decision making or other management process of coastal fisheries at the site

- other - could encompass people involved with or has an interest in the project and are willing to be interviewed 
If you agree to take part, I will interview you at a mutually suitable, safe and in public places to ensure and protect both our privacy and comfort. I will ask you questions about your involvement in coastal fisheries, your thoughts on current practices and potential management ideas. I also would like to record some general personal observations in relation to your activities and engagement in fisheries management work. You have the right to not be included in the observation and also to withdraw at any point should you no longer feel comfortable in engaging with the research. Observations will generally be between the time of interview and potentially before and after as well. I will indicate this to you upon your consent.

The interview will take between 30 minutes to 1 hour. I will audio record the interview with your permission and write it up later. You can choose to not answer any question or stop the interview at any time, without giving a reason. You can withdraw from the study by contacting me at any time before $31^{\text {st }}$ July 2018 . If you withdraw, the information you provided will be destroyed or returned to you.

What will happen to the information you give?

This research is confidential. This means that the researcher named below will be aware of your identity but the research data will be combined and your identity will not be revealed in any reports, presentations, or public documentation. However, you should be aware that in small projects your identity might be obvious to others in your community.

Only my supervisors, the transcriber (who will be required to sign a confidentiality agreement) and I will read the notes or transcript of the interview. The interview transcripts, summaries and any recordings will be kept securely and would be used in future by the researcher for further studies

What will the project produce?

The information from my research will be used in my Masters thesis, journal article publications and presented at local and international conferences / symposiums.

If you accept this invitation, what are your rights as a research participant?

You do not have to accept this invitation if you don't want to. If you do decide to participate, you have the right to:

- choose not to answer any question;

- choose not to be included for personal observations but agree to the interview

- $\quad$ ask for the recorder to be turned off at any time during the interview

- $\quad$ withdraw from the study before $27^{\text {th }}$ August 2018.

- $\quad$ ask any questions about the study at any time;

- $\quad$ receive a written summary of your interview upon request 
- Receive a written record of my observations upon request 
If you have any questions or problems, who can you contact?

If you have any questions, either now or in the future, please feel free to contact [Amanda Thomas / Chinnamma Reddy):

Student:

Name: Chinnamma Reddy

University email address:

Chinnamma.reddy@vuw.ac.nz
Supervisor:

Name: Amanda Thomas

Role: Lecturer

School: Geography, Earth Science and

Environment

Email: amandathomas@vuw.ac.nz

Name: Professor Vijay Naidu

Role: Lecturer

School of Government, Development and International Affairs, The University of the South Pacific.

Laucala Bay Campus

Suva, Fiji Islands

Tel (679) 3232093

Email: naidu v@usp.ac.fj

Human Ethics Committee information

If you have any concerns about the ethical conduct of the research you may contact the Victoria University HEC Convenor: Dr Judith Loveridge. Email hec@vuw.ac.nz or telephone +64-4-463 6028 . 


\section{TE WHARE WĀNANGA O TE ŨPOKO O TE IKA A MĀUI

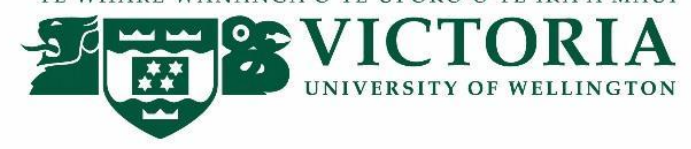 \\ Reframing coastal fisheries management in Fiji. \\ CONSENT TO INTERVIEW and OBSERVATION}

This consent form will be held for 1 year.

Researcher: Chinnamma Reddy, School of Geography, Earth Sciences and Environment, Victoria University of Wellington.

- I have read the Information Sheet and the project has been explained to me. My questions have been answered to my satisfaction. I understand that I can ask further questions at any time.

- I agree to take part in an audio recorded interview only (and /or) < delete as appropriate $>$ be observed undertaking activities in relation to the project.

- $\quad$ I agree / do not agree < delete as appropriate> to be photographed.

I understand that:

- I may withdraw from this study at any point before $27^{\text {th }}$ August 2018, and any information that I have provided will be returned to me or destroyed.

- Any information I provide will be kept confidential to the researcher and the supervisor and the transcriber.

- I understand that the results will be used for a Master's thesis, and / or journal article publications and / or presented at local and international conferences / symposiums.

- My name will not be used in reports, nor will any information that would identify me unless otherwise consented to.

- $\quad$ I would like a summary of my interview (upon request): $\square \quad$ Yes

- I would like to receive a copy of the final report and have added my email Yes address below.

Date: 
Name of participant:

Contact Details: 


\section{Appendix D: Interview Guide}

Draft Interview Schedule

Chinnamma Reddy 300414754

Topic Guides

Introductions and welcome

- Meet and greet, introduce myself to participant, provide a brief overview of background and interest in marine management, current studies at Victoria University and research aspirations

- Seek permission and confirmation for audio recording

- Complete relevant Information and Consent forms

- Explain to participants the interview schedule -3 main thematic questions taking about $45 \mathrm{~min}-60 \mathrm{mins}$

- Ensure participant and self are comfortable before beginning interview.

Key: Translated text in these fonts: Itaukei and Fiji Hindi.

1.0 Participants background / Nomu ikilalika / Aap ki pechan

1.1. Please introduce yourself providing name, role and background in fisheries/marine management

Kerekere mo cavuta mada na nomu I yaca kei na nomu I tavi ena loma in koro/ vanua ni cakacaka.

Apna naam aur kham ke bare me bataiye.

2.0 Values towards Marine Management

2.1 What factors affect your participation in fisheries management?

Na cava e so na vuna ni o lai qoli?

Khon waja hain jo aap samundar jate ho? Khya aap ko koi rok tok ki waja hain?

2.2 How do you feel about current management practices?

Nacava na nomu irai baleta na kena i vakayagataki nai sasalu ni wai?

Aap ka kya soch hain abhi ke machri marne ke system pe?

2.3 Have you felt on any occasion unable to fully participate or engage in sustainable practices because of external factors for e.g financial, cultural or traditional obligations

(captured in 2.2 above)

2.4 Why did you feel / react / act the way you did 
(captured in 2.2 above)

3.0 Community fisheries management

3.1 How does your community engage in fisheries activity / management

Tukuna mada na veika eso me beleta na tovo ni qoliqoli ena gauna oqo.

Kya aap abhi ke machri marane ke tariko ke bhare me bata sakta hain? Khon log machri marte hain?

3.2 How does institutions such as churches and schools affect your fisheries engagement

Na cava na nodra I tavi na vale ni lotu kei na koroivuli ena nomu lai qoli?

Kya school aur dharm ka koi len den hain aap ke machari marne se?

3.3 What role / How does family affect your engagement in fisheries activities or management.

Na cava na nodra itavi na nomu vuvale ena vuke ni lei qoli sena kena maroroi?

Khya aap ki pariwar apko madat karte hain machari marne me, aur kis tara karte hain?

3.4 Which factors (from the ones discussed or provided above) affect your engagement in fisheries management the most?

Captured in 3.3 above.

4.0 Engagement and Participation

4.1 What are your views in regards to fisheries management or engagement by people who are not resource custodians?

Na cava na nomu irai baleta na nodra lai qoli o ira mai tuba?

Aap ka khiya bichar hain machri marna wale jo yah aka na hain?

4.2 How are they currently involved in fisheries or fishing activities in your community?

Na cava na nodra i walewale ni qoli?

Kis tarah weh machari marte hain?

4.3 Do you think involvement should include non-resource users in fisheries activities / management - How do you think their involvement or participation may be improved or included?

Na cavu na nomu I nanuma ne nodra I qoliqoli o ira na mai tuba? Mera tou va tavi 
kina na kena maroroi nai salusalu? 
Kya aap ka bichar hain machari marne wale se jo machari ke surkasha or bacho ke liye kam karna chate hain?

4.4 What policy level changes need to happen, are there current mechanisms for allowing this to happen?

Na cava so na veivuke me ra solia mai na matanitu me baleta nai qoliqoli?

Sarkar ke taraf se kya madat chaiye aap ko.

5.0 Integrating cultural values and Coexistence into fisheries management

5.1 Are you aware of the recent adoption of Indentured laborers descendants into the Rewa and Ba Provinces? (If yes then go to questions, if not then provide brief background of the process)

Na cava na nomuni rai me baleta na nodra sa vakayacori tu na yaca "luvedra na ratu" mai na tikina o Ba kei Rewa?

Kya aap girmitya ke bhare mein jain te ho jo ki aab "luvedra na ratu" ke naam se janajate hain Rewa aur Ba mein?

5.2 Are you aware of any particular events or activities related to fisheries that you have participated in? How did you feel about this?

Khiya aap kabhi yain ke log ke saat machri marne gaye hain?

5.3 Could you describe how you see good fisheries management? Who is involved, what are the mechanisms, conflict resolution mechanisms etc

Aap ke hisab se acha machri marne ke tarika kya hain? Aur kis tara se machari ko bacha $\mathrm{k}$ rekana chaiye hain.

5.2 In your view does the adoption/reconciliation process contribute to integrating cultural / social values and cultural coexistence towards fisheries management in communities?

Na cava na nomu irai me baleta na veimaliwai vata keiratou na kai india.

Kya aap sochete hain abhi aur ane wale sambandho ke bare main? 